Florida International University FIU Digital Commons

FIU Electronic Theses and Dissertations

University Graduate School

$12-2-1994$

\title{
Anthropometric estimates for Colombian adults
}

Orlando A. Corredor

Florida International University

DOI: $10.25148 /$ etd.FI14061523

Follow this and additional works at: https://digitalcommons.fiu.edu/etd

Part of the Engineering Commons

\section{Recommended Citation}

Corredor, Orlando A., "Anthropometric estimates for Colombian adults" (1994). FIU Electronic Theses and Dissertations. 2643.

https://digitalcommons.fiu.edu/etd/2643

This work is brought to you for free and open access by the University Graduate School at FIU Digital Commons. It has been accepted for inclusion in FIU Electronic Theses and Dissertations by an authorized administrator of FIU Digital Commons. For more information, please contact dcc@fiu.edu. 


\section{FLORIDA INTERNATIONAL UNIVERSITY}

Miami, Florida

\section{ANTHROPOMETRIC ESTIMATES FOR COLOMBIAN ADULTS}

A thesis submitted in partial satisfaction of the

requirements for the degree of

MASTER OF SCIENCE

IN

INDUSTRIAL ENGINEERING

by

Orlando A. Corredor 
To: Gordon R. Hopkins

Engineering and Design

This thesis, written by Orlando A. Corredor, and entitled ANTHROPOMETRIC ESTIMATES FOR COLOMBIAN ADULTS, having been approved in respect to style and intellectual content, is referred to you for judgement.

We have read this thesis and recommend that it be approved.

\section{Chin Sheng Chen}

German Nunez

Mark L. Resnick, Major Professor

December 2, 1994:

The thesis of Orlando A. Corredor is approved.

Dean Gordon R. Hopkins

College of Engineering and Design

Dr. Richard L. Campbell

Dean of Graduate Studies

Florida International University, 1994 
This thesis is dedicated to my family and friends who have patiently given me their support during the preparation of this study. 


\section{ACKNOWLEDGMENTS}

I would like to thank the members of my committee for their assistance,

encouragement and criticism in the course of preparation of this study. A special thanks to my major professor, Dr. Marc L. Resnick, for his invaluable support, comments, and patience.

My thanks are also extended to Zair Rolling, who was part of the measuring team, and to the Colombian community organization directors and members who recognized and participated voluntarily in this study. 


\title{
ABSTRACT OF THE THESIS
}

\section{ANTHROPOMETRIC ESTIMATES FOR COLOMBIAN ADULTS}

by

\author{
Orlando A. Corredor \\ Florida International University, 1994 \\ Miami, Florida \\ Professor Marc Resnick, Major Professor
}

Knowledge of anthropometric dimensions is important for the design of workspaces and equipment. In a developing country, such as Colombia, no anthropometric survey for Colombian adults has yet been published. Therefore, the purpose of this study is to assemble a Colombian adult anthropometric data set sufficiently accurate for design applications. An anthropometric survey was conducted on 134 Colombian adults living in South Florida. Twenty body dimensions were measured. Moreover, an anthropometric estimation method was selected, described and validated to be used as a reference when measurement of the user population is not possible. Anthropometric estimates, using the scaling ratio method, and those obtained in the survey were analyzed and compared with other population data. Tables are assembled and dimensional models are suggested which may be used as a design tool. 
II- ANTHROPOMETRY SURVEY

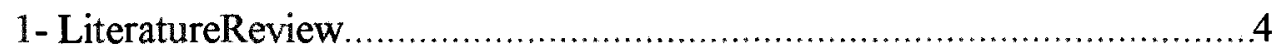

1.1- Colombian Anthropometric Studies................................... 4

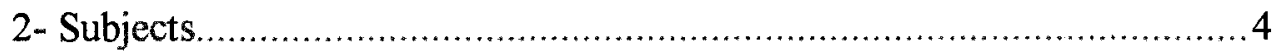

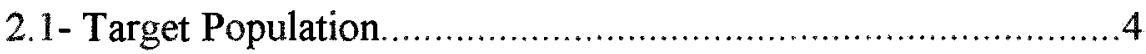

2.2- Sample Size Determination..............................................5

2.2.1 - Population Dimension Variability Estimation.............7

2.2.2- Accuracy and Confidence Level............................ 9

2.2.3- Sample Size Calculation........................................9

2.2.4- Sample Stratification............................................. 10

2.3- Population Recruitment and Restrictions............................. 13

3- Anthropometric Concerns ............................................................. 13

3.1- Selection and Standardization of Terminology and Techniques. 13

3.2- Anthropometric Dimensions................................................ 14

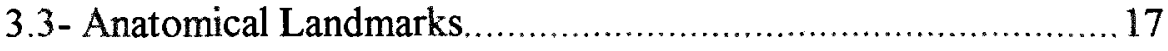

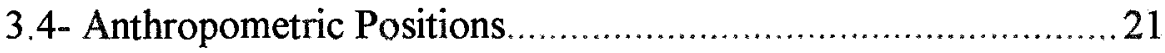

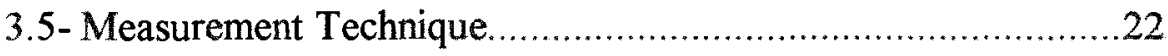

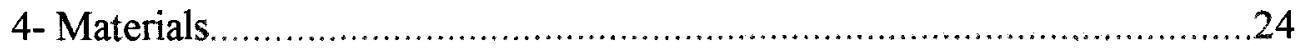

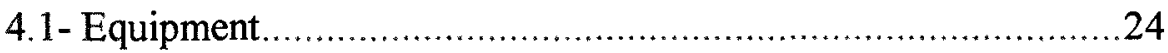

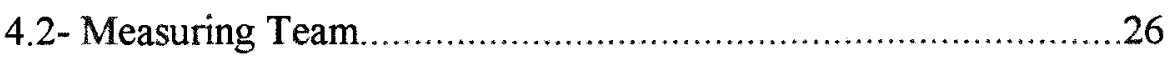

4.3- Measurement Session Place ................................................ 26

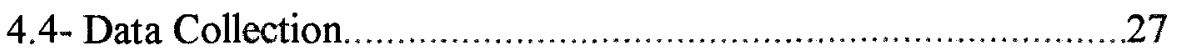

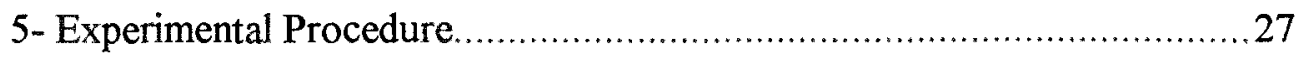

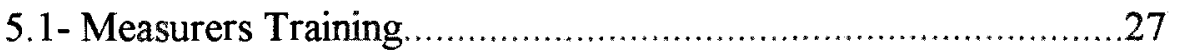

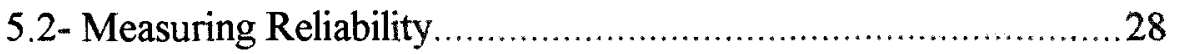

5.2.1- Within and Between Observer..............................29

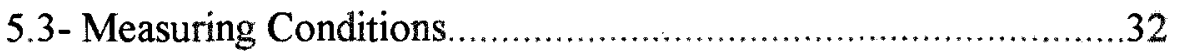

5.4- Measurement Session.................................................. 32

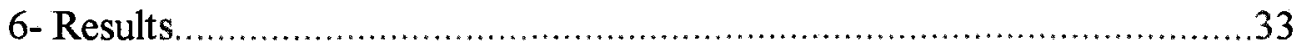




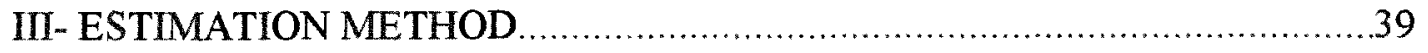

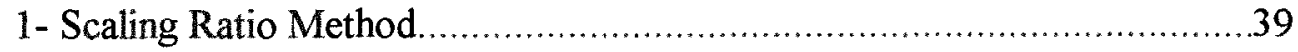

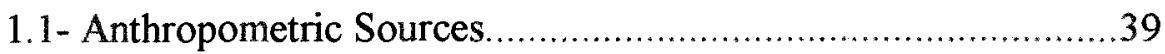

1.2- Dimensions Selection........................................................40

1.3- Experimental Procedure ................................................ 44

1.3.1- Coefficients and Scaling Factors...............................44

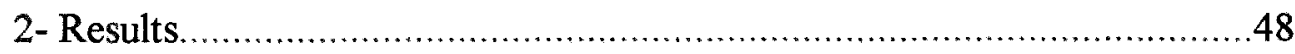

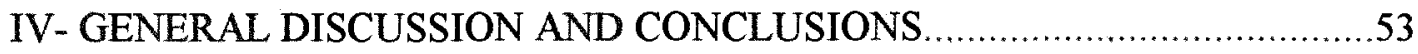

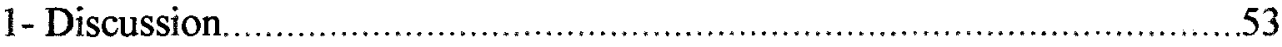

1.1- Anthropometric Survey.................................................... 53

1.1.1- Comparison with Previous Investigations ................. 53

1.1.2- Comparison with Other Populations.........................53

A- Latin American Populations................................53

B- European and Japanese Populations....................55

C- U.S. Population............................................... 54

1.2- Scaling Ratio Method.....................................................58

1.2.1-Method Reliability ............................................58

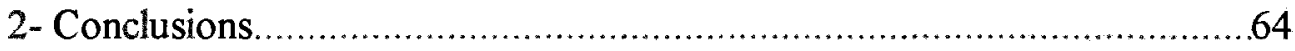

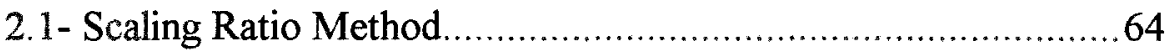

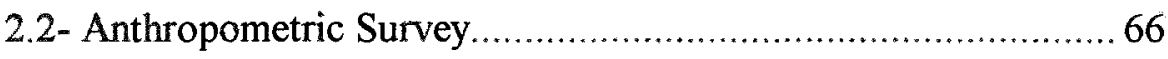

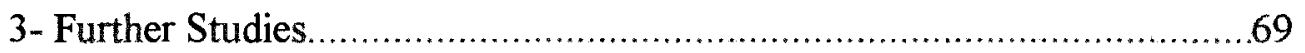

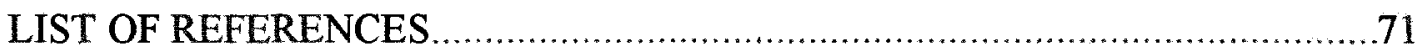

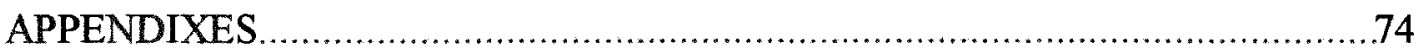

A- Manual of Measurement Procedures.................................................. 74

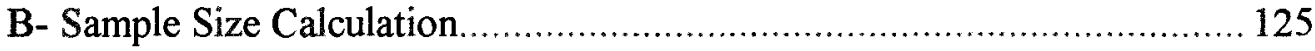

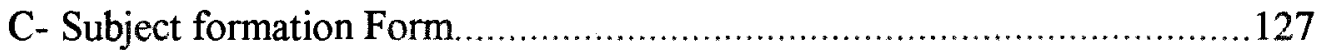




\section{LIST OF TABLES}

TABLE

PAGE

1- Largest Hispanic Groups by National Origins in U.S. (1990). 6

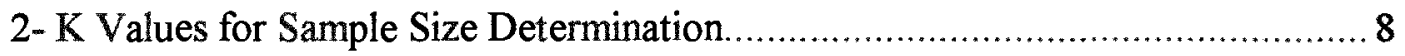

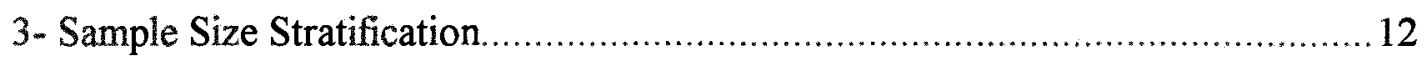

4- Measurement Reliability - Within and Between Observer Tests..........................31

5- Anthropometric Estimates for Colombian Male Adults......................................35

6- Anthropometric Estimates for Colombian Female Adults................................36

7- Selected Anthropometric Data From Male Reference Populations.................... 45

8- Selected Anthropometric Data From Female Reference Populations................. 46

9- Scaling Factors of the Distribution of Stature for Males....................................49

10- Scaling Factors of the Distribution of Stature for Females .............................50

11- Comparison of Anthropometric Male Percentiles Between Scaling Ratio

Estimates and Survey Results.

12- Comparison of Anthropometric Female Percentiles Between Scaling Ratio

Estimates and Survey Results

13- Anthropometric Comparison Between Colombian Adult Male Population and other Similar Ethnic Populations. 
14- Anthropometric Comparison Between Colombian Adults (Male and Female),

European, and Japanese Populations......

15- Anthropometric Comparison Between Colombian Adults (Male and Female), and American Population

16- Errors in Prediction of Anthropometric Male Percentile Values Using the

Scaling Ratio Method.

17- Errors in Prediction of Anthropometric Female Percentile Values Using Scaling

Ratio Method 61

18- Absolute Error Values.

19- Margin of Error for the 50th Percentile Values of Survey's Dimensions .65

20- Percentage of Accommodation for Colombian Population in Imported

Equipment. 68 


\section{LIST OF FIGURES}

FIGURE

PAGE

1-Colombian Geographical Division

2- Selected Standing Anthropometric Dimensions.

3- Selected Sitting Anthropometric Dimensions

4- Selected Anatomical Points

5- Selected Anatomical Points 20

6- Selected Standard Postures.

7- Grid System 25

8- Dimensional Model for the 5th Percentile of the Colombian Adult Female 37

9- Dimensional Model for the 95th Percentile of the Colombian Adult Male 38

10- Selected Anthropometric Dimensions From the Male Reference Populations.... 42

11- Selected Anthropometric Dimensions From the Female Reference Populations. 43

12- Males Error Distribution. 62

13- Females Error Distribution .62 


\section{CHAPTER I - INTRODUCTION}

The goal of engineering anthropometry is to obtain a set of physical measurements that accurately describe the user population. It is essential that the sample be truly representative of the population and the designer be aware of the population from which the data are taken. Therefore, ergonomists are often called to supply designers with anthropometric data of different sexes, ages, races and nationalities. Because of the great variety of people within different ethnicities, the generalizability of anthropometric data measured from a single group is very limited. However, measuring every dimension of every ethnic group would be costly and a prohibitively time consuming task. This tradeoff commonly presents problems for ergonomists and designers; consequently, they are frequently forced to prepare anthropometric tables based on estimations rather than on measurement.

Everywhere, knowledge of anthropometric dimensions for user populations has become a critical requisite in the design of products, machines, furniture, clothing, work places, etc. In a developing country such as Colombia, where industrial growth is rapidly progressing, no anthropometric survey sufficiently comprehensive for practical purposes has yet been published. The most significant contribution has been a survey of stature and weight conducted by The Colombian Ministry of Public Health. (MINSALUD, 1980). 
Consequently, designers, engineers, physicians and architects have to rely on anthropometric data from American and European populations since these are virtually the only available sources. Currently, the Colombian industry is in the process of modernization, and some of the systems used are produced locally, such as home and office furniture, clothes, hand tools, even car assembly, in addition to a wide variety of consumable items. However, heavy machines, military equipment, automobiles, control rooms, personal computers and other sophisticated systems are mainly imported from the U.S., Europe, and Japan, and most of them were not designed to fit the Colombian user. Consequently, the utilization of these products and equipment tends to cause operational difficulties, job related fatigue, injuries, lower productivity and other design related problems.

An anthropometric survey was therefore carried out on 134 Colombian adults living in South Florida. Twenty functional dimensions were measured. In addition, an anthropometric data estimation method was selected, described and validated to be used as a reference when measurement of user population will not be possible. Roebuck, Kromer, and Thomson (1975) and Pheasant (1988) have listed several techniques for data estimation; some of them are: correlations, regressions, sum and difference of dimensions, scaling ratio, etc. The Scaling Ratio Method used by Barkla (1961), in which the parameters (i.e. mean and standard deviation) of unknown variables are scaled from those 
of stature was selected as a reference estimation method..

The main objective of this study was to analyze, discuss and compare, with other populations, the survey and estimation method findings, and to assemble a Colombian adult anthropometric data set which will be sufficiently comprehensive, accurate and useful for general design applications. 


\section{CHAPTER II - ANTHROPOMETRIC SURVEY}

\section{1- LITERATURE REVIEW.}

\section{1- COLOMBLAN ANTHROPOMETRIC STUDIES.}

In Colombia, anthropometric data are scarce. Unfortunately, no anthropometric survey sufficiently extensive for practical applications has yet been published. The most significant contribution to the subject has been a survey of stature and weight conducted by The Colombian Ministry of Public Health. (MINSALUD) in 1980. The sample was chosen to be representative of the general population in terms of age and geographical distribution. Moreover, several surveys concerned with the Colombian population have been published, but these studies were limited to demographic rather than anthropometric variables.

\section{2- SUBJECTS.}

\section{1- TARGET POPULATION.}

South Americans have traditionally been the least likely among the Latin Americans to emigrate to The United States. Lately their number have increased substantially, led by the Colombians, followed by Ecuadorians and Peruvians. Currently, more than a million South Americans live in The United States. Table 1 shows the largest Hispanic groups by 
national origins in U.S.

According to the 1990 U.S. Census, 378,726 Colombians live in the United States;

$83,643(22 \%)$ of them live in Florida and 53,582 (14.2\%) live in Dade County. In addition, an indeterminate number of Colombian immigrants have arrived in Florida in the last 4 years. For this reason, the Colombian population living in South Florida was considered as a representative sample of the general Colombian population, and was taken as a reference target population to conduct this anthropometric survey.

\section{2- SAMPLE SIZE DETERMINATION.}

In an anthropometric survey it is usually impossible or economically undesirable to measure every individual in the target population. Instead a representative group of individuals is selected from the target population. The selected sample must be large enough to assure the accuracy and representiveness of the results while being small enough for the survey to stay within economic constraints (Roebuck et al. 1975).

Anthropometric data are usually distributed in a reasonably normal Gaussian distribution. Hence in this study, estimation of the required sample size was conducted using the regular parametric statistics method. In this method, calculations are done using: (a) an estimate of the dispersion or variability of the dimension that will be measured or used as a reference, (b) a required level of accuracy of the final results, and (c) the desired 
Table 1

Largest Hispanic Groups by National Origins in U.S. (1990)

Country Population

1- Mexico

$13,393,208$

2- $\quad$ Puerto Rico

$2,651,615$

3- Cuba

$1,053,197$

4- Salvador

565,081

5- Dominican $\mathbf{R}$

520,151

6- Colombia

378,726

7- $\quad$ Guatemala

268,779

8- Nicaragua

202,658

9- Ecuador

191,196

10- Peru

175,035

11- Honduras

131,066

12- Argentina

100,921

TOTAL

$19,631,633$ 
confidence coefficient.

Assuming normal distribution of the measured variable, the required sample size (N) can be estimated from the following formula:

$$
\mathrm{N}=[(\mathrm{K} * \mathrm{SD}) / \mathrm{d}]^{2}
$$

Where:

$\mathrm{N}=$ Sample size required.

$\mathrm{SD}=$ Estimated standard deviation of data.

$\mathrm{d}=$ The desired accuracy of the measurement, how close we wish our estimate to be to the true value of the population parameter (d units).

$\mathrm{K}=$ Statistical value on the standard normal distribution for the confidence limit of interest (see Table 2), how certain we wish to be that our estimate will be within the selected number of units of the value of the parameter.

\subsection{1- POPULATION DIMENSION VARIABILITY ESTIMATION.}

Taking into consideration the dimensions selected for this study and those reported in other anthropometric surveys, stature, was selected as a reference dimension, to be used in 
Table 2

$\underline{\mathrm{K} \text { Values for Sample Size Determination }}$

Statistical value

K

1.96

1.65

1.15

1.04
Confidence Limit

$\%$

95

90

75

70 
the sample size calculation, due to its design relevance and its statistical characteristics (normal frequency distribution, variability value and lowest coefficient of variation).

In order to obtain an accurate estimated value of the reference dimension's standard deviation, a small pilot study was conducted. In this study 20 Colombian adults, 10 male and 10 female, were randomly selected and measured using the procedures described in Appendix A. Results showed a standard deviation of $59 \mathrm{~mm}$.

\subsection{2- ACCURACY AND CONFIDENCE LEVEL.}

In the design process, the range of a dimension within the user population which is of interest is generally between the 5 th percentile female value and the 95 th percentile male value. This ensures accommodation of at least 90 percent of the population. Therefore, the accuracy of estimates of the 5 th or 95 th percentile values should be at least as good as the accuracy of an individual measurement.

Taking into consideration the statistical parameters of the dimension selected as a reference and the results of the Stature Measurement Reliability Tests, it was decided therefore to use an accuracy level of 10 millimeters with a confidence limit of 95 percent in the sample size calculation.

\subsection{3- SAMPLE SIZE CALCULATION.}


Sample size was determinated using "Stature" as a reference dimension, with a standard deviation of 59.0 millimeters, a level of accuracy of 10 millimeters, and a confidence level of $95 \%$. The results, included in Appendix B, showed that the minimum sample size required to achieve the desired degree of precision was 134 people.

With this sample size, the standard error of the 5 or 95 percentile partition value was equal to the measurement accuracy; therefore, 134 subjects was regarded as an adequate sample size for the survey.

\subsection{4- SAMPLE STRATIFICATION.}

In order to enable our measurement data to be applicable to the total Colombian adult population, the required sample size (134 subjects) was stratified according to a height distribution which came from the stature's statistics reported by MINSALUD in 1980 .

In addition, the country was divided into 6 geographical regions: Atlantic, Bogota, Central, Oriental, Pacific and others, (see Figure 1). Required sample size for each height interval was then chosen according to the population's sex percentage in each region. Eight subjects that could not be recruitment from a determinate region were replaced by others with similar stature characteristics, but from other regions, in order to maintain the height interval required. Table 3 shows the stratified composition of the required sample size. 
Figure 1. Colombian Geographical Division.

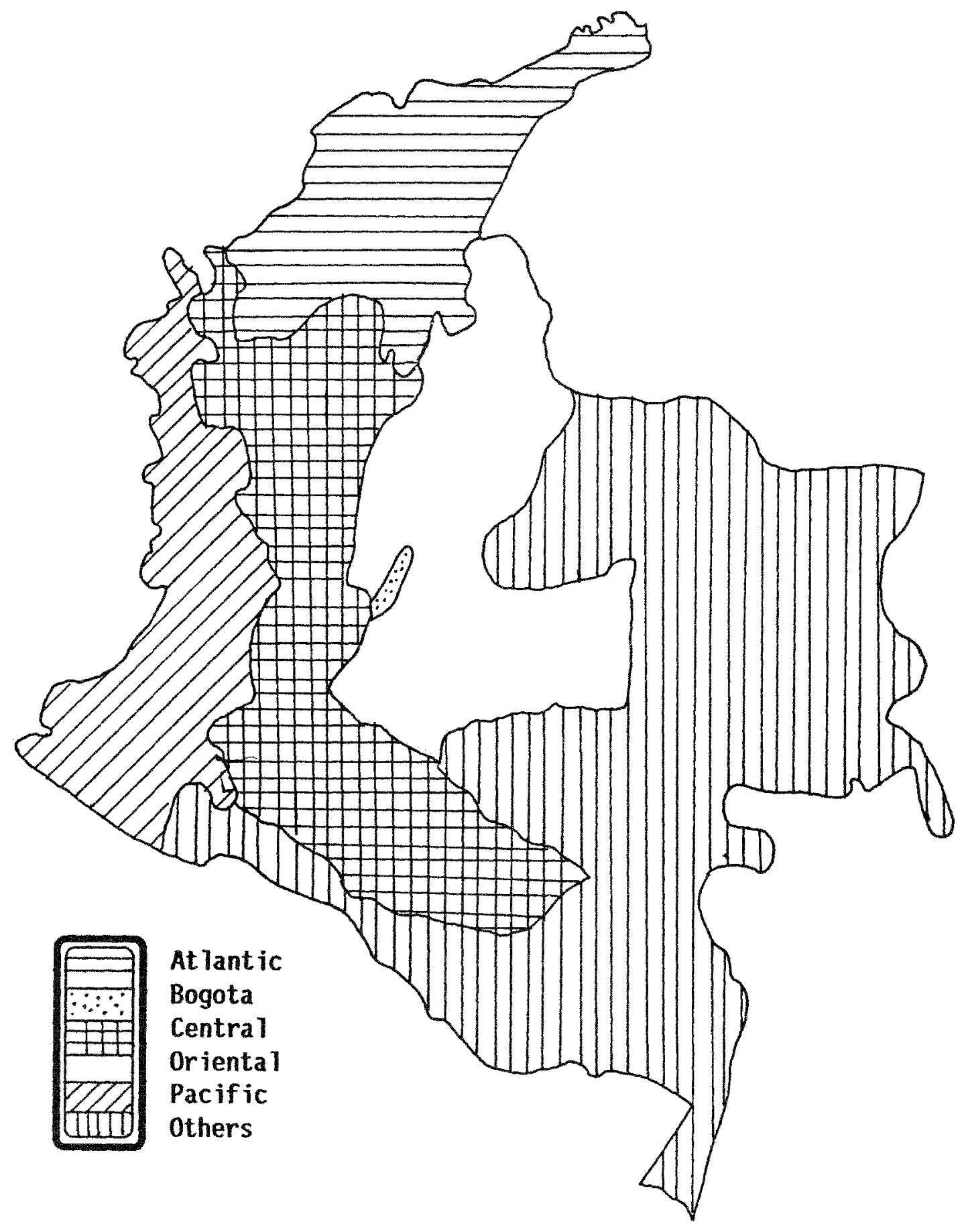


Table 3

\section{Sample Size Stratification}

\begin{tabular}{|c|c|c|c|c|c|c|c|c|c|c|c|}
\hline \multicolumn{2}{|c|}{ Interval } & \multirow[t]{2}{*}{$\%$} & \multicolumn{3}{|c|}{ Required Sample } & \multicolumn{6}{|c|}{ Regions } \\
\hline p\%ile & $\mathrm{mm}$ & & $\mathrm{T}$ & M & F & 1 & 2 & 3 & 4 & 5 & 6 \\
\hline$<5$ & $<1541$ & 5 & 5 & 2 & 3 & 1 & 1 & 1 & 1 & 1 & 0 \\
\hline $5<10$ & $1542-1566$ & 5 & 6 & 3 & 3 & 1 & 1 & 1 & 1 & 1 & 1 \\
\hline $10<20$ & $1567-1596$ & 10 & 14 & 7 & 7 & 3 & 2 & 3 & 2 & 2 & 2 \\
\hline $20<30$ & $1597-1618$ & 10 & 14 & 7 & 7 & 3 & 2 & 3 & 2 & 2 & 2 \\
\hline $30<40$ & $1619-1637$ & 10 & 14 & 7 & 7 & 3 & 2 & 3 & 2 & 2 & 2 \\
\hline $40<50$ & $1638-1655$ & 10 & 14 & 7 & 7 & 3 & 2 & 3 & 2 & 2 & 2 \\
\hline $50<60$ & $1656-1672$ & 10 & 14 & 7 & 7 & 3 & 2 & 3 & 2 & 2 & 2 \\
\hline $60<70$ & $1673-1691$ & 10 & 14 & 7 & 7 & 3 & 2 & 3 & 2 & 2 & 2 \\
\hline $70<80$ & $1692-1713$ & 10 & 14 & 7 & 7 & 3 & 2 & 3 & 2 & 2 & 2 \\
\hline $80<90$ & $1714-1743$ & 10 & 14 & 7 & 7 & 3 & 2 & 3 & 2 & 2 & 2 \\
\hline $90<95$ & $1744-1768$ & 5 & 6 & 3 & 3 & 1 & 1 & 1 & 1 & 1 & 1 \\
\hline$>95$ & $>1769$ & 5 & 5 & 2 & 3 & 1 & 1 & 1 & 1 & 1 & 0 \\
\hline
\end{tabular}

$\begin{array}{llllllllllll}\text { TOTAL } & 100 & 134 & 66 & 68 & & 28 & 20 & 28 & 20 & 20 & 18\end{array}$




\section{3- POPULATION RECRUITMENT AND RESTRICTIONS.}

In order to attain the required sample size, subjects were contacted through the Colombian Consulate and other Colombian associations in South Florida. Subjects, all of all of whom took part on a voluntary basis, were selected randomly and covered all socioeconomic groups. Moreover, to be considered as part of the survey sample, subjects were required to fulfill the following requirements:

1. Geographical location: Colombian people living in South Florida.

2. First generation: Less than 5 years living in U.S.

3. Health: Normal without any serious disease or physical handicap.

4. Sex: Male and female.

5. Ages: $20-64$ years.

\section{3- ANTHROPOMETRIC CONCERNS.}

\section{1- SELECTION AND STANDARDIZATION OF TERMINOLOGY AND TECHNIQUES.}

The selection of anthropometric dimensions, anatomical landmarks, anthropometric positions and measurement techniques included in the survey were based on an analysis of each dimensions' relevance for general design purposes, and on international standard lists of anthropometric techniques and terminology (International Standards Organization 
[ISO], 1983; Hertzberg, 1968; Taner, 1969; and National Aeronautics and Space

Administration [NASA], 1978).

\section{2- ANTHROPOMETRIC DIMENSIONS.}

Examination resulted in a list of 20 linear dimensions, standing and sitting, which are shown in Figures 2 and 3. Definitions are given below in the order in which they were considered in the analysis of data.

1. Stature: The height of the top of the head.

2. Eye height: The height of the inner corner of the eye.

3. Shoulder height: The height of the acromion.

4. Waist height: The height of the waist level.

5. Dactylion height: The height of the tip of the middle finger measured with the arm, hand, and finger extended downward.

6. Elbow height: The height of radiale.

7. Hip breadth: The maximum breadth of the lower torso.

8. Wrist height: The height of the stylion.

9. Upper limb length: The vertical distance from the acromion to the tip of the middle finger.

10. Span: The distance between the tips of the right and left middle fingers when the 
Figure 2. Selected Standing Anthropometric Dimension.
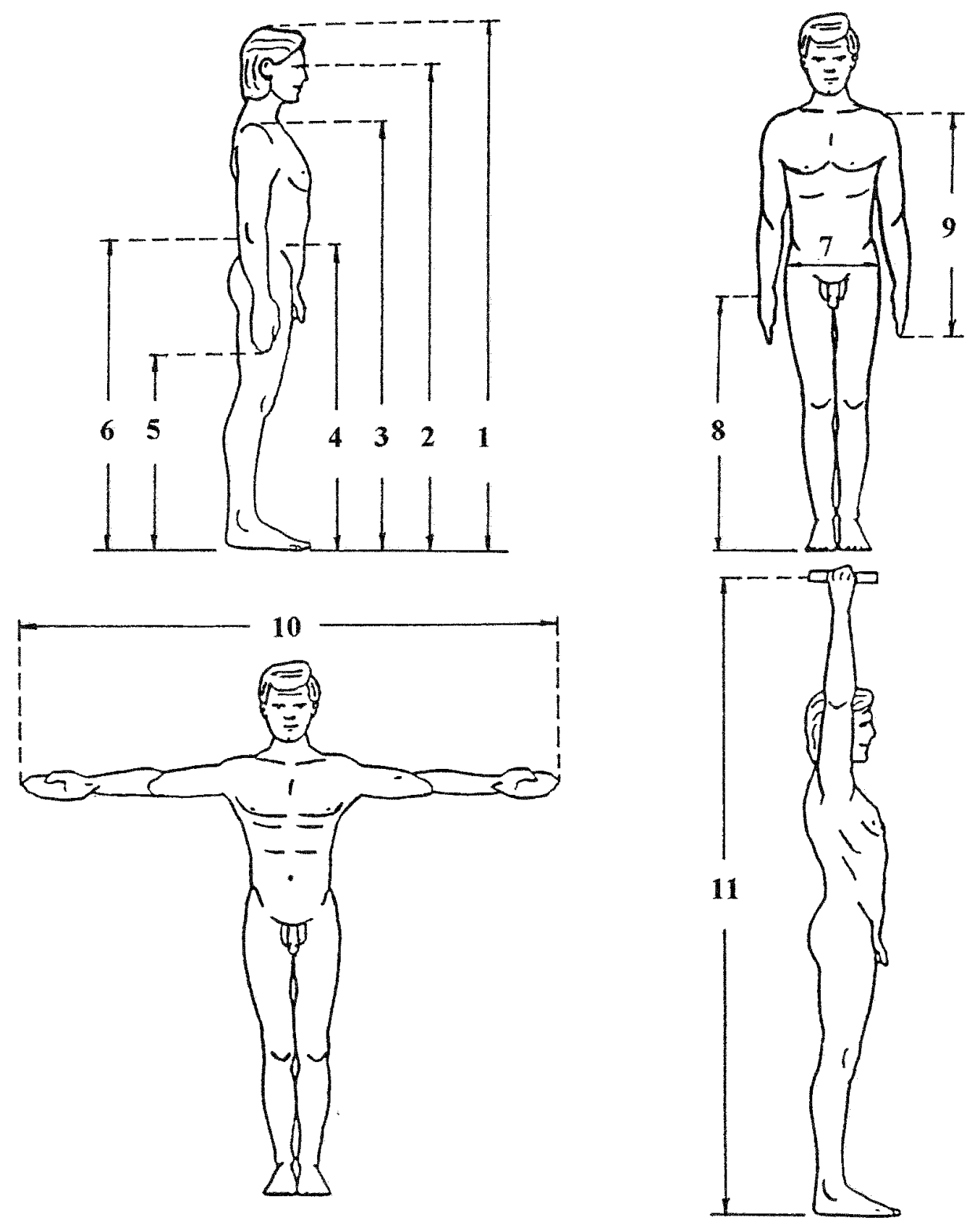

(1) Stature, (2) Eye height, (3) Shoulder height, (4) Waist height, (5) Dactylion height,

(6) Elbow height, (7) Hip breadth, (8) Wrist height, (9) Upper limb length, (10) Span, and (11) Vertical grip reach. 
Figure 3. Selected Sitting Anthropometric Dimensions.
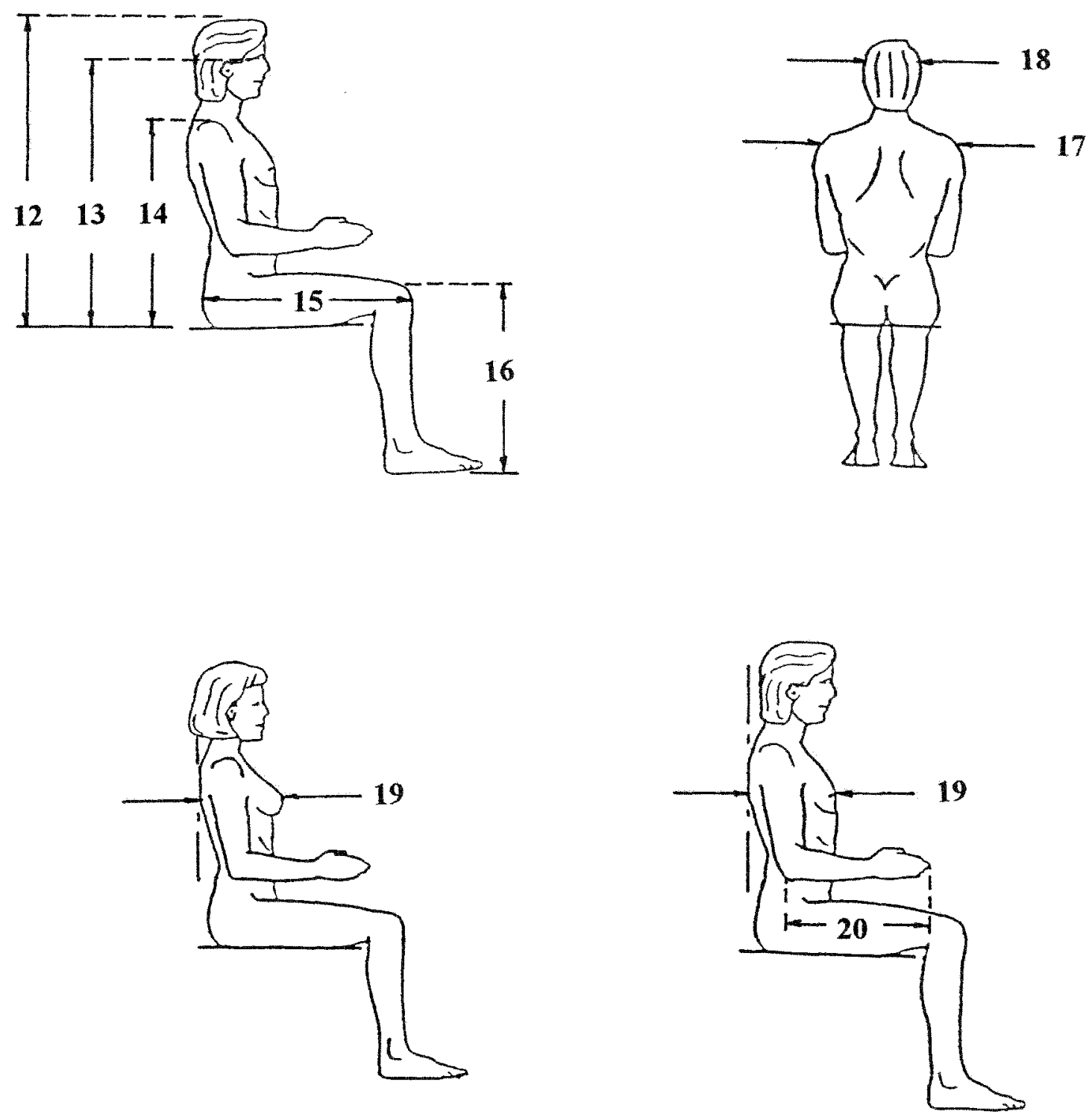

(12) Sitting height, (13) Sitting eye height, (14) Sitting shoulder height, (15) Buttock knee length, (16) Knee height, (17) Shoulder breadth, (18) Head breadth, (19) Chest (bust) depth, and (20) Elbow fingertip length. 
subject's arms are extended laterally.

11. Vertical grip reach: The height of a pointer held horizontal in the subject's fist when the arm is maximally extended upward.

12. Sitting height: The height, from the sitting surface, to the top of the head.

13. Sitting eye height: The height of the inner corner of the eye.

14. Sitting shoulder height: The height of acromion above the sitting surface.

15. Buttock knee length: The horizontal distance from the rearmost surface of the buttocks to the front of the kneecaps.

16. Knee height: The height, from the footrest surface to the musculature just above the knee.

17. Shoulder breadth: The distance across the shoulders from right to left acromions.

18. Head breath: The maximum breadth of the head.

19. Chest-bust depth: Chest: The depth of the torso measured at nipple level. Bust: The horizontal distance from the subject's back to the tip of her bra.

20. Elbow fingertip length: The distance from the tip of the elbow to the tip of the longest finger.

\section{3- ANATOMICAL LANDMARKS.}

Critical anatomical landmarks were located with reference to definite points of the 
skeleton to facilitate palpation of the landmarks. Figures 4 and 5 show selected anatomical points.

Anatomical points used in locating body landmarks were grouped according to their position on the body, and their definitions are given below:

1. The head:

- Canthus: The inner corner of the eye.

- Parietal: Convex bones, that form part of the walls of the calvaria.

- Vertex: The most superior part of the skull.

2. The upper limb:

- Acromion: The most prominent posterior lateral bony of the spine of the scapula, point of the shoulder.

- Dactylion: The tip of the distal phalange of the middle finger.

- Olecranon: The most posterior aspect border of the ulna.

- Radial Stylion: The distal end of the radious.

3. The lower limb:

- Buttock or gluteal region: The prominence on each side formed by the gluteal muscles.

- Hip: The region between the iliac crest and the greater trochanter of the femur.

- Patella: Is a triangular sesamoid bone, embedded in the quadriceps femoris tendon.

- Soles or plantar surfaces: The inferior surface of the foot. 
Figure 4. Selected Anatomical Points.

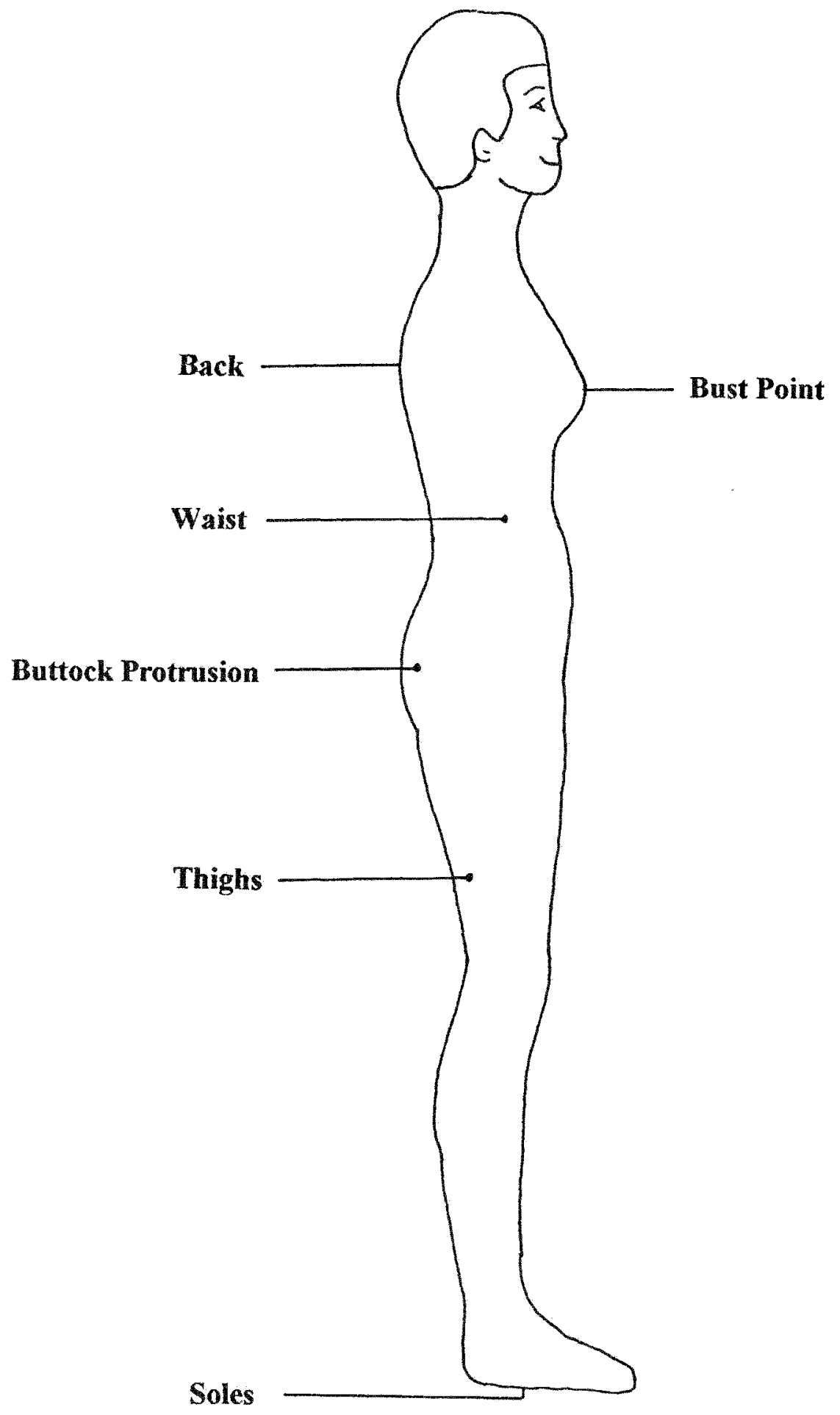


Figure 5. Selected Anatomical Points.

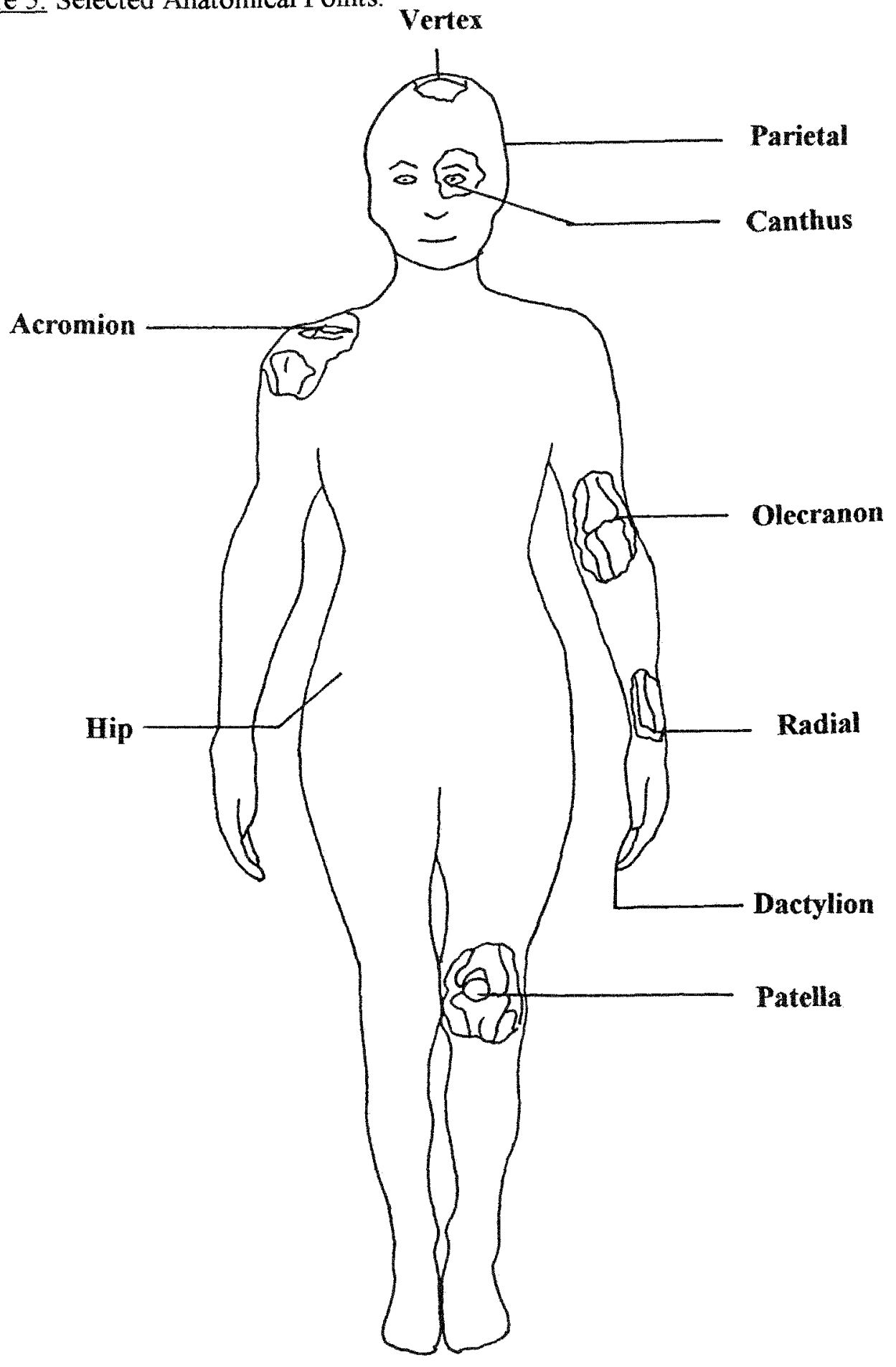




\section{The trunk:}

- Chest: The anterior surface of the torax, overlying the pectoral muscles.

- Waist: Part of the body between the ribs and the hips.

After palpation of the landmarks, anatomical reference points were placed and marked with small crosses using a skin pencil when possible. Small crosses where used because the intersection of two lines was more satisfactory than a dot as a measuring point of reference.

\section{4- ANTHROPOMETRIC POSITION.}

To avoid variations in subject positioning, measurements were taken with subjects in one of the two standard positions: standing or sitting erect. In addition, when the subject's position was important and he or she was measured in a position other than one of these two, position was described in the measurement procedure.

For the measurements made on the body standing erect, the subject's body weight is evenly distributed between both feet, heels together as closely as possible, legs and torso straight without stiffness and head erect with the line of vision parallel to the floor. The arms hang straight but loosely at the sides with the palms alongside but not touching the thighs.

To assume the standard posture in sitting erect, the subject sits on a cushionless flat 
surface, feet on an adjustable footrest so that the knees are flexed to 90 degrees, the long axis of the thighs parallel. The trunk is erect without stiffness and the head is also erect with the path of vision parallel to the plane of the floor. The upper arms are hanging loosely at the sides with elbows flexed at 90 degrees while forearms and hands are held at right angles to the body (NASA, 1978). Figures 6 shows selected anthropometric standard postures.

\section{5- MEASUREMENT TECHNIQUE.}

Procedures followed in taking each measurement were determined after a wide review of techniques in the literature including procedures reported by Hertzberg (1968), NASA (1978), and Lohman, Roche, Martorell (1988).

A manual of measurement procedures, Appendix A, was compiled to be used by the measurement team as a reference book during the training period and in the measuring session. The manual is divided into four parts: The first, introduction, describes the survey and manual aims. The second describes in detail ,for each dimension, the following: (a) dimension definition, (b) landmarks definitions, (c) position of subject, (d) position of measurer, (e) procedure to be followed in taking measurement, and (f) remarks. The third part, is composed of an anatomical and anthropometric terminology glossary, and the fourth shows an illustrated glossary of the anatomical planes, orientations and landmarks. 
Figure 6. Selected Standard Postures.

Standing
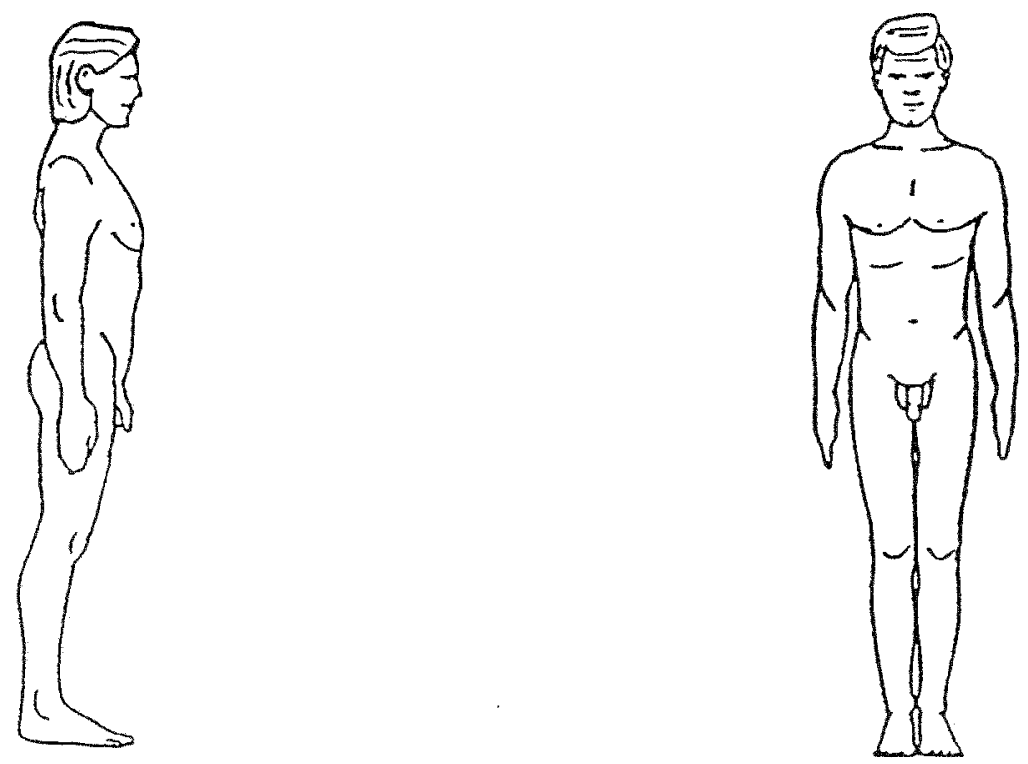

Sitting
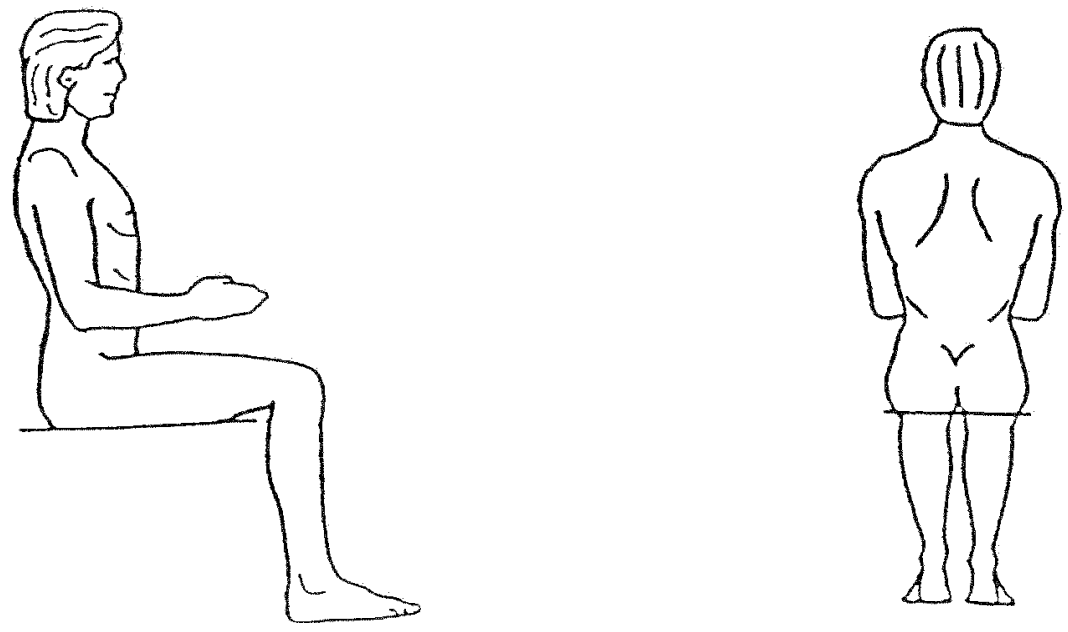


\section{4-MATERIALS.}

\section{1- EQUIPMENT.}

In order to allow a rapid and accurate measurement of the linear dimensions required during the survey, a grid system was designed and manufactured on campus. It consisted of two sheets of plywood hinged together so they stand at right angles; then, pieces of millimeter paper were laminated, to prevent paper wear and tear, and fastened on the walls in such position that they formed a tape measurer on the walls, (see Figure 7). Subjects could be placed in front of the grid, and the projections of the body landmarks to the grid could be used to determine the dimension's values.

Certainly body dimensions could not be projected onto the grid system mentioned above, therefore, several anthropometric instruments, (GPM anthropometer, straight and spreading calipers, and measuring tape), were used to measure these dimensions.

The most important was the anthropometer, which consists of a graduated rod with a sliding branch at a right angle to the rod. This sliding branch allows reaching behind corners and folds of the body whose distances from the reference are read from the scale rod. The rod itself can usually be sectioned for ease of transport and storage. The anthropometer has one branch permanently affixed to its top part. This allows distance measurements between the fixed and the sliding branches: this set up is called a sliding caliper. 
Figure 7. Grid System.

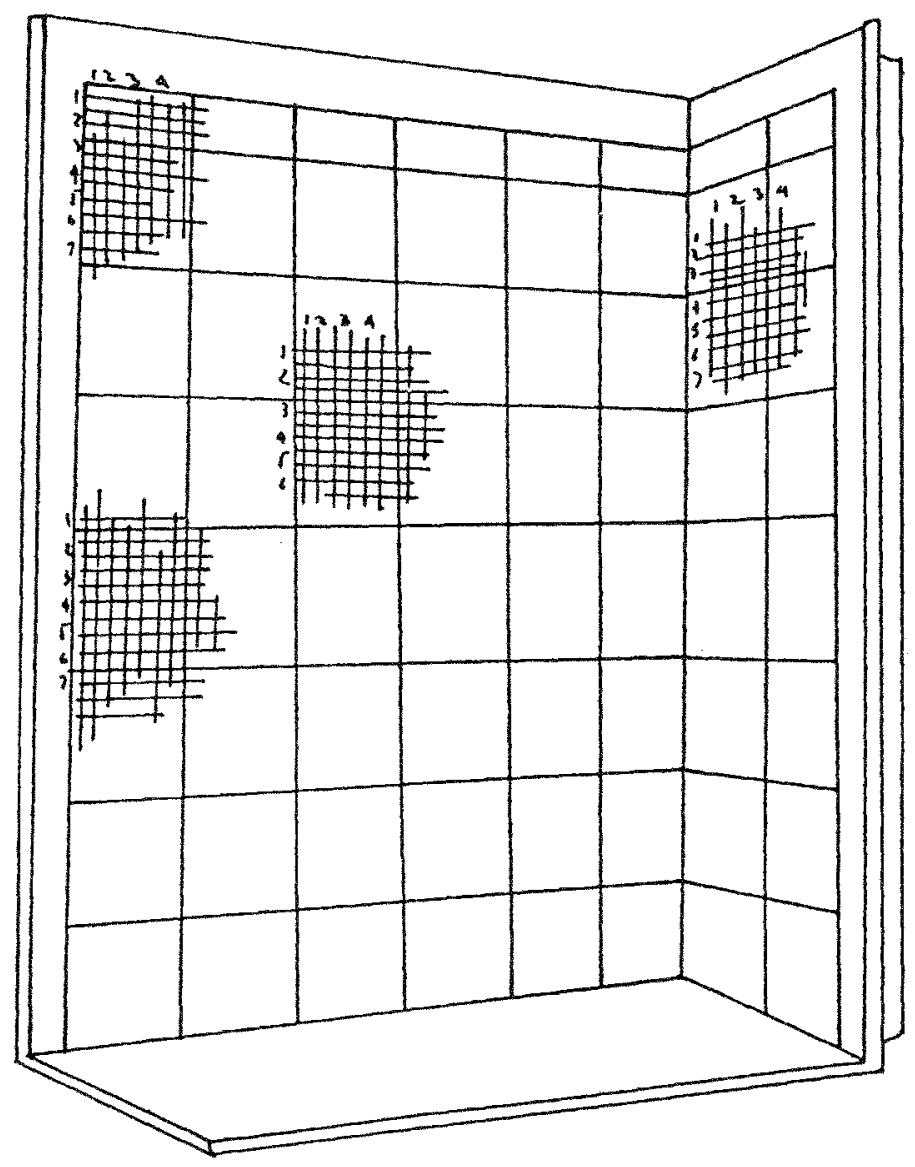


In addition, a spreading caliper was used to take some measurements, it consists of two curved branches which are joined in a hinge, and the distance between the tips of the two opposing ends are read on a scale which is attached in a convenient place between the two parts of the caliper.

An adjustable footrest and a table were employed to obtain the sitting measurements; moreover, skin pencils, measurement manuals and recording forms were utilized in the measurement session.

Instruments used in this study recorded measurements in the metric system, and all physical measurements readings were recorder in millimeters. To maintain accuracy, instruments were periodically calibrated against reliable standard gage blocks. Gage blocks are small blocks of hard dimensionally stable steel or other material, made up in sets which can be stacked up to provide accurate dimensions in the calibration process.

\section{2- MEASUREMENT TEAM.}

To ensure maximum reliability on the measurement process a work team was selected. It consisted of 2 measurers, the principal investigator of this project and a student of the Industrial Engineering graduate program at Florida International University.

\section{3- MEASUREMENT SESSION PLACE.}


All measurement session took place in the Ergonomics Laboratory at Florida

International University, Miami, Florida. To provide an appropiate workplace environment during the measuring session, anthropometric equipment was positioned in such way that it provided enough room and comfort for subjects and measurers;

furthermore, temperature in the laboratory was air conditioned at 22-25 Celsius degrees.

\section{4- DATA COLLECTION.}

In order to collect the subject data required in the survey, a special recording form was designed. The form was divided into two parts: The first included the following subject information: (a) date of birth, (b) age, (c) sex, (d) name, (e) place of birth, (f) occupation, and $(\mathrm{g})$ date of measurement. The second included a list of dimension to be taken in the survey. The data collection form is included in Appendix C.

\section{5- EXPERIMENTAL PROCEDURE.}

\section{1- MEASURERS TRAINING.}

Before beginning the training period, a manual of measurement procedures (which described in detail the survey aims, the placing of the necessary body landmarks, and the methods to be followed in taking measurements), was supplied to each measurer to be examined and used as a reference book during the training and in the field work. 
A training period of one week prior to commencing any field measurements was carried out. Initially the two measurers trained together to ensure, as far as possible, cooperation within the team, familiarity with the care and operation of the equipment, and standardization of landmarks, postures and measuring technique. The training period was also used to test the equipment, different designs of field work layout, and the consistency between trials for a given measurer and between different measurers (accuracy).

\section{2- MEASUREMENTS RELIABILITY.}

To check on consistency in the measuring process before permanent measurements began, estimates of the reliability of measurers taken by the work team were obtained. Two reliability tests were conducted: Within-observer and between observers.

Observers reliability was measured using the Standard Error of Measurement (SEM) technique, which is based on the differences between the actual readings and the mean. Thorndike (1982) defined SEM for a given body dimension as:

$$
\mathrm{SEM}=\mathrm{SD} *(1-\mathrm{r})^{1 / 2}
$$

Where:

$\mathrm{SD}=$ Standard deviation of the readings (equal in the two readings). 
$r=$ Correlation or reliability coefficient, with

$$
r=\{[(X-\bar{X}) *(Y-\bar{Y})] /(n-1)] /\left[\left(\text { variance }^{1 / 2}\right)^{*}(\text { variance } y)\right]
$$

where $r$ is the covariance of each pair of readings $x$ and $y$ averaged across all pair of

readings divided by the product of the variance's square root of all pairs of readings $\mathrm{x}$ and y. The smaller the statistic (SEM) the greater is the reliability of the observer. The value of the statistic lies in being able to make statements about the limits within which the true value of a given body dimension lies on a certain percentage of occasions. For large samples, the bounds will encompass the true body dimension on $95 \%$ of occasions.

$$
\pm(1.96) *(\mathrm{SEM})
$$

\subsection{1- WITHIN AND BETWEEN OBSERVER RELIABILITY TEST.}

For these tests, each observer measured 20 subjects, 10 male and 10 female, in 5 different positions using the procedures described in Appendix A. For the first test, within observer reliability, all dimensions were taken twice by each observer, and subjects were completely repositioned for the second set of measurements. For each observer, the SEM was calculated for each body dimension; moreover, because of the variation between 
observers in the SEM for a given dimension, an average of the SEM values was

calculated. This pooled value gives estimates of within observer variation, and draws attention to dimensions where there is little or considerable variation in measurement.

Results are shown in Table 4. Examination of results for all body dimension across observers shows a low degree of variation, with a reliability coefficient (r) ranged from 0.9350 to 0.9970 , the SEM varied from $3.29 \mathrm{~mm}$ to $5.74 \mathrm{~mm}$, and the SEM averaged from $4.37 \mathrm{~mm}$ to $4.74 \mathrm{~mm}$.

For the second test, between observer reliability, body dimensions were measured by both observers. The subject was completely repositioned between measurements by each observer, and the SEM was calculated for each body dimension. Results are shown in Table 4. Results between observers also showed a low degree of variation, with a reliability coefficient (r) ranged from 0.9474 to 0.9964 , and the SEM varied from $4.03 \mathrm{~mm}$ to $6.93 \mathrm{~mm}$.

In general, reliability results showed that for given body dimensions, the within and between observer reliability were very high, to a first order of approximation in most cases, and that no measurement on any body dimension is absolutely precise.

In order to establish the accuracy bounds for all anthropometric dimensions, it was decided to use the SEM average value of $5 \mathrm{~mm}$, and a confidence limit of $95 \%$.

Therefore, the accuracy bounds 
Table 4

Measurement Reliability - Within and Between Observer Tests

Within Observer Test

\begin{tabular}{|c|c|c|c|c|c|c|}
\hline \multirow[b]{3}{*}{ Dimension } & \multicolumn{4}{|c|}{ Observer } & \multicolumn{2}{|c|}{ Average } \\
\hline & \multicolumn{2}{|c|}{ A } & \multicolumn{2}{|c|}{ B } & & \\
\hline & $r$ & SEM & $r$ & SEM & $r$ & SEM \\
\hline Stature & 0.997 & 3.73 & 0.992 & 5.742 & 0.994 & 4.736 \\
\hline Shoulder height & 0.993 & 4.806 & 0.994 & 4.434 & 0.993 & 4.62 \\
\hline Hip breadth & 0.935 & 5.457 & 0.979 & 3.297 & 0.957 & 4.377 \\
\hline Sitting height & 0.981 & 5.326 & 0.99 & 3.905 & 0.985 & 4.615 \\
\hline Shoulder breadth & 0.964 & 5.244 & 0.976 & 3.784 & 0.97 & 4.514 \\
\hline Minimum & 0.935 & 3.73 & 0.976 & 3.297 & 0.957 & 4.377 \\
\hline Maximum & 0.997 & 5.457 & 0.994 & 5.742 & 0.994 & 4.736 \\
\hline
\end{tabular}

\section{Between Observers Test}

\begin{tabular}{llc} 
& \multicolumn{2}{c}{ Observers A and B } \\
\cline { 2 - 3 } Dimension & $\mathrm{r}$ & $\mathrm{SEM}$ \\
& & \\
\hline Stature & 0.996 & 4.037 \\
Shoulder height & 0.986 & 6.931 \\
Hip breadth & 0.947 & 4.845 \\
Sitting height & 0.983 & 4.972 \\
Shoulder breadth & 0.969 & 4.881 \\
Minimum & $\mathbf{0 . 9 4 7}$ & $\mathbf{4 . 0 3 7}$ \\
Maximum & $\mathbf{0 . 9 9 6}$ & $\mathbf{6 . 9 3 1}$ \\
\hline
\end{tabular}

Note. $\mathrm{r}=$ Reliability Coefficient, and SEM = Standard Error of Measurement. 


$$
\mathrm{x} \pm(1.96) *(5) \text { or } \mathrm{x} \pm 10 \mathrm{~mm}
$$

will encompass the true body dimension on $95 \%$ of occasions.

\section{3- MEASURING CONDITIONS.}

All measurement sessions were carried out in the period between June and September 1994. To minimize inconvenience to subjects, measurements were taken in as short a period of time as possible. It was found that all measurements could be taken on one subject in 10 minutes by a measuring team. However, an average of 8 subjects was measured each day. The whole time taken for measurements in the field was approximately 20 days. During the measurement session, all subjects were required to be

seminude or lightly clothed and bare footed. For this purpose, a fitting room was provided for the subjects.

\section{4- MEASUREMENT SESSION.}

During a brief interview prior to the measuring session, subjects were informed about the study aims, risks and confidentially. In addition, they were asked to provide a written informed consent and some details about their ages, places of birth, places of family origin 
and occupations.

For the measuring session, subjects were required to be bare footed and to be seminude or lightly clothed. Measurers located certain landmarks on the bodies of the subjects, and marked them with a small crosses using a skin pencil when possible.

After all landmarks were marked, subjects were properly positioned in a standard posture, and a set of 20 body dimensions, three measurements for each, were conducted following the procedures described in Appendix A. Furthermore, three subjects that discontinued participation before the measurement session was completed were replaced by others with the same required characteristics.

Finally, subject's anthropometric data were transcribed onto a special form and the average of the three trials for each dimension was calculated and used as final data for anthropometric analysis.

\section{6- RESULTS.}

Descriptive statistics were summarized in terms of ranges, means, standard deviations (SD), coefficients of variation (CV), standard errors of the means (SEM), and percentiles. Percentiles values $, 1 \mathrm{st}, 5$ th, 50 th, 95 th, and 99 th, were included to permit various criterion levels to be chosen. Statistical parameters were computed from the male and female populations by using computerized statistical analysis software, and their results are 
summarized in Tables 5 and 6.

In the design process, the range of a dimension within the user population which is of interest is generally between the 5 th percentile female value and the 95 th percentile male value, this ensure accommodation of at least 95 th percent of the population. Therefore, based on the anthropometric data given in Tables 5 and 6 , dimensional models were calculated for the 5 th percentile female and the 95 th percentile male. Figures 8 and 9 showed the dimensional models for the Colombian adult male and female respectively. 
Table 5

\section{Anthropometric Estimates for Colombian Male Adults}

\begin{tabular}{|c|c|c|c|c|c|c|c|c|c|c|c|c|}
\hline \multirow[b]{2}{*}{ \# } & \multirow[b]{2}{*}{ Dimension } & \multicolumn{2}{|c|}{ Range } & \multirow[b]{2}{*}{ Mean } & \multirow[b]{2}{*}{ S.D. } & \multirow[b]{2}{*}{ C. of V. } & \multirow[b]{2}{*}{ S.E.M. } & \multicolumn{3}{|c|}{ Percentiles } & \multirow[b]{2}{*}{95 th } & \multirow[b]{2}{*}{$99 \mathrm{~h}$} \\
\hline & & Min. & Max. & & & & & $1 \mathrm{st}$ & 5 th & 50 th & & \\
\hline 1 & Stature & 1488 & 1813 & 1654 & 65.7 & 4 & 8.1 & 1501 & 1546 & 1654 & 1762 & 1807 \\
\hline 2 & Eye height & 1367 & 1696 & 1530 & 64.6 & 4.2 & 7.9 & 1380 & 1424 & 1530 & 1636 & 1680 \\
\hline 3 & Shoulder height & 1194 & 1519 & 1373 & 61.5 & 4.5 & 7.6 & 1231 & 1237 & 1374 & 1475 & 1517 \\
\hline 4 & Waist height & 913 & 1209 & 1010 & 60.6 & 6 & 7.5 & 869 & 911 & 1011 & 1110 & 1152 \\
\hline 5 & Dactylion height & 511 & 706 & 621.1 & 37.3 & 6 & 4.6 & $\$ 34$ & 560 & 621 & 682 & 708 \\
\hline 6 & Elbow height & 893 & 1152 & 1037 & 50 & 4.8 & 6.1 & 921 & 956 & 1038 & 1120 & 1155 \\
\hline 7 & Hip breadth & 254 & 362 & 315.3 & 28.7 & 9.1 & 3.5 & 248 & 268 & 315 & 362 & 382 \\
\hline 8 & Wrist height & 691 & 1007 & 809.2 & 45.7 & 5.6 & 5.6 & 703 & 734 & 809 & 884 & 916 \\
\hline 9 & Upper limb length & 673 & 813 & 731.5 & 31.9 & 4.4 & 3.9 & 657 & 679 & 732 & 784 & 806 \\
\hline 10 & Span & 1542 & 1841 & 1697 & 71.5 & 4.2 & 8.8 & 1531 & 1580 & 1697 & 1815 & 1864 \\
\hline 11 & Vertical grip reach & 1569 & 2245 & 1974 & 108.9 & 5.5 & 13.4 & 1720 & 1795 & 1974 & 2152 & 2228 \\
\hline 12 & Sitting height & 786 & 964 & 866.8 & 46.9 & 5.4 & 5.8 & 758 & 790 & 867 & 944 & 976 \\
\hline 13 & Sitting eye height & 663 & 868 & 748 & 48 & 6.4 & 5.9 & 636 & 669 & 748 & 827 & 860 \\
\hline 14 & Sitting shoulder height & 497 & 667 & 567.9 & 36.3 & 6.4 & 4.5 & 483 & 508 & 568 & 627 & 652 \\
\hline 15 & Buttock knee length & 484 & 630 & 553.9 & 29.7 & 5.4 & 3.7 & 485 & 505 & 554 & 603 & 623 \\
\hline 16 & Knee height & 406 & 618 & 507.2 & 32.4 & 6.4 & 4 & 432 & 454 & 507 & 560 & 583 \\
\hline 17 & Shoulder breadth & 347 & 485 & 424.8 & 27.3 & 6.4 & 3.4 & 361 & 380 & 425 & 470 & 488 \\
\hline 18 & Head breadth & 143 & 173 & 156.1 & 6.2 & 4 & 0.8 & 142 & 146 & 156 & 166 & 171 \\
\hline 19 & Chest depth & 176 & 296 & 245.2 & 27.4 & 11.2 & 3.4 & 181 & 200 & 245 & 290 & 309 \\
\hline 20 & Elbow fingertip length & 409 & 491 & 449.6 & 17.1 & 3.8 & 2.1 & 410 & 422 & 450 & 478 & 489 \\
\hline
\end{tabular}

Note. Adults aged $20-64$ years. All dimensions in millimeters. 


\section{Anthropometric Estimates for Colombian Female Adults}

\begin{tabular}{|c|c|c|c|c|c|c|c|c|c|c|c|c|}
\hline \multirow[b]{2}{*}{$\#$} & \multirow[b]{2}{*}{ Dimension } & \multicolumn{2}{|c|}{ Range } & \multirow[b]{2}{*}{ Mean } & \multirow[b]{2}{*}{ S.D. } & \multirow[b]{2}{*}{ C.of V. } & \multirow[b]{2}{*}{ S.E.M. } & \multicolumn{3}{|c|}{ Percentiles } & \multirow[b]{2}{*}{ 95th } & \multirow[b]{2}{*}{99 th } \\
\hline & & Min. & Max. & & & & & $1 \mathrm{st}$ & 5 th & 50 th & & \\
\hline 1 & Stature & 1449 & 1649 & 1545 & 52.4 & 3.4 & 6.5 & 1423 & 1459 & 1545 & 1631 & 1668 \\
\hline 2 & Eye height & 1337 & 1583 & 1431 & 51.4 & 3.6 & 6.4 & 1312 & 1348 & 1432 & 1516 & 1552 \\
\hline 3 & Shoulder height & 1192 & 1376 & 1276 & 46.5 & 3.6 & 5.8 & 1168 & 1200 & 1277 & 1353 & 1358 \\
\hline 4 & Waist height & 879 & 1039 & 958.7 & 42.4 & 4.4 & 5.3 & 860 & 889 & 959 & 1028 & 1058 \\
\hline 5 & Dactylion height & 527 & 677 & 593.2 & 36 & 6 & 4.5 & 509 & 534 & 593 & 652 & 677 \\
\hline 6 & Elbow height & 896 & 1063 & 975.4 & 39.9 & 4.1 & 4.9 & 882 & 910 & 975 & 1041 & 1068 \\
\hline 7 & Hip breadth & 268 & 444 & 314.9 & 26.3 & 8.3 & 3.3 & 254 & 272 & 315 & 358 & 376 \\
\hline 8 & Wrist height & 683 & 847 & 764.2 & 37 & 4.9 & 4.6 & 678 & 704 & 764 & 825 & 850 \\
\hline 9 & Upper limb length & 603 & 735 & 673.9 & 29 & 4.3 & 3.6 & 606 & 626 & 674 & 722 & 742 \\
\hline 10 & Span & 1453 & 1871 & 1573 & 78.2 & 5 & 9.7 & 1391 & 1445 & 1573 & 1701 & 1755 \\
\hline 11 & Vertical grip reach & 1529 & 1996 & 1842 & 82.1 & 4.5 & 10.2 & 1651 & 1708 & 1842 & 1977 & 2034 \\
\hline 12 & Sitting height & 758 & 913 & 827.4 & 32.3 & 3.9 & 4 & 752 & 774 & 827 & 880 & 903 \\
\hline 13 & Sitting eye height & 647 & 798 & 708.2 & 29.8 & 4.2 & 3.7 & 639 & 659 & 708 & 757 & 778 \\
\hline 14 & Sitting shoulder height & 447 & 660 & 557 & 32 & 5.8 & 4 & 482 & 504 & 557 & 610 & 632 \\
\hline 15 & Buttock knee length & 450 & 607 & $\$ 29.2$ & 29.9 & 5.7 & 3.7 & 460 & 480 & 529 & 578 & 599 \\
\hline 16 & Knee height & 431 & 528 & 473.4 & 23 & 4.9 & 2.9 & 420 & 436 & 473 & 511 & 527 \\
\hline 17 & Shoulder breadth & 338 & 417 & 371.2 & 13.6 & 3.7 & 1.7 & 340 & 349 & 371 & 393 & 403 \\
\hline 18 & Head breadth & 137 & 172 & 151.4 & 7.1 & 4.7 & 0.9 & 135 & 140 & 151 & 163 & 168 \\
\hline 19 & Chest depth & 174 & 570 & 256.1 & 48.2 & 18.8 & 6 & 144 & 177 & 256 & 335 & 368 \\
\hline 20 & Elbow fingertip length & 359 & 446 & 407.6 & 19.1 & 4.7 & 2.4 & 363 & 376 & 408 & 439 & 452 \\
\hline
\end{tabular}

Note. Adults aged 20 - 64 years. All dimensions in millimeters. 
Figure 8. Dimensional Model for 5th Percentile of the Colombian Adult Female.
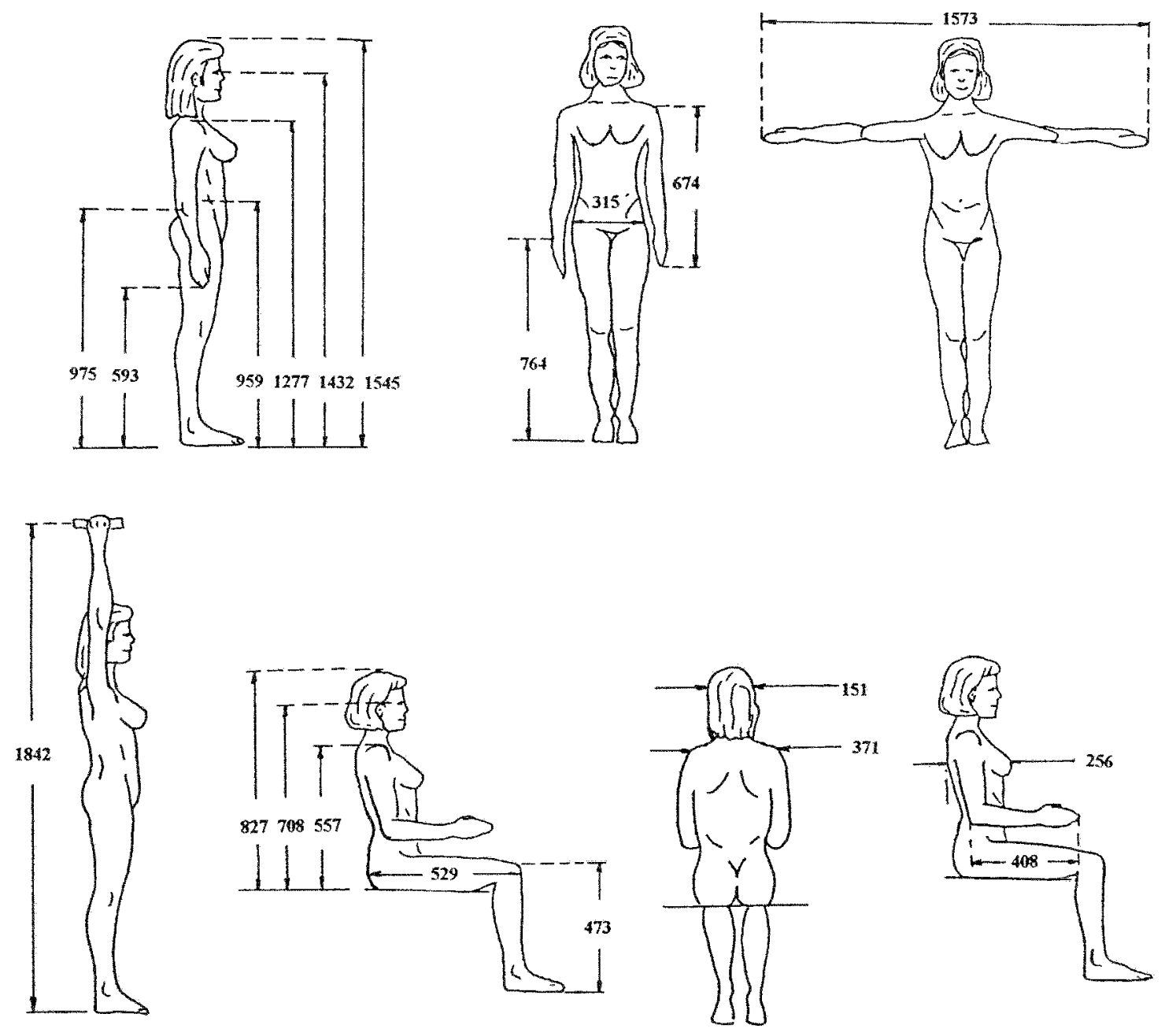

Note. All dimensions in millimeters. 
Figure 9. Dimensional Model for 95th Percentile of the Colombian Adult Male.
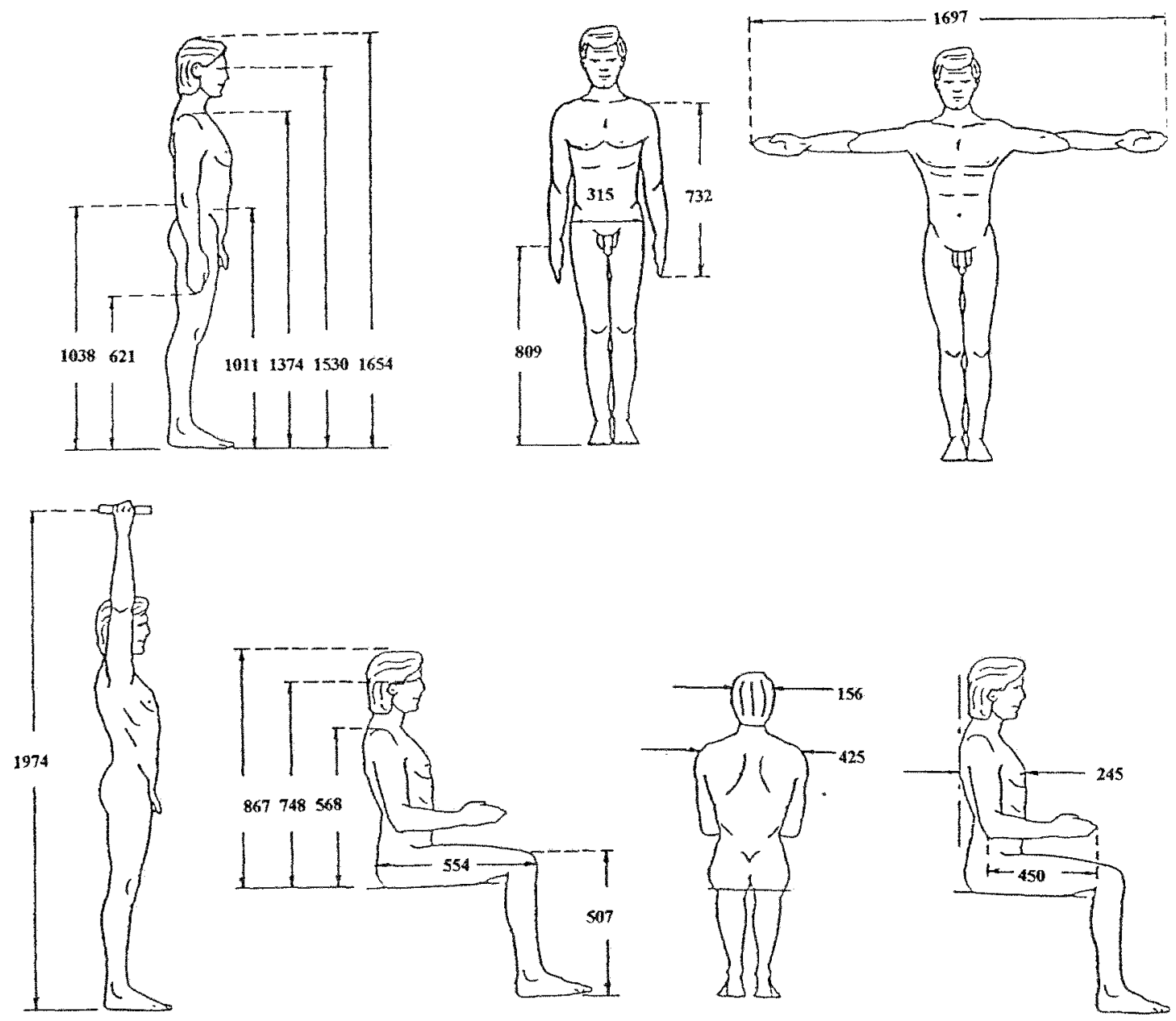

Note. All dimensions in millimeters. 


\section{CHAPTER III - ESTIMATION METHOD}

\section{1- SCALING RATIO METHOD.}

\section{1- ANTHROPOMETRIC SOURCES.}

Anthropometric data for Latin American populations have not been well documented.

There have been some large scale anthropometric surveys, but most of them have been conducted only for the military sector. The most important is a survey conducted by Dobbins and Kindick (1972), on 1850 army personal from various Latin American countries. Eighteen countries were included, 10 from South America, 6 from Central American and one from the Caribbean. The largest population was from Chile: 411 , a few more than 200 subjects were from both Colombia and Ecuador; and between 100 and 200 from other countries: Bolivia, Panama, Peru, and Venezuela. For the civilian populations, few surveys have been conducted, and most of them only included male subjects.

Therefore, there is a need for civilian, male and female, accurate anthropometric data.

Anthropometric data sources dealing with adult Latin American populations were collected and divided into two groups: A and B. Sources in group A were considered as a "Reference Population", and they were required, as much as possible, to be similar in age, sex, and ethnicity to the Colombian adult population for whom anthropometric estimates were required. Group A included the following male populations: (a) Brazilian (Ferreira, 
1988), (b) Latin American Armed Forces (Dobbins and Kindick, 1972), (c) Mexican

(Kelly, 1947), and (d) Puerto Rican (Thieme, 1959). For the Latin American female populations few representative anthropometric studies were found; therefore, a selection of international female anthropometric data was compiled to be used as a reference population. Sources selected also were required to be similar in age, sex and to have a mean stature value close to $1650 \mathrm{~mm}$, which was the mean stature value of the Colombian female population reported by MNSALUD (1980). Group A included the following female sources: (a) Chinese (Pheasant, 1988), (b) Indian (Eveleth and Tanner, 1976), (c) Japanese (NASA, 1978), (d) Polish (Batogowska and Slowikowski, 1973), (e) Puerto Rican (Thieme, 1959), and (F) Turkish (Gonen, Kalinkara and Ozgen, 1991).

Group B was considered as a "Target Population" for which estimates of various dimensions were required. It included the results of the Colombian adult anthropometric survey conducted in this study. Only the following stature data was used for predictive purposes: (a) Male: mean of $1654 \mathrm{~mm}$ and standard deviation of $65.7 \mathrm{~mm}$, and (b) Female: mean of $1545 \mathrm{~mm}$ and standard deviation of $52.4 \mathrm{~mm}$.

\section{2- DIMENSIONS SELECTION.}

Selection of anthropometric dimensions to be included in the study was based on an analysis of each dimensions relevance for general design proposes, and on the availability 
of dimension information in the reference populations. Dimensions selected from comparison between studies, were required to be defined and measured using the same technique; moreover, dimensions which were calculated on estimation techniques rather than direct measurement were excluded.

Examination resulted in a list of 18 linear dimensions, 11 for male and 18 for female, which are shown in Figures 10 and 11 respectively. Definitions are given below in the order in which they were considered in the data analysis.

1. Eye height: The height of the inner corner of the eye.

2. Shoulder height: The height of the acromion.

3. Waist height: The height of the waist level.

4. Dactylion height: The height of the tip of the middle finger measured with the arm, hand, and finger extended downward.

5. Elbow height: The height of the radiale.

6. Hip breadth: The maximum breadth of the lower torso.

7. Upper limb length: The vertical distance from the acromion to the tip of the middle finger.

8. Span: The distance between the tips of the right and left middle fingers when the subject's arms are maximally extended laterally.

9. Vertical grip reach: The height of a pointer held horizontal in the subject's fist when the 
Figure 10. Selected Anthropometric Dimensions from Male Reference Populations.
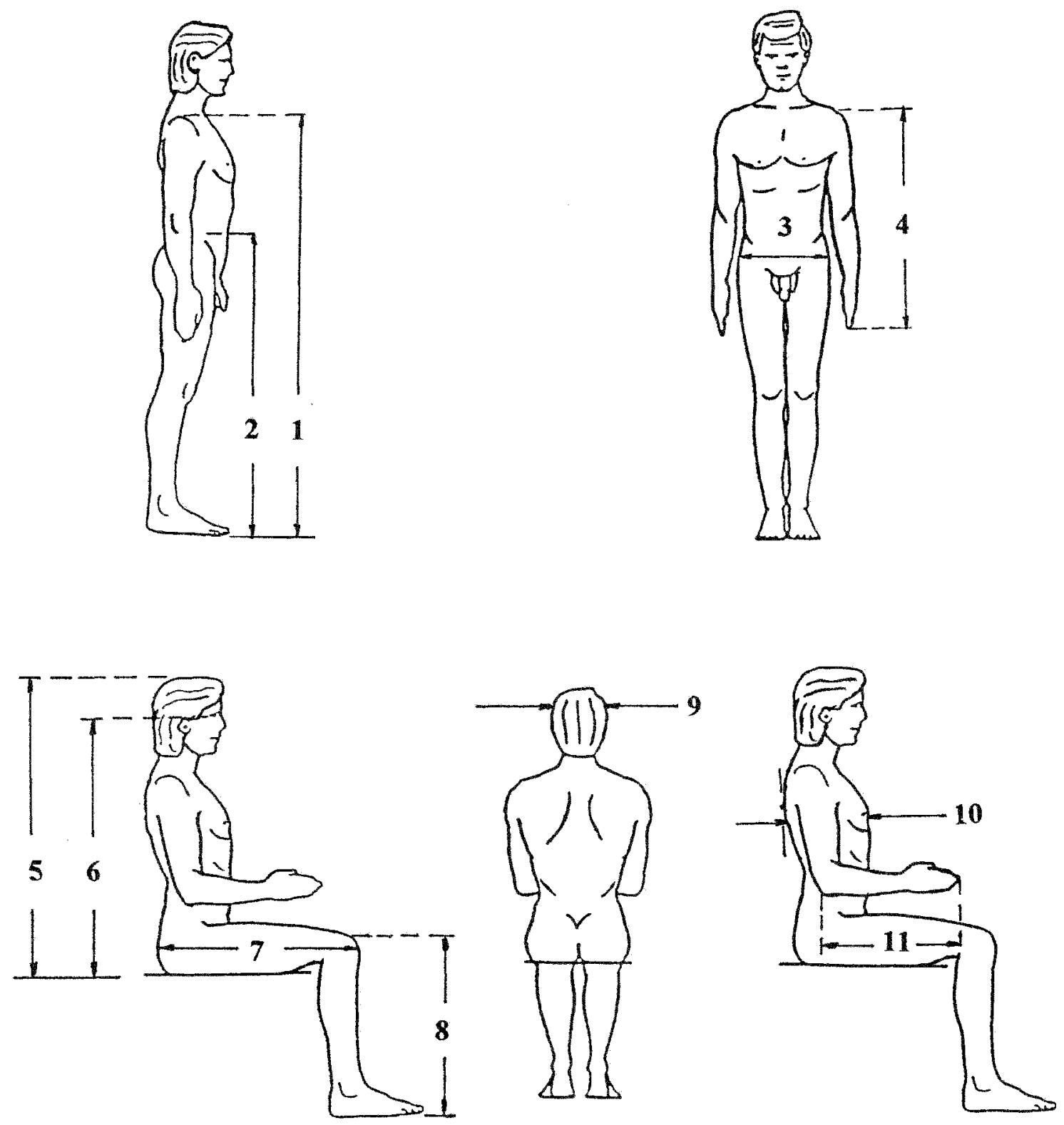

(1) Shoulder height, (2) Waist height, (3) Hip breadth, (4) Upper limb length, (5) Sitting height, (6) Sitting eye height, (7) Buttock knee length, (8) Knee height, (9) Head breadth, (10) Chest depth, and (11) Elbow fingertip length. 
Figure 11. Selected Anthropometric Dimensions from Female Reference Populations.
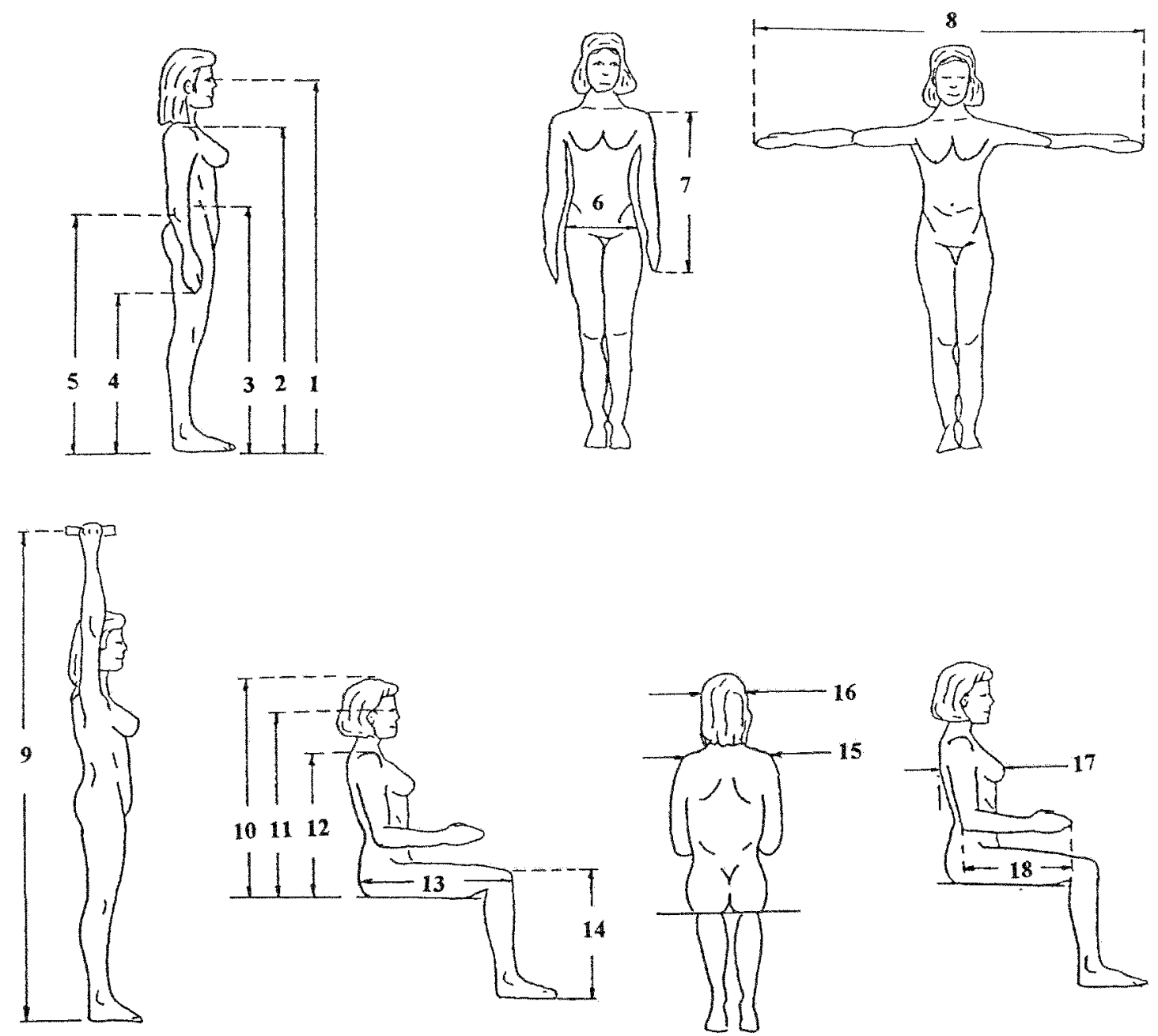

(1) Eye height, (2) Shoulder height, (3) Waist height, (4) Dactylion height, (5) Elbow height, (6) Hip breadth, (7) Upper limb length, (8) Span, (9) Vertical grip reach, (10) Sitting height, (11) Sitting eye height, (12) Sitting shoulder height, (13) Buttock knee length, (14) Knee height, (15) Shoulder breadth, (16) Head breadth, (17) Chest (bust) depth, and (18) Elbow fingertip length. 
arm is maximally extended upward.

10. Sitting height: The height, from the sitting surface, to the top of the head.

11. Sitting eye height: The height of the inner corner of the eye.

12. Sitting shoulder height: The height of acromion above the sitting surface.

13. Buttock knee length: The horizontal distance from the rearmost surface of the buttocks to the front of the kneecaps.

14. Knee height: The height, from the footrest surface to the musculature just above the knee.

15. Shoulder breadth: The distance across the shoulders from right to left acromion.

16. Head breath: The maximum breadth of the head.

17. Chest-Bust depth: Male: The depth of the torso measured at nipple level. Female: The horizontal distance from the subject's back to the tip of her bra.

18. Elbow fingertip length: The distance from the tip of the elbow to the tip of the longest finger.

Tables 7 and 8 show the selected dimensions' anthropometric data for the male and female reference populations respectively.

\section{3- EXPERIMENTAL PROCEDURE.}

\subsection{1- COEFFICIENTS AND SCALING FACTORS.}


Table 7

Selected Anthropometric Data from Male Reference Populations

Population

Dimension

Latin Arnmy Puerto Rican Mexican Brazilian

Mean SD Mean SD Mean SD Mean SD

* Stature

$\begin{array}{llllllll}1670 & 59 & 1645 & 64.3 & 1659 & 54.4 & 1699 & 67\end{array}$

1 Shoulder height

$1376 \quad 55$

2 Waist height

$1009 \quad 48$

3 Hip breadth

$321 \quad 17$

4 Upper limb length

$\begin{array}{llll}731 & 39.1 & 732 & 33.8\end{array}$

5 Sitting height

$867 \quad 32$

$870 \quad 29.6 \quad 881$

35

6 Sitting eye height

$737 \quad 40$

$\begin{array}{llll}7 & \text { Buttock knee length } \quad 568 \quad 27\end{array}$

8 Knee height

$512 \quad 25$

9 Head breadth

$\begin{array}{llllll}152 & 0.6 & 150 & 5.75 & 150 & 5.05\end{array}$

10 Chest depth

$228 \quad 17$

$209 \quad 12.9$

11 Elbow fingertip length $\quad 459 \quad 22$

Note. All dimensions in millimeters. 
Table 8

Selected Anthropometric Data from Female Reference Populations

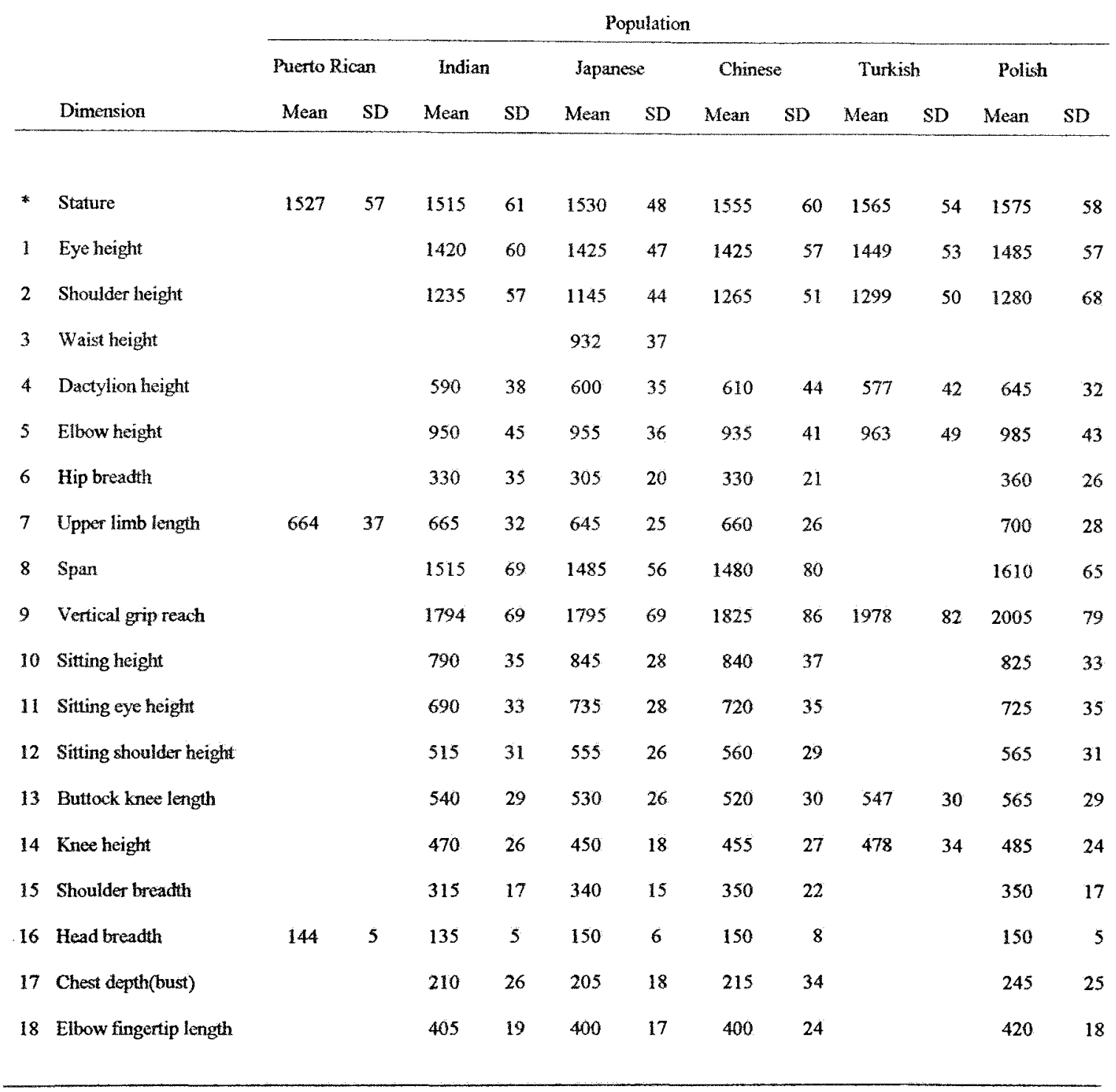

Note. All dimensions in millimeters. 
For each population and dimension in group A (reference population), two

coefficients, e1 and e2 were obtained:

$$
\begin{gathered}
\mathrm{el}=\mathrm{Md} / \mathrm{Ms} . \\
\mathrm{e} 2=\mathrm{Sd} / \mathrm{Ss} .
\end{gathered}
$$

where Md is the mean value of the dimension in the population; Ms is the mean stature in the population; $\mathrm{Sd}$ is the standard deviation of the dimension in the population; and $\mathrm{Ss}$ is the standard deviation of the stature in the population.

For each dimension, taking male and female data separately, arithmetic means E1 and $\mathrm{E} 2$ of values el and $\mathrm{e} 2$ of the reference populations were calculated:

$$
\begin{aligned}
& E 1=\sum_{i=1}^{n}(e 1) / n . \\
& E 2=\sum_{i=1}^{n}(e 2) / n .
\end{aligned}
$$

where $\mathrm{n}$ varied depending on the dimension considered, since not all dimensions were available in all the populations.

Scaling factors (E1 and E2) derived from the group A (reference population) were 
used to predict the statistical parameters of other body dimension in group B (target population). For each dimension, the 1st, 5th, 50th, 75th, 95th and 99th percentile values were calculated using the following expression:

$$
\mathrm{ph} \% \text { ile }=(\mathrm{E} 1 * \mathrm{MsB})-(\mathrm{Z} * \mathrm{E} 2 * \mathrm{SsB})
$$

where E1 and E2 are the related dimension's scaling factor, MsB is the mean stature of the group B (target population), SsB is the standard deviation stature of group B (target population), and $\mathrm{Z}$ is a constant for the percentile concerned in a normal distribution.

\section{2- RESULTS.}

Tables 9 and 10 summarized the minimum and maximum e values as well as the average scaling factors (E1 and E2) values for male and female subjects respectively.

For purposes of method validation, anthropometric estimates for the 1st, 5th, 50th, 95th and 99th percentiles were also calculated based on the scaling ratios given in Tables 9 and 10, and on the stature's statistics results of the survey conducted as a reference in this study (Chapter II). Estimates for the male and female subjects are shown and compared with the true results of the reference survey in Tables 11 and 12 respectively. 
Table 9

Scaling Factors of the Distribution of Stature for Males

\section{Scaling Factors}

$\begin{array}{llllll}\text { el } & \text { E1 } & \text { e1 } & \text { e2 } & \text { E2 } & \text { E2 }\end{array}$

Dimension

Min. Mean Max.

Min. Mean Max.

\begin{tabular}{|c|c|c|c|c|c|c|c|}
\hline 1 & Shoulder height & & 0.824 & & & 0.932 & \\
\hline 2 & Waist height & & 0.604 & & & 0.814 & \\
\hline 3 & Hip breadth & & 0.192 & & & 0.288 & \\
\hline 4 & Upper limb length & 0.441 & 0.443 & 0.444 & 0.608 & 0.615 & 0.621 \\
\hline 5 & Sitting height & 0.518 & 0.521 & 0.524 & 0.525 & 0.536 & 0.544 \\
\hline 6 & Sitting eye height & & 0.441 & & & 0.678 & \\
\hline 7 & Buttock knee length & & 0.340 & & & 0.458 & \\
\hline 8 & Knee height & & 0.307 & & & 0.424 & \\
\hline 9 & Head breadth & 0.090 & 0.091 & 0.092 & 0.010 & 0.064 & 0.092 \\
\hline 10 & Chest depth & 0.126 & 0.131 & 0.136 & 0.238 & 0.263 & 0.288 \\
\hline & Elbow fingertip lengt & & 0.275 & & & 0.373 & \\
\hline
\end{tabular}


Table 10

Scaling Factors of the Distribution of Stature for Females

\section{Scaling Factors}

Dimension

el E1 el

Min. Mean Max. e2 E2 e2

Min. Mean Max.

$\begin{array}{llllllll}1 & \text { Eye height. } & 0.916 & 0.931 & 0.943 & 0.937 & 0.975 & 0.983 \\ 2 & \text { Shoulder height. } & 0.748 & 0.804 & 0.83 & 0.85 & 0.96 & 1.172 \\ 3 & \text { Waist height. } & & 0.609 & & & 0.771 & \\ 4 & \text { Dactylion height. } & 0.369 & 0.39 & 0.41 & 0.552 & 0.684 & 0.785 \\ 5 & \text { Elbow height. } & 0.601 & 0.619 & 0.627 & 0.683 & 0.764 & 0.907 \\ 6 & \text { Hip breadth. } & 0.199 & 0.214 & 0.229 & 0.35 & 0.447 & 0.574 \\ 7 & \text { Upper limb length. } & 0.422 & 0.433 & 0.444 & 0.443 & 0.521 & 0.664 \\ 8 & \text { Span. } & 0.952 & 0.986 & 1.022 & 1.121 & 1.188 & 1.333 \\ 9 & \text { Vertical grip reach. } & 1.173 & 1.214 & 1.273 & 1.131 & 1.375 & 1.511 \\ 10 & \text { Sitting height. } & 0.521 & 0.534 & 0.552 & 0.569 & 0.585 & 0.617 \\ 11 & \text { Sitting eye height. } & 0.455 & 0.465 & 0.48 & 0.541 & 0.578 & 0.603 \\ 12 & \text { Sitting shoulder h. } & 0.34 & 0.355 & 0.363 & 0.483 & 0.517 & 0.542 \\ 13 & \text { Buttock knee length. } & 0.334 & 0.349 & 0.359 & 0.475 & 0.513 & 0.548 \\ 14 & \text { Knee height. } & 0.293 & 0.302 & 0.31 & 0.375 & 0.46 & 0.637 \\ 15 & \text { Shoulder breadth. } & 0.208 & 0.219 & 0.225 & 0.279 & 0.313 & 0.367 \\ 16 & \text { Head breadth. } & 0.089 & 0.095 & 0.098 & 0.082 & 0.104 & 0.133 \\ 17 & \text { Chest depth (bust). } & 0.134 & 0.142 & 0.156 & 0.375 & 0.45 & 0.567 \\ 18 & \text { Elbow fingertip 1. } & 0.257 & 0.263 & 0.308 & 0.31 & 0.344 & 0.431\end{array}$




\section{Table 11}

Comparison of Anthropometric Male Estimates Between Scaling Ratio and Survey

$\underline{\text { Results }}$

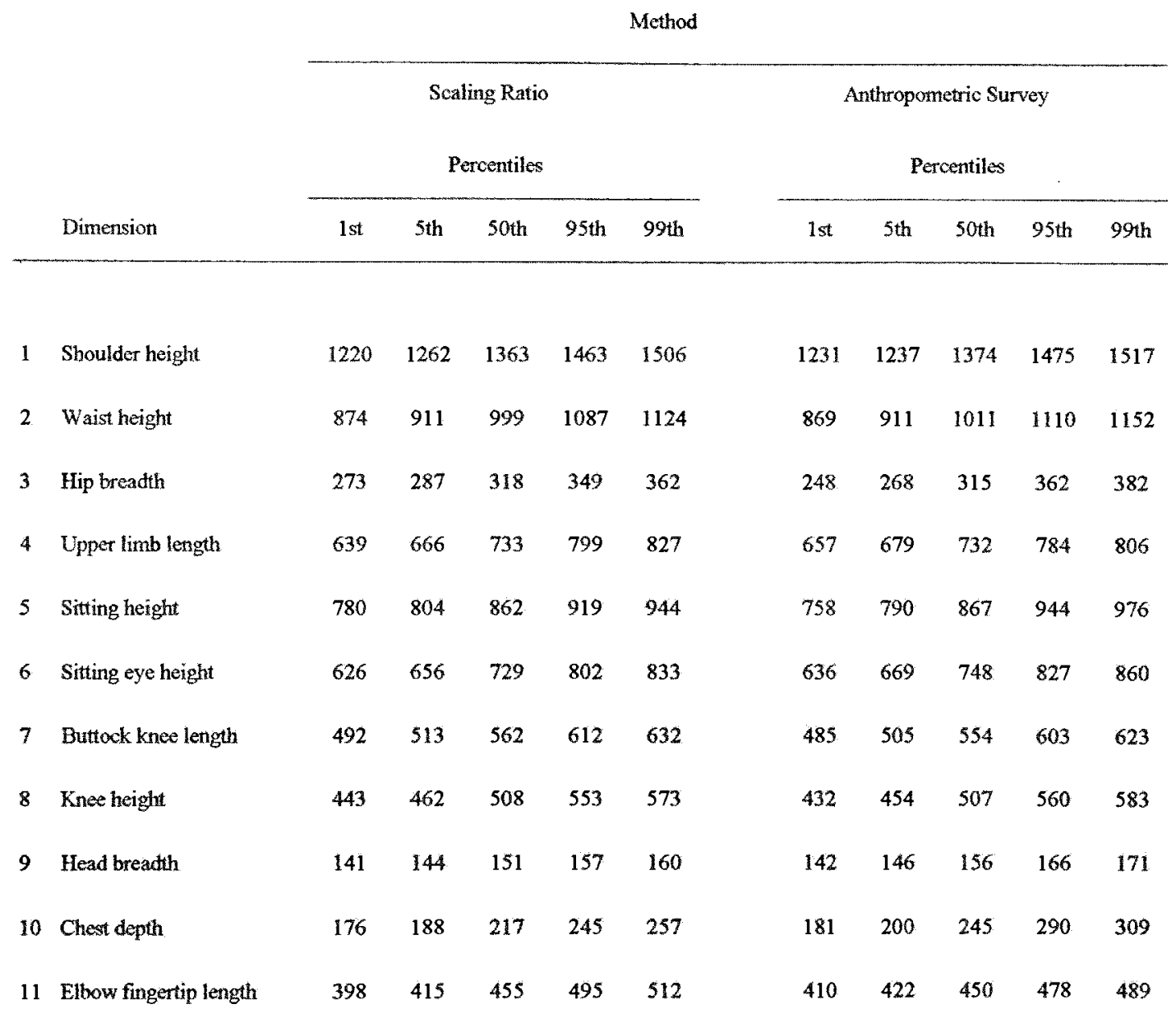

Note. All dimensions in millimeters. 
Table 12

Comparison of Anthropometric Female Estimates Between Scaling Ratio and Survey

\section{$\underline{\text { Results }}$}

\begin{tabular}{|c|c|c|c|c|c|c|c|c|c|c|c|}
\hline \multirow{4}{*}{\multicolumn{2}{|c|}{ Dimension }} & \multicolumn{10}{|c|}{ Method } \\
\hline & & \multirow{2}{*}{\multicolumn{5}{|c|}{$\begin{array}{l}\text { Scaling Ratio } \\
\text { Percentiles }\end{array}$}} & \multirow{2}{*}{\multicolumn{5}{|c|}{$\begin{array}{c}\text { Anthroponetric Survey } \\
\text { Percentiles }\end{array}$}} \\
\hline & & & & & & & & & & & \\
\hline & & Ist & 5th & $50 \mathrm{th}$ & 95th & 99 th & 1 st & 5th & 50 th & 95th & 99th \\
\hline 1 & Eye height & 1319 & 1355 & 1438 & 1522 & 1557 & 1312 & 1348 & 1432 & 1516 & 1552 \\
\hline 2 & Shoulder height & 1125 & 1160 & 1242 & 1325 & 1359 & 1168 & 1200 & 1277 & 1353 & 1358 \\
\hline 3 & Waist height & 847 & 875 & 941 & 1007 & 1035 & 860 & 889 & 959 & 1028 & 1058 \\
\hline 4 & Dactylion height & 519 & 544 & 603 & 661 & 686 & 509 & 534 & 593 & 652 & 677 \\
\hline 5 & Elbow height & 863 & 891 & 956 & 1022 & 1050 & 882 & 910 & 975 & 1041 & 1068 \\
\hline 6 & Hip breadth & 276 & 292 & 331 & 369 & 385 & 254 & 272 & 315 & 358 & 376 \\
\hline 7 & Upper limb length & 605 & 624 & 669 & 714 & 733 & 606 & 626 & 674 & 722 & 742 \\
\hline 8 & Span & 1378 & 1421 & 1523 & 1625 & 1668 & 1391 & 1445 & 1573 & 1701 & 1755 \\
\hline 9 & Vertical grip reach & 1708 & 1757 & 1876 & 1994 & 2044 & 1651 & 1708 & 1842 & 1977 & 2034 \\
\hline 10 & Sitting height & 754 & 775 & 825 & 875 & 896 & 752 & 774 & 827 & 880 & 903 \\
\hline 11 & Sitting eye height & 648 & 669 & 718 & 768 & 789 & 639 & 659 & 708 & 757 & 778 \\
\hline 12 & Sitting shoulder height & 485 & 504 & 548 & 593 & 612 & 482 & 504 & 557 & 610 & 632 \\
\hline 13 & Buttock knee length & 477 & 495 & 539 & 583 & 602 & 460 & 480 & 529 & 578 & 599 \\
\hline 14 & Knee height & 410 & 427 & 467 & 506 & 523 & 420 & 436 & 473 & 511 & $\$ 27$ \\
\hline 15 & Shoulder breadth & 300 & 311 & 338 & 365 & 377 & 340 & 349 & 371 & 393 & 403 \\
\hline 16 & Head breadth & 134 & 138 & 147 & 156 & 159 & 135 & 140 & 151 & 163 & 168 \\
\hline 17 & Chest depth(Bust) & 164 & 181 & 219 & 258 & 274 & 144 & 177 & 256 & 335 & 368 \\
\hline 18 & Elbow fingertip length & 364 & 377 & 406 & 436 & 448 & 363 & 376 & 408 & 439 & 452 \\
\hline
\end{tabular}

Note. All dimensions in millimeters. 


\section{CHAPTER IV - GENERAL DISCUSSION AND CONCLUSIONS}

\section{1- DISCUSSION.}

\section{1- ANTROPOMETRIC SURVEY.}

\subsection{1- COMPARISON WITH PREVIOUS INVESTIGATIONS.}

There has never been an anthropometric survey of the Colombian population, so it is difficult to compare the current survey findings with those of the general Colombian population. The most recent study of Colombian adults, conducted by MINSALUD et al. in 1980 , found very similar stature values. The mean male stature of $1654 \mathrm{~mm}$ in the present survey is only $1 \mathrm{~mm}$ smaller, while the female stature of $1545 \mathrm{~mm}$ is $7 \mathrm{~mm}$ taller. However, comparing survey results with those estimates from the scaling ratio analysis (see Chapter III), all body measurements were close, except chest depth in the male population and shoulder height, span and bust depth in the female population. (see Tables 11 and 12 respectively).

\subsection{2- COMPARISON WITH OTHER POPULATIONS.}

\section{A- LATIN AMERICAN POPULATIONS.}

In this study, Colombian anthropometric data were compared with other surveys to identify the unique anthropometric characteristics of the Colombian population. Table 13 
shows a comparison of anthropometric data between the Colombian male adult population and other similar ethnic male populations. Body differences amongst Latin American populations were minimal. In general the Colombian male adults are taller than the Puerto Ricans, but smaller than the Brazilian and Mexican adults.

\section{B- EUROPEAN AND JAPANESE POPULATIONS.}

Comparisons were also made with some European populations. Results, Table 14, show that there are significant differences in the body build. In general Colombian adults (male and female) are smaller than the British, French and German adults, taller than the Indian adults, and very similar to the Japanese.

\section{C- U.S. POPULATION.}

Compared with the American population, Colombian adult males and females are smaller in all body measurements except head breadth and chest (bust) depth. The difference in the mean stature for females is as large as $80 \mathrm{~mm}$, and the difference of 101 $\mathrm{mm}$ for males is of great practical significance. Moreover, differences were more pronounced in the male population than the female population, (see Table 15). Moreover, stature and sitting height mean values were compared to examine the differences among those countries exporting man machine systems to Colombia, (U.S., Germany and Japan). 
Table 13

Anthropometric Comparison Between Colombian Adult Male Population and Other

Similar Ethnic Male Populations

Dimension

Population

Stature

Head Breadth

Sitting Height

Colombian

Puerto Rican (1)

Mexican (2)

Brazilian (3)

Latin A. Army (4)

\section{4}

1645

1659

1699

1670
156

867

150

150

870

881

152

867

Note. All dimensions in millimeters.

Sources. (1) Thieme, 1959; (2) Kelly, 1947; (3) Ferreira, 1988; and (4) Dobbins \& Kindick, 1972. 
Table 14

Anthropometric Comparison Between Colombian Adults (Male and Female), Europeans and Japanese Populations

Dimensions

Population

\begin{tabular}{llcccc}
\hline Stature & Sitting Height & Upper Limb \\
& & & Length \\
& & & & \\
M & F & M & F & M & F
\end{tabular}

Colombian

British (1)

French (1)

German (1)

Japanese (1)
16451545

$1745 \quad 1615$

$1715 \quad 1600$

$1745 \quad 1635$

$1655 \quad 1530$ $\begin{array}{ll}867 & 827\end{array}$

915855

$910 \quad 860$

$800 \quad 740$

$900 \quad 845$ $\begin{array}{ll}732 & 674\end{array}$

$785 \quad 710$

$770 \quad 705$

$\begin{array}{ll}785 & 720\end{array}$

$715 \quad 645$

Note. $\mathrm{M}$ and $\mathrm{F}$ are abbreviations for male and female respectively. All dimensions in millimeters. Source. (1) Pheasant, 1988. 
Table 15

Anthropometric Comparison Between Colombian Adults (Male and Female), and the American Population

\begin{tabular}{|c|c|c|c|c|}
\hline \multirow[b]{3}{*}{ Dimension } & \multicolumn{4}{|c|}{ Population } \\
\hline & \multicolumn{2}{|c|}{ Colombian } & \multicolumn{2}{|c|}{ American (1) } \\
\hline & $\mathbf{M}$ & $\mathbf{F}$ & $\mathbf{M}$ & $\mathrm{F}$ \\
\hline Stature & 1654 & 1545 & 1755 & 1625 \\
\hline Eye height & 1530 & 1432 & 1710 & 1525 \\
\hline Shoulder height & 1374 & 1277 & 1440 & 1325 \\
\hline Elbow height & 1038 & 975 & 1105 & 1020 \\
\hline Upper limb length & 732 & 674 & 790 & 715 \\
\hline Sitting height & 867 & 827 & 915 & 860 \\
\hline Sitting eye height & 748 & 708 & 800 & 750 \\
\hline Buttok knee length & 554 & 529 & 600 & 575 \\
\hline Head breadth & 156 & 151 & 155 & 145 \\
\hline Chest depth (bust) & 245 & 256 & 255 & 255 \\
\hline
\end{tabular}

Note. $\mathbf{M}$ and $\mathbf{F}$ are abbreviations for male and female respectively. All dimensions in millimeters. Source. (1) Pheasant, 1988. 


\section{2- SCALING RATIO METHOD.}

\subsection{1- METHOD RELIABILITY.}

The accuracy of anthropometric estimates using the scaling ratio method depends on the availability of appropiate data sources for the reference and target populations.

Sources chosen for this study, to the best of the author's knowledge, were those with the greatest similarity to the Colombian adult population in terms of age, sex and ethnicity; and those most representative of the Latin American population.

In order to evaluate the scaling ratio method reliability, scaling factors derived from reference populations were used to predict the true results of the survey conducted as a reference (Chapter II). For these predictions only the sex, stature mean and standard deviation of the reference survey were used. Moreover, comparisons were made between the predicted percentile values of each dimension, and the real percentile values from the reference survey (see Tables 11 and 12). Differences then were calculated, in millimeters and as percentages of the real values, using the following formulas:

$$
\begin{gathered}
\mathrm{d}=\text { predicted }- \text { real } . \\
d \%=[(\text { predicted }- \text { real }) * 100] / \text { real } .
\end{gathered}
$$

Tables 16 and 17 list the errors in predicting the 1st, 5th, 50th, 95th and 99th 
percentiles for the male and female respectively. For both populations, errors were approximately normally distributed (see Figures 12 and 13). For male population, errors were distributed with a mean of $-5 \mathrm{~mm}$ and a standard deviation of $17 \mathrm{~mm}$. Of the 55 comparisons, $93 \%$ of the errors fell within the range of $0 \pm 30 \mathrm{~mm}$. For the female population, errors were distributed with a mean of $-7 \mathrm{~mm}$ and a standard deviation of 25 $\mathrm{mm}$. Of the 90 comparisons, $83 \%$ of the errors fell within the range of $0 \pm 30 \mathrm{~mm}$.

The 50th percentile was chosen as a reference value in the validation process. For each dimension, absolute error values of the 50th percentile were arranged in order of overall error for male and female subjects (see Table 18). There was not any direct relation between the error amount and the dimension concerned. Roebuck et al. (1975) has also reported that larger errors are not associated with larger dimensions; nor are they associated with those dimensions known to be poorly correlated with stature.

Using a 95th percent confidence limit, calculation of the margins of error were made for the 50th percentile values of the dimensions in the target population (Colombian anthropometric survey). Calculations were carried out using the following formula:

SEM * 1.96 .

where SEM is the dimension's standard error of the mean, and 1.96 is a statistical value 
Table 16

Errors in Prediction of Anthropometric Male Percentile Values Using the Scaling Ratio

Method.

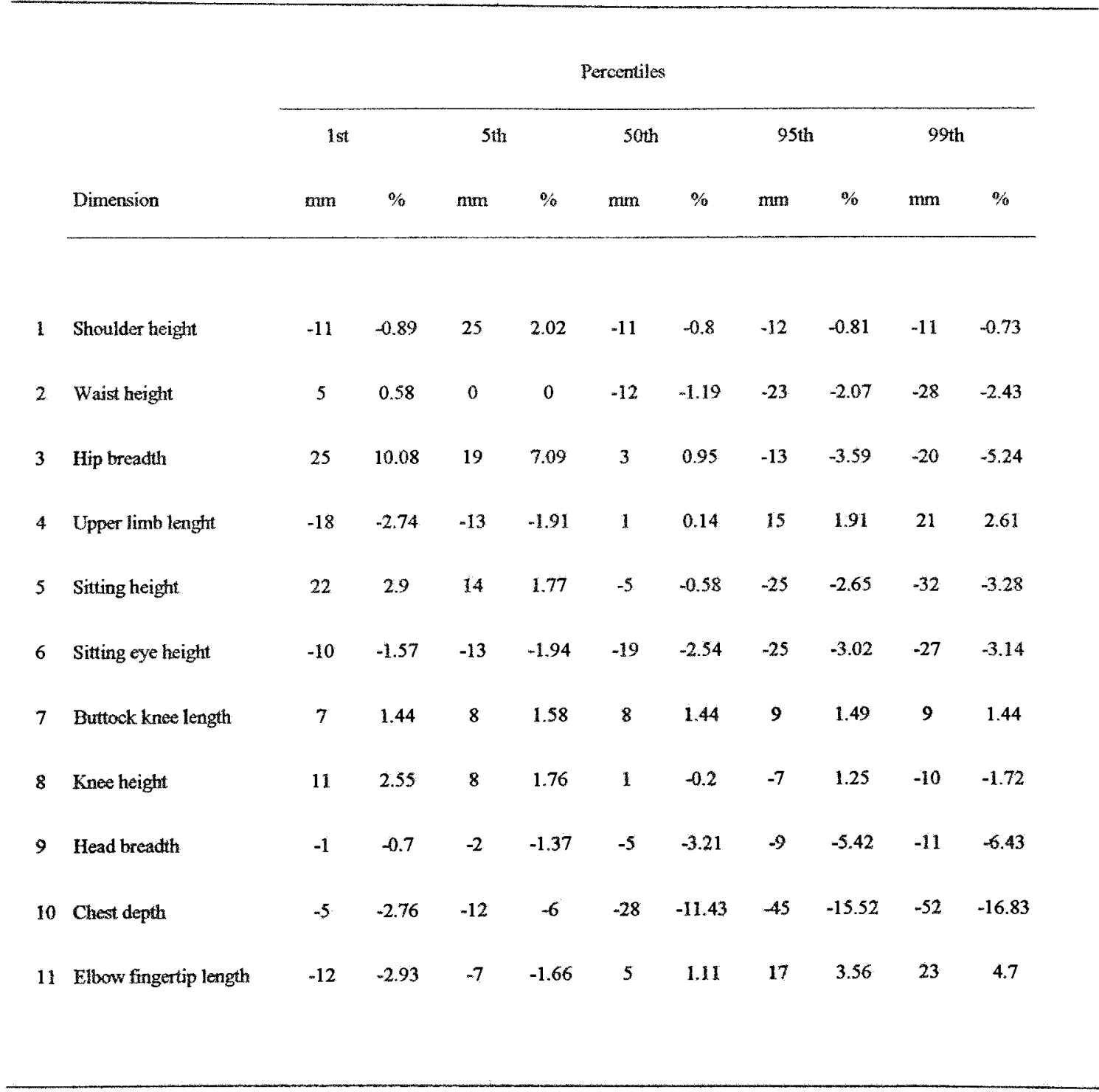




\section{Table 17}

Errors in Prediction of Anthropometric Female Percentile Values Using the Scaling Ratio Method.

\begin{tabular}{|c|c|c|c|c|c|c|c|c|c|c|c|}
\hline & \multicolumn{11}{|c|}{ Percentiles } \\
\hline & \multirow[b]{2}{*}{ Dimension } & \multicolumn{2}{|c|}{$1 \mathrm{st}$} & \multicolumn{2}{|c|}{5 th } & \multicolumn{2}{|c|}{$50 \mathrm{th}$} & \multicolumn{2}{|c|}{ 95th } & \multicolumn{2}{|c|}{ 99th } \\
\hline & & $\operatorname{mn}$ & $\%$ & $\min$ & $\%$ & $\mathrm{~mm}$ & $\%$ & $\mathrm{~mm}$ & $\%$ & $\mathrm{~mm}$ & $\%$ \\
\hline 1 & Eye height & 7 & 0.56 & 7 & 0.49 & 6 & 0.45 & 6 & 0.41 & 5 & 0.35 \\
\hline 2 & Shoulder height & -43 & -3.68 & -40 & -3.36 & -35 & -2.73 & -28 & -2.09 & 1 & 0.1 \\
\hline 3 & Waist height & -13 & -1.54 & -14 & -1.61 & -18 & -1.89 & -21 & -2.03 & -23 & -2.17 \\
\hline 4 & Dactylion height & 10 & 1.97 & 10 & 1.83 & 10 & 1.61 & 9 & 1.43 & 9 & 1.34 \\
\hline 5 & Elbow height & -19 & -2.15 & -19 & -2.12 & -19 & -1.91 & -19 & -1.82 & -18 & $-1,72$ \\
\hline 6 & Hip breadth & 22 & 8.68 & 20 & 7.43 & 16 & 4.96 & 11 & 3.08 & 9 & 2.45 \\
\hline 7 & Upper limb length & -1 & -0.1 & -2 & -0.29 & -5 & -0.74 & -8 & -1.14 & -9 & -1.27 \\
\hline 8 & Span & -13 & -0.91 & -24 & -1.64 & -50 & -3.16 & -76 & -4.44 & -87 & -4.93 \\
\hline 9 & Vertical grip reach & 57 & 3.44 & 49 & 2.9 & 34 & 1.83 & 17 & 0.85 & 10 & 0.47 \\
\hline 10 & Sitting height & 2 & 0.21 & 1 & 0.1 & -2 & -0.24 & -5 & -0.53 & -7 & -0.72 \\
\hline 11 & Sitting eye height & 9 & 1.39 & 10 & 1.48 & 10 & 1.47 & 11 & 1.47 & 11 & 1.41 \\
\hline 12 & Sitting shoulder height & 3 & 0.7 & 0 & 0 & -9 & -1.53 & .17 & -2.8 & -20 & -3.23 \\
\hline 13 & Buttock knee length & 17 & 3.6 & 15 & 3.15 & 10 & 1.93 & 5 & 0.92 & 3 & 0.47 \\
\hline 14 & Knee height & -10 & -2.28 & -9 & -2.05 & -6 & -1.36 & -5 & -0.99 & 4 & -0.81 \\
\hline 15 & Shouldet breadth & -40 & -11.7 & -38 & -10.7 & -33 & -8.8 & -28 & -7.06 & -26 & -6.56 \\
\hline 16 & Head breadth & -1 & -0.68 & -2 & -1.54 & -4 & -2.80 & -7 & -4.47 & -9 & -5.08 \\
\hline 17 & Chest depth(Bust) & 20 & 14.20 & 4 & 2.10 & -37 & -14.30 & -77 & -22.90 & -94 & -25.45 \\
\hline 18 & Elbow fingertip length & 1 & 0.37 & 1 & 0.21 & -2 & -0.41 & -3 & -0.71 & -4 & -0.81 \\
\hline
\end{tabular}


Figure 12. Males Error Distribution.

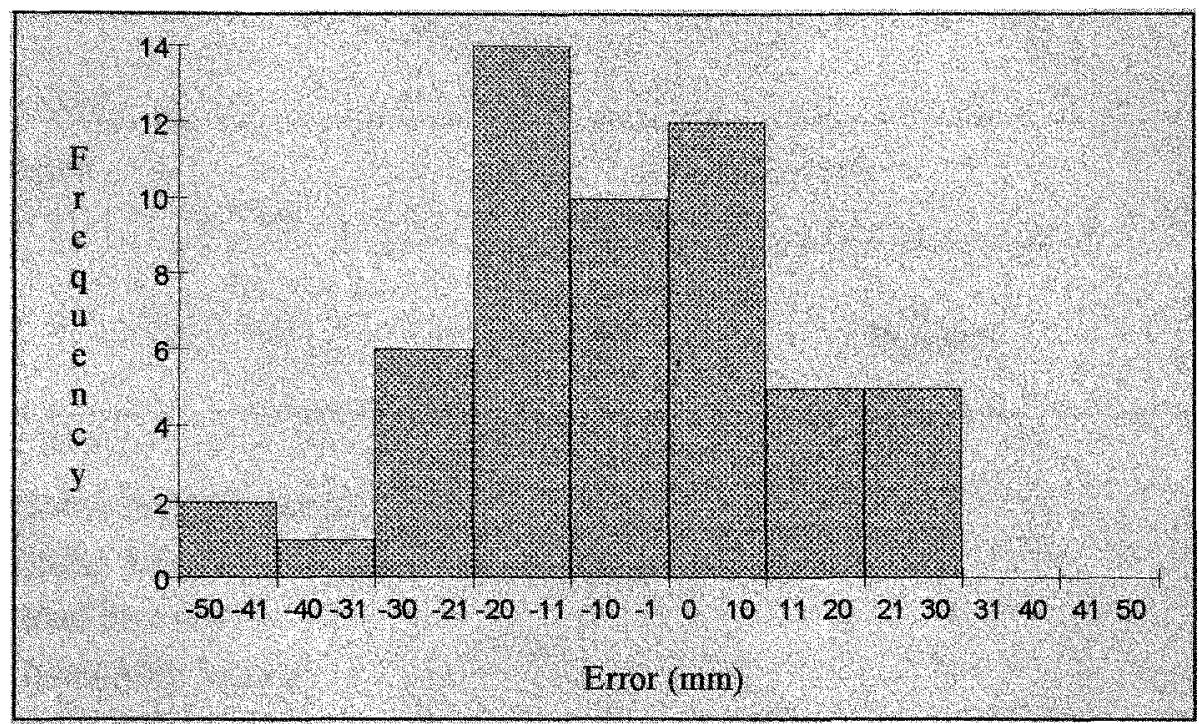

Figure 13. Females Error Distribution.

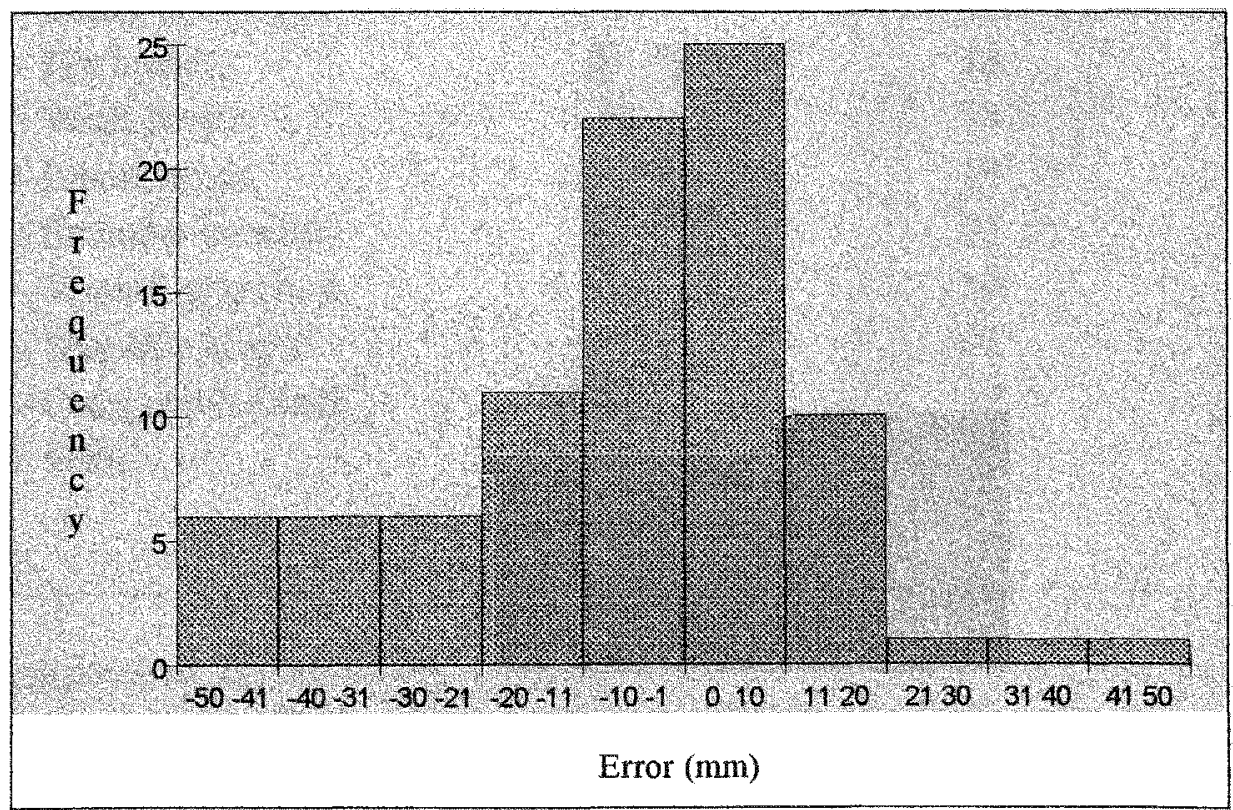


Table 18

Absolute Error Values

Dimension

Absolute Error

Males

Females

1- Elbow fingertip length

5

2

2- Sitting height

5

2

3- Head breadth

5

4

4- Upper limb length

1

5

5- Eye height

- 6

6- Knee height

1

6

7- Sitting shoulder height

- 9

8- Dactylion height

- 10

9- Buttock knee length

8

10

10- Sitting eye height

19

10

11- Hip breadth

3

16

12- Waist height

12

18

13- Elbow height

$\begin{array}{ll}12 & 19\end{array}$

14- Shoulder breadth

- 33

15- Vertical grip reach

- 34

16- Shoulder height

11

35

17- Chest depth (bust)

28

37

18-Span

Note. Absolute errors in millimeters. 
concerned with the 95 th confidence limit. Confidence limits values were then compared with the errors made in predicting the dimensions concerned. For the male population comparison showed that 8 of the 11 estimates fell within these confidence limits, and errors are modest in comparison with those which may occur in correcting for clothing, shoes etc. But, for the female population only 5 of the 18 estimates fell within these confidence limits, see Table 19.

These considerations suggest that errors associated with the use of estimated data are small when using reference populations similar in age, sex and ethnicity to the population for whom anthropometric estimates are required, but larger when using reference populations of different ethnicities of the target population. It is concluded therefore that in this study the anthropometric data estimated using the scaling ratio method can be considered as a valid representation of the anthropometrics of the general adult Colombian population.

\section{2- CONCLUSIONS.}

\section{1- SCALING RATIO METHOD.}

Since anthropometric surveys are both costly and time consuming, designers are frequently forced to estimate the data they require. Sometimes, there are populations for whom stature parameters are known, but for whom other anthropometric data are 
Table 19

Margin of Error for the 50th Percentile Values of the Survey's Dimensions

Dimension

Males

Females

ME Error $\quad$ ME Error

1- Elbow fingertip length

2- Sitting height

3- Head breadth

4- Upper limb length

5- Eye height

6- Knee height

7- Sitting shoulder height

8- Dactylion height

9- Buttock knee length

10- Sitting eye height

11 - Hip breadth

12- Waist height

13- Elbow height

14- Shoulder breadth

15- Vertical grip reach

16- Shoulder height

17- Chest depth (bust)

18-Span

$\begin{array}{llll}4 & 5 & 5 & 2 \\ 11 & 5 & 8 & 2 \\ 2 & 5 & 2 & 4 \\ 7 & 1 & 7 & 5 \\ - & - & 13 & 6 \\ 8 & 1 & 6 & 6 \\ - & - & 8 & 9 \\ - & - & 9 & 10 \\ 7 & 8 & 7 & 10 \\ 12 & 19 & 7 & 10 \\ 7 & 3 & 6 & 16 \\ 15 & 12 & 10 & 18 \\ - & - & 10 & 19 \\ - & - & 3 & 33 \\ - & - & 20 & 34 \\ 15 & 11 & 11 & 35 \\ 7 & 28 & 11 & 37 \\ - & - & 19 & 50\end{array}$

Note. $M E=$ Margin of Error; all dimensions in millimeters. 
insufficient. In other cases, when resources are limited for a detailed investigation, a survey of stature may be possible. In either circumstance, if appropriate reference populations are available, the scaling ratio method can be used for estimation purposes, and will provide data sufficiently accurate for some design applications.

The scaling ratio method used in this study, for estimation of anthropometric data, proved to be satisfactory for accurate and rapid data collection. The set of data obtained may be considered as a valid representation of the anthropometry of the male adult Colombian population, and it will provide a basis for design purposes to be currently applied to the actual user population not only in Colombia, but also in other countries where these data are required.

The use of anthropometric data in the design process will depend on the designers criteria, which define the accuracy and limits within which a satisfactory match between user and equipment will be considered achieved; therefore, when designing with estimated data, instead of real data, discretion always must be employed.

\section{2- ANTHROPOMETRY SURVEY.}

In general, the Colombian adult (male and female) is smaller than the American, British, French, German, and Brazilian adult; and similar to the Japanese, Mexican, and Puerto Rican adult. Anthropometry of Colombian male adults when compared with those 
of American males show that machinery designed for the stature of $90 \%$ of American males would accommodate approximately only $58 \%$ of the Colombian male population. Table 20 shows the percentage of Colombian adult population (male and female) that will be accommodated in systems imported from other industrialized countries.

Special care should be taken with standing work surfaces, overhead reaches, and seating level in systems and workstations manufactured in U.S. and European countries and intended to be used by the Colombian population. Obviously, considering these anthropometric differences when buying and using imported equipment will prevent many users design related problems.

Earlier, there was a lack of awareness about anthropometric aspects in the design and operation of equipment. However, designers are now developing a consciousness about ergonomics, and if the appropiate anthropometric data are available, they may wish to use them in the design process. It is therefore intended that the anthropometric survey tables, measurement reference manual, and dimensional models published here will constitute a Colombian anthropometric data base which may be used for general design purposes.

Moreover, anthropometric data base can be utilized by designers to provide appropiate design dimensional specifications for equipment, furniture and industrial workplace layouts manufactures, local and abroad, helping in this way to the development of the Colombian industry, and so of benefit to the Colombian workers. Anthropometric tables 
Table 20

Percentage of Accommodation for Colombian Population in Imported Equipment

Dimension

Stature

Country
Male

Female

$\%$

$\%$
$\%$

Sitting Height

Male

Female

Germany

55

68

52

80

Japan

92

96

64

80

U.S.

58

68

60

80

Note. Equipment designed to accommodate 90 th $\%$ of the native population. 
can be also utilized for other populations in Latin America with similar somatic

characteristics.

\section{3- FURTHER STUDIES.}

Anthropometric tables generated in this study should be applied in workplace layout designs and tested in real industrial settings to evaluate their benefits in terms of improved worker productivity, satisfaction, comfort, and safety. Study findings have also given a good basis for further research; it is therefore recommended that future Colombian anthropometric surveys be conducted for children and disabled Colombian population. An extensive and accurate anthropometric study of Latin American male and female populations is also needed.

Anthropometrists normally collect statistics for a particular sex and race. In most instances, a mixture of individuals with different ethnicities is the target population.

Therefore, to design or evaluate anthropometric systems, relevant anthropometric data should be collected for a collective mixture of populations and not for particular individuals. Currently, in the U.S. a substantial proportion of workers are Hispanic, Asians or from the middle east. According to the 1990 U.S. Census, Hispanics of all races, who present 24 million people and $9 \%$ of the population today, would climb to 81 million and $21 \%$ by 2050 and become the biggest minority group. Hence, further anthropometric 
studies involving the Hispanic and other populations living and working in the U.S., are suggested. 


\section{REFERENCES}

Barkla, D. (1961). The estimation of body measurements of British population in relation to seat design. Ergonomics, $\underline{4}, 123-135$.

Batogowska, A., \& Slowikowski, J. (1974). Anthropometric atlas of the Polish adult population for designer use. Warsaw: Instytut Wzornictwa Przemystowego.

Colombian Ministry of Public Health. (1980). National study of health. Santafe de Bogota, Colombia: MINSALUD Printing Government.

Dobbins, D. A., \& Kindick, C. M. (1972). Anthropometry of the Latin American armed forces (Report No. 7209002). Fort Clayton, Canal Zone, U.S. Army Tropic Test Center.

Eveleth, P. B., \& Tanner, J.M. (1976). Worldwide variation in human growth. Cambridge: University Press.

Ferreira, D. M. (1988). Pesquisa anthropometrica e biomeccanica dos operarios de la industria de transformacao RJ [ Anthropometry and biomecanic study of the operators of the RJ industry] Brasil: Instituto Nacional de Tecologia.

Gonen, E., Kalinkara, V., \& Ozgen, O. (1991). Anthropometry of Turkish women. Applied Ergonomics, 22.6, 409-411.

Hertzberg, H. T.(1968). The conference on standardization of anthropometric 
techniques and terminology. American Journal of Physical Anthropology, 28, 1-16.

ISO 7250. (1983). Basic list of anthropometric measurements. Geneva: International Standards Organization.

Kelly, A. R. (1947). Physical anthropology of Mexican population in Texas; a study in race mixture. New Orleans: Middle American Research Institute.

Lohman, T. G., Roche, A. F., \& Martorell, R. (1988). Anthropometric standardization reference manual. Champaign, Illinois: Human Kinetics Books.

National Aeronautics and Space Administration. (1978). Anthropometric source book (Report 1024). Yellow Springs, OH: Scientific and Technical Information Office.

Pheasant, S. (1988). Bodyspace anthropometry, ergonomics and design. London: Taylor and Francis.

Roebuck, Jr., J. A. , Kroemer, K. H. E. \& Thomson, W. G. (1975). Engineering anthrppometry methods. New York: Wiley.

Tanner, J. M., \& Weiner, J. S. (1949). The reliability of the photogrammetric method of anthropometry with a description of a miniature camera technique. American Journal of Physical Anthropometry, 7 (2), 145-185.

Thieme, F. P. (1959). The Puerto Rican population: A study in human biology. Ann Arbor: University of Michigan.

Thorndike, R. (1982). Data collection and analysis: Basic statistics. Western Washington 
University. New York: Gudner Press.

U.S. Bureau of the Census. (1990). Ethnic and Hispanic branch: Special tabulations.

Series P-60, Washington, D.C.: Government Printing Office. 


\section{Appendix A}

\section{Measurement Procedures Manual}

\section{1-Introduction.}

Due to the lack of a comprehensive and representative source of Colombian anthropometric data, a survey will be conducted, in order to assemble an anthropometric data set which will be sufficiently comprehensive and accurate for general design and estimation applications.

The survey will be carried out in the ergonomics laboratory at Florida International University, Miami, Florida. A set of 20 body dimensions, in standing and sitting positions, will be taken from a sample of 134 Colombian adults, male and female, living in south Florida and ages ranged 20-64 years. Subjects will participate and selected on a voluntary and random basis respectively, covering a total mix of Colombian geographical regions. Dimensions will be chosen according to their relevance in general design proposes and in international anthropometric standard lists. Measurements procedures and techniques to be followed in the survey will be determinated after a wide review of literature; consequently, a manual of procedures will be compiled to be used by the measurement team as a reference book during the training period and in the measuring session. $\mathrm{A}$ 
special designed grid system and other traditional anthropometric instruments will be used throughout the survey. Measurements will be taken by a trained team, and anthropometric data will be recorded in a special form. A detailed statistical analysis (range, mean, standard deviation, coefficient of variation, standard error and percentiles) will be carried out using a statistical software, and its results will be presented, discussed, and compared with those of other populations. Finally, survey comments and conclusions will be drawn.

This manual of measurement procedures is divided into four parts: The first, introduction, describes the survey and manual aims. The second describes in detail, for each dimension, the following: (a) dimension definition, (b) landmarks definitions, (c) position of the subject, (d) position of measurer, (e) procedure to be followed in taking measurement, and (f) remarks. The third part, is composed of an anatomical and anthropometric terminology glossary, and the fourth shows an illustrated glossary of the anatomical planes, orientations and landmarks. 


\section{2-Measurement Procedures.}

\section{1-STATURE}

Landmarks

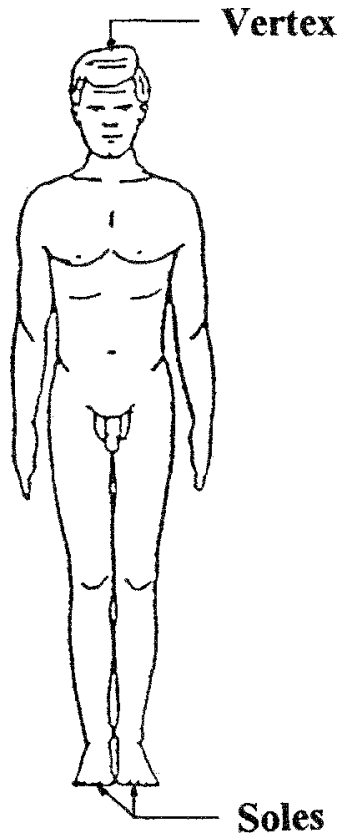

\section{Position}

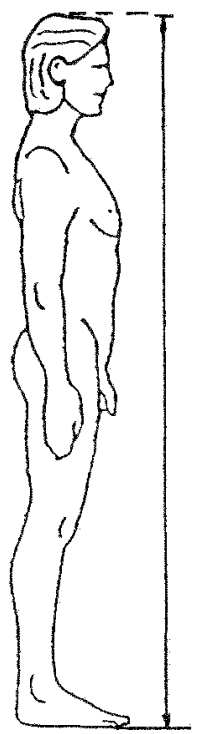

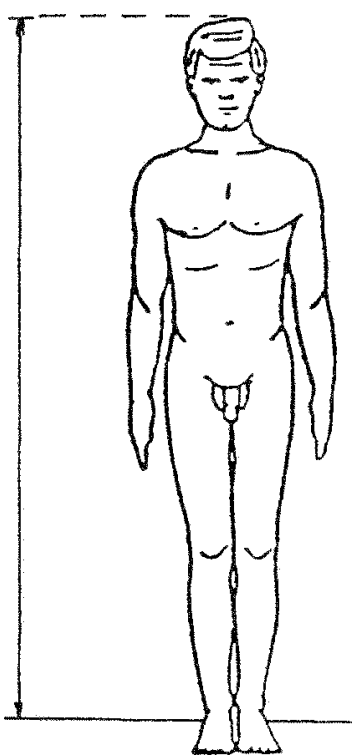

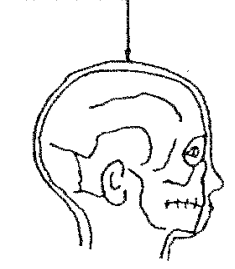

Soles

Definition: The height of the top of the head .

Landmarks: The most superior part of the skull, (vertex), and the inferior surfaces of the feet, (soles or plantar surfaces).

Instruments: Movable anthropometer.

Position of subject: The subject stands on a flat surface, and his or her body weight is evenly distributed on both feet, heels together as closely as possible, legs and torso straight without stiffness and head erect with the line of vision parallel to the floor. The 
arms hang straight but loosely at the sides with the palms alongside but no touching the thighs. Subject remains in this position while the measurement is taken.

Position of measurer: The measurer stands at the subject's right side.

Procedure: The anthropometer's lower part is set on the floor surface while the upper part is hold and balance in a vertical position in the measurer's right hand. The moving arm of the anthropometer is lowered with the left hand until the blade point rest onto specified landmark (vertex). The hair texture is taken into consideration when exploring the top of the head, and sufficient pressure is used to bring the blade point piece of the anthropometer to the level of the vertex. When the subject and measurer are also positioned, the subject is instructed to take a deep breath, and the measurement is made just before the subject exhales. The measurer should observe the level of the anthropometer blade without parallax; hence a small stool may be required. The measurement is recorded to the nearest millimeter.

Remarks: Measurement is repeated three times. The subject has to step off after the first measurement, and take position again in between measurements. It is mportant that the recorder observe both the position of the subject to avoid slouching and also the position of the anthropometer to ensure that it is vertical and the blade is brought down in the midline of the head. If too much pressure is applied to the anthropometer blade, it may slide to one side off the vertex. 


\section{2- EYE HEIGHT}
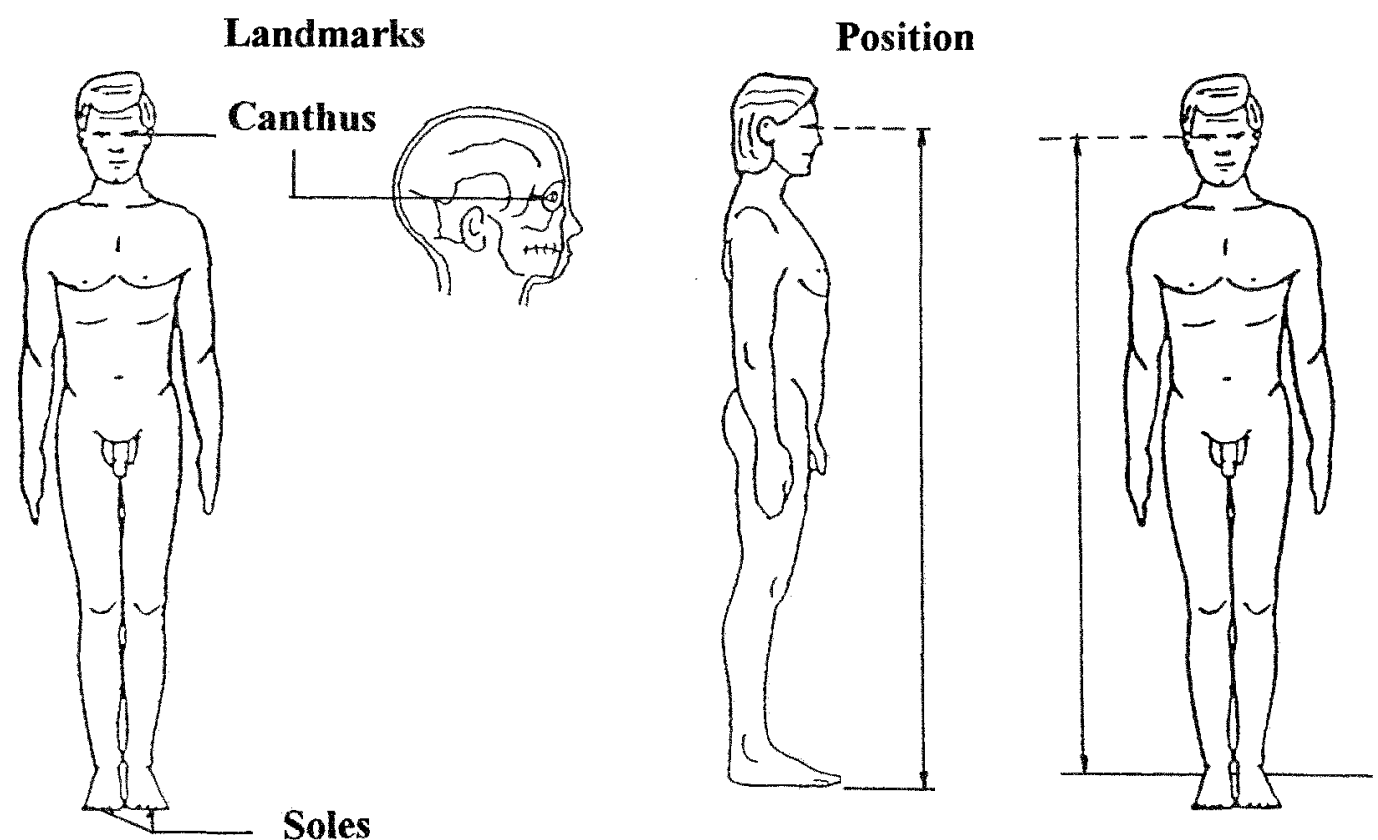

Definition: The height of the inner corner of the eye.

Landmarks: The inner corner of the eye,(canthus), and the inferior surfaces of the feet, (soles or plantar surfaces).

Instruments: Movable anthropometer.

Position of subject: The subject stands on a flat surface, and his or her body weight is evenly distributed on both feet, heels together as closely as possible, legs and torso straight without stiffness and head erect with the line of vision parallel to the floor. The arms hang straight but loosely at the sides with the palms alongside but no touching the 
thighs. Subject remains in this position while the measurement is taken.

Position of measurer: The measurer stands at the subject's right side.

Procedure: The anthropometer's lower part is set on the floor surface while the upper part is hold and balance in a vertical position in the measurer's right hand. The moving arm of the anthropometer is lowered with the left hand until the blade point rests onto specified landmark (inner cantus of the eye). When the subject and measurer are also positioned, the subject is instructed to take a deep breath, and the measurement is made just before the subject exhales. The measurer should observe the level of the anthropometer blade without parallax; hence a small stool may be required. The measurement is recorded to the nearest millimeter.

Remarks: Measurement is repeated three times. The subject has to step off after the first measurement, and take position again in between measurements. It is important that the recorder observe both the position of the subject to avoid slouching and also the position of the anthropometer to ensure that it is vertical and the blade is brought down onto the specified landmark. 


\section{3- SHOULDER HEIGHT}

Landmarks

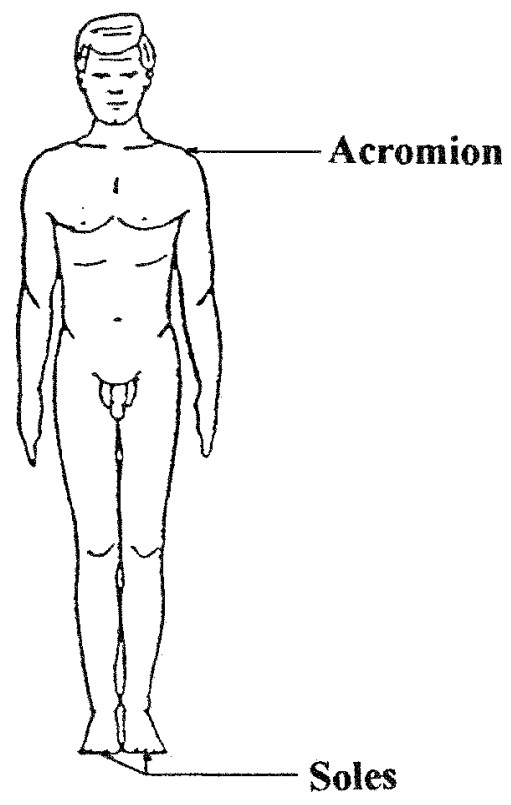

Position

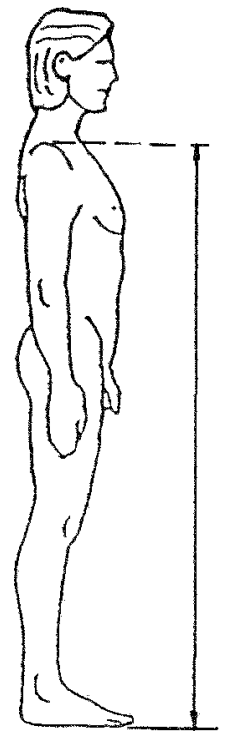

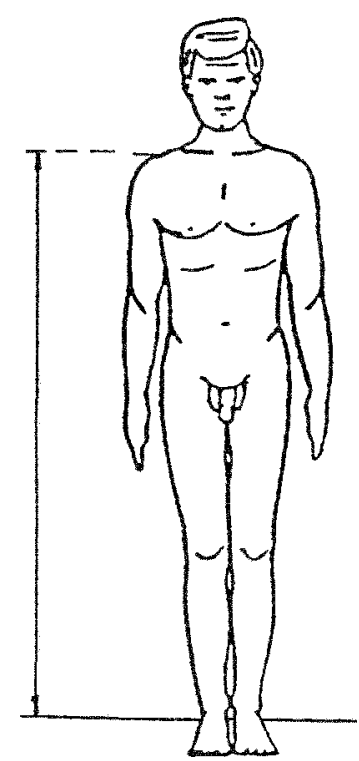

Definition: The height of the acromion.

Landmarks: The most prominent posterior lateral bony of the spine of the escapula or point of the shoulder, (acromion), and the inferior surfaces of the feet, (soles or plantar surfaces).

Instruments: Movable anthropometer.

Position of subject: The subject stands on a flat surface, and his or her body weight is evenly distributed on both feet, heels together as closely as possible, legs and torso straight without stiffness and head erect with the line of vision parallel to the floor. The 
arms hang straight but loosely at the sides with the palms alongside but no touching the thighs. Subject remains in this position while the measurement is taken.

Position of measurer: The measurer stands at the subject's right side facing landmark as placed.

Procedure: The anthropometer's lower part is set on the floor surface while the upper part is hold and balance in a vertical position in the measurer's right hand. The moving arm of the anthropometer is lowered with the left hand until the blade point rests onto specified landmark (most upper prominent bony of the acromion). When the subject and measurer are also positioned, the subject is instructed to take a deep breath, and the measurement is made just before the subject exhales. The measurer should observe the level of the anthropometer blade without parallax. The measurement is recorded to the nearest millimeter.

Remarks: Measurement is repeated three times. The subject has to step off after the first measurement, and take position again in between measurements. It is important that the recorder observe both the position of the subject to avoid slouching and also the position of the anthropometer to ensure that it is vertical and the blade point is brought down onto the specified landmark. If too much pressure is applied to the anthropometer blade, it may slide to one side off the landmark. 

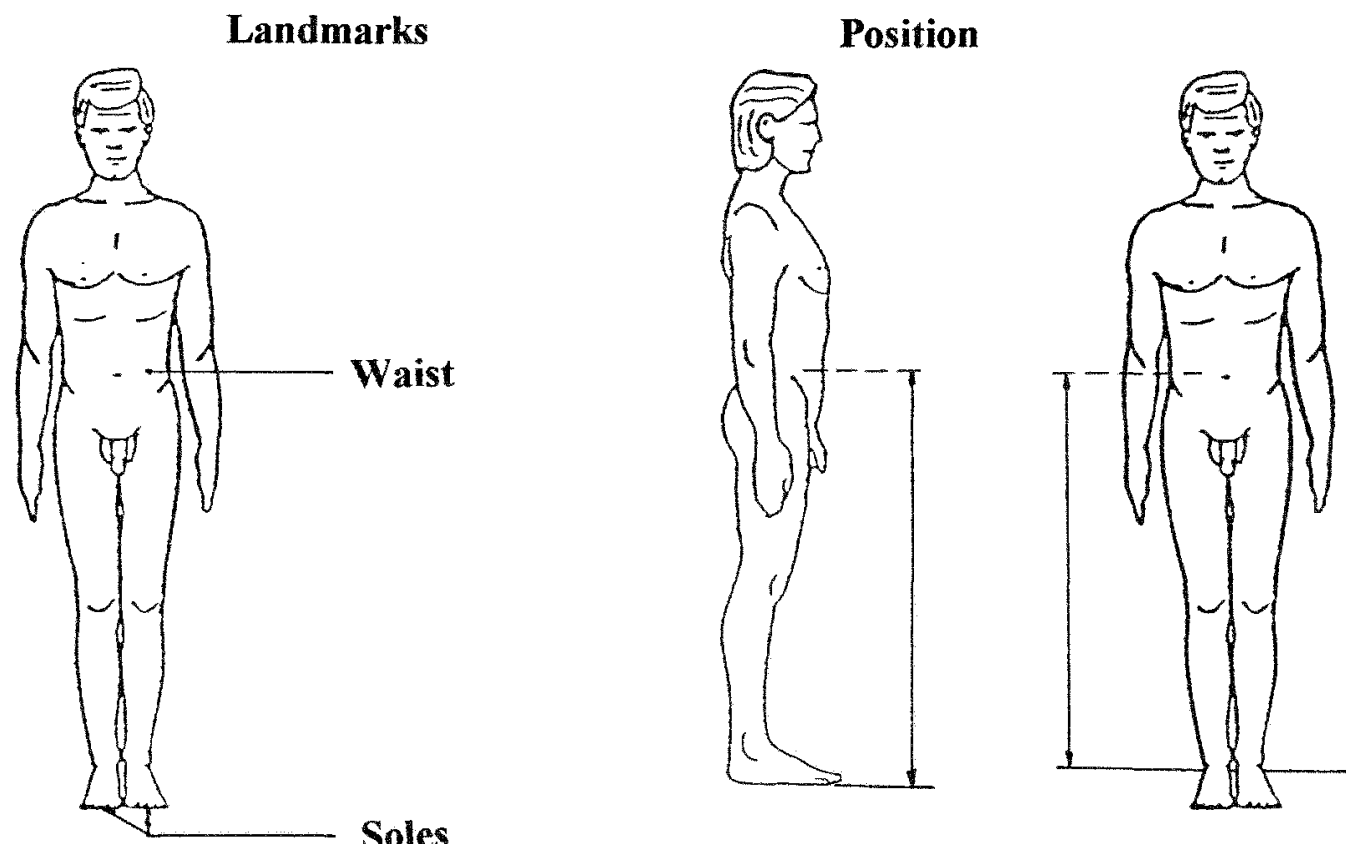

Definition: The height of waist level.

Landmarks: The middle point of the body between the ribs and the hips, (waist), and the inferior surfaces of the feet, (soles or plantar surfaces).

Instruments: Movable anthropometer.

Position of subject: The subject stands on a flat surface, and his or her body weight is evenly distributed on both feet, heels together as closely as possible, legs and torso straight without stiffness and head erect with the line of vision parallel to the floor. The arms hang straight but loosely at the sides with the palms alongside but no touching the 
thighs. Subject remains in this position while the measurement is taken.

Position of measurer: The measurer stands at the subject's right side facing landmark as placed.

Procedure: The anthropometer's lower part is set on the floor surface while the upper part is hold and balance in a vertical position in the measurer's right hand. The moving arm of the anthropometer is lowered with the left hand until the blade point rests onto specified landmark (waist). When the subject and measurer are also positioned, the subject is instructed to take a deep breath, and the measurement is made just before the subject exhales. The measurement is recorded to the nearest millimeter.

Remarks: Measurement is repeated three times. The subject has to step off after the first measurement, and take position again in between measurements. It is important that the recorder observe both the position of the subject to avoid slouching and also the position of the anthropometer to ensure that it is vertical and the blade point is brought down onto the specified landmark. 

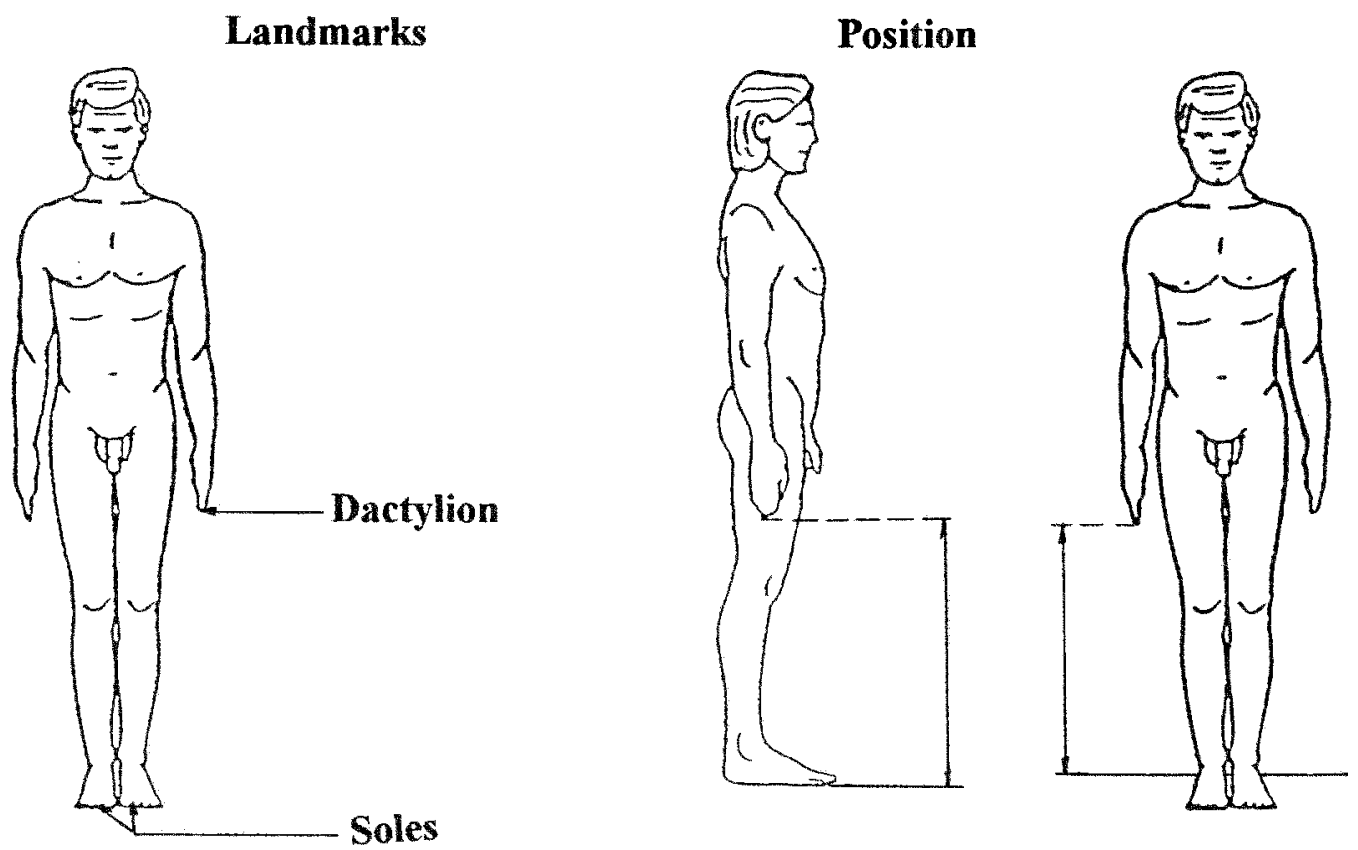

Definition: The height of the tip of the middle finger measured with the arm, hand, and finger extended downward.

Landmarks: The tip of the distal phalange of the middle finger, (dactylion), and the inferior surfaces of the feet, (soles or plantar surfaces).

Instruments: Movable anthropometer.

Position of subject: The subject stands on a flat surface, and his or her body weight is evenly distributed on both feet, heels together as closely as possible, legs and torso straight without stiffness and head erect with the line of vision parallel to the floor. The 
arms hang straight but loosely at the sides with the palms alongside but no touching the thighs. Subject remains in this position while the measurement is taken.

Position of measurement: The measurer usually find it most convenient to sit in front of the subject.

Procedure: The anthropometer's lower part is set on the floor surface while the upper part is hold and balance in a vertical position in the measurer's right hand. The moving arm of the anthropometer is lowered with the left hand until the blade point rests onto specified landmark (tip of the middle finger). When the subject and measurer are also positioned, the subject is instructed to take a deep breath, and the measurement is made just before the subject exhales. The measurement is recorded to the nearest millimeter. Remarks: Measurement is repeated three times. The subject has to step off after the first measurement, and take position again in between measurements. It is important that the recorder observe both the position of the subject to avoid slouching and also the position of the anthropometer to ensure that it is vertical and the blade point is brought down onto the specified landmark. 
Landmarks

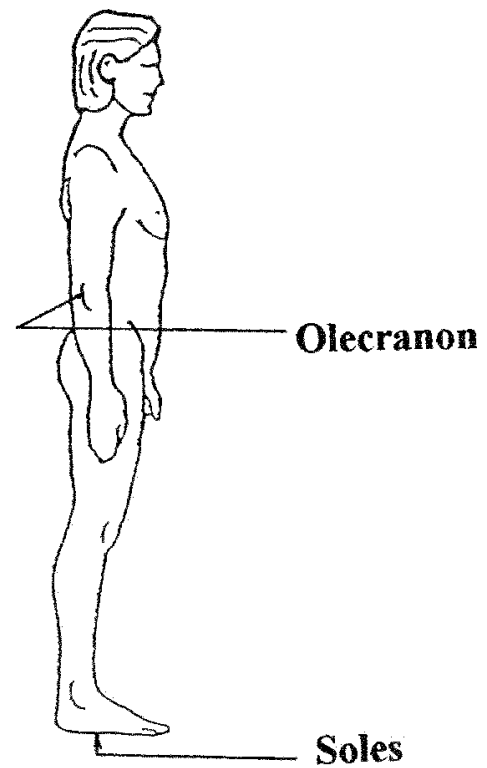

Position

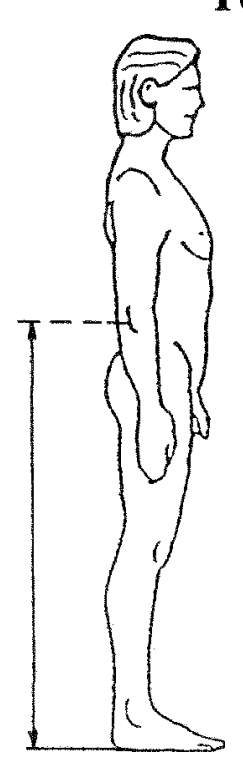

Definition: The height of radiale.

Landmarks: The most posterior point of the olecranon and the inferior surfaces of the feet, (soles or plantar surfaces).

Instruments: Movable anthropometer.

Position of subject: The subject stands on a flat surface, and his or her body weight is evenly distributed on both feet, heels together as closely as possible, legs and torso straight without stiffness and head erect with the line of vision parallel to the floor. The arms hang straight but loosely at the sides with the palms alongside but no touching the 
thighs. Subject remains in this position while the measurement is taken.

Position of measurer: The measurer stands at the subject's right side facing landmark as placed.

Procedure: The anthropometer's lower part is set on the floor surface while the upper part is hold and balance in a vertical position in the measurer's right hand. The moving arm of the anthropometer is lowered with the left hand until the blade point rests onto specified landmark (most posterior point of the olecranon). When the subject and measurer are also positioned, the subject is instructed to take a deep breath, and the measurement is made just before the subject exhales. The measurement is recorded to the nearest millimeter.

Remarks: Measurement is repeated three times. The subject has to step off after the first measurement, and take position again in between measurements. It is important that the recorder observe both the position of the subject to avoid slouching and also the position of the anthropometer to ensure that it is vertical and the blade point is brought down onto the specified landmark. 


\section{7- HIP BREADTH}
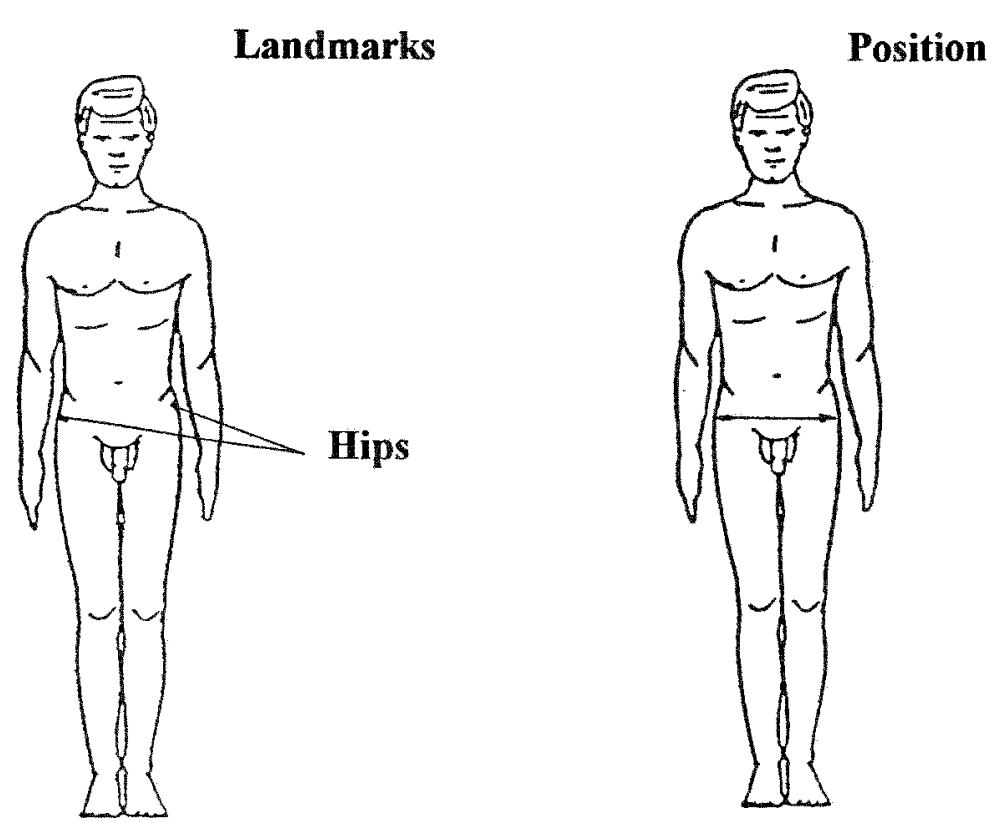

Definition: The maximum breadth of the lower torso.

Landmarks: The most lateral borders of the hips.

Instruments: Caliper or anthropometer configured as a sliding beam caliper.

Position of subject: The subject stands on a flat surface, and his or her body weight is evenly distributed on both feet, heels together as closely as possible, legs and torso straight without stiffness and head erect with the line of vision parallel to the floor. The arms need to be away from the area of measurement, preferably folded across the chest. Subject remains in this position while the measurement is taken. 
Position of measurer: The measurer stands back of the subject.

Procedure: The caliper or anthropometer is hold so that its blades are between the index and middle fingers and resting on the base of the thumb. The fixed arm is positioned to make firm contact with the most prominent lateral bony prominence of the left hip, while the sliding arm is aligned with the most distal palpable point of the right hip. The measurement is recorded to the nearest millimeter.

Remarks: Measurement is repeated three times. The subject has to step off after the first measurement, and take position again in between measurements. It is important that the recorder observe both the position of the subject to avoid slouching and also the position of the anthropometer to ensure that blade point is brought onto the specified landmark. 

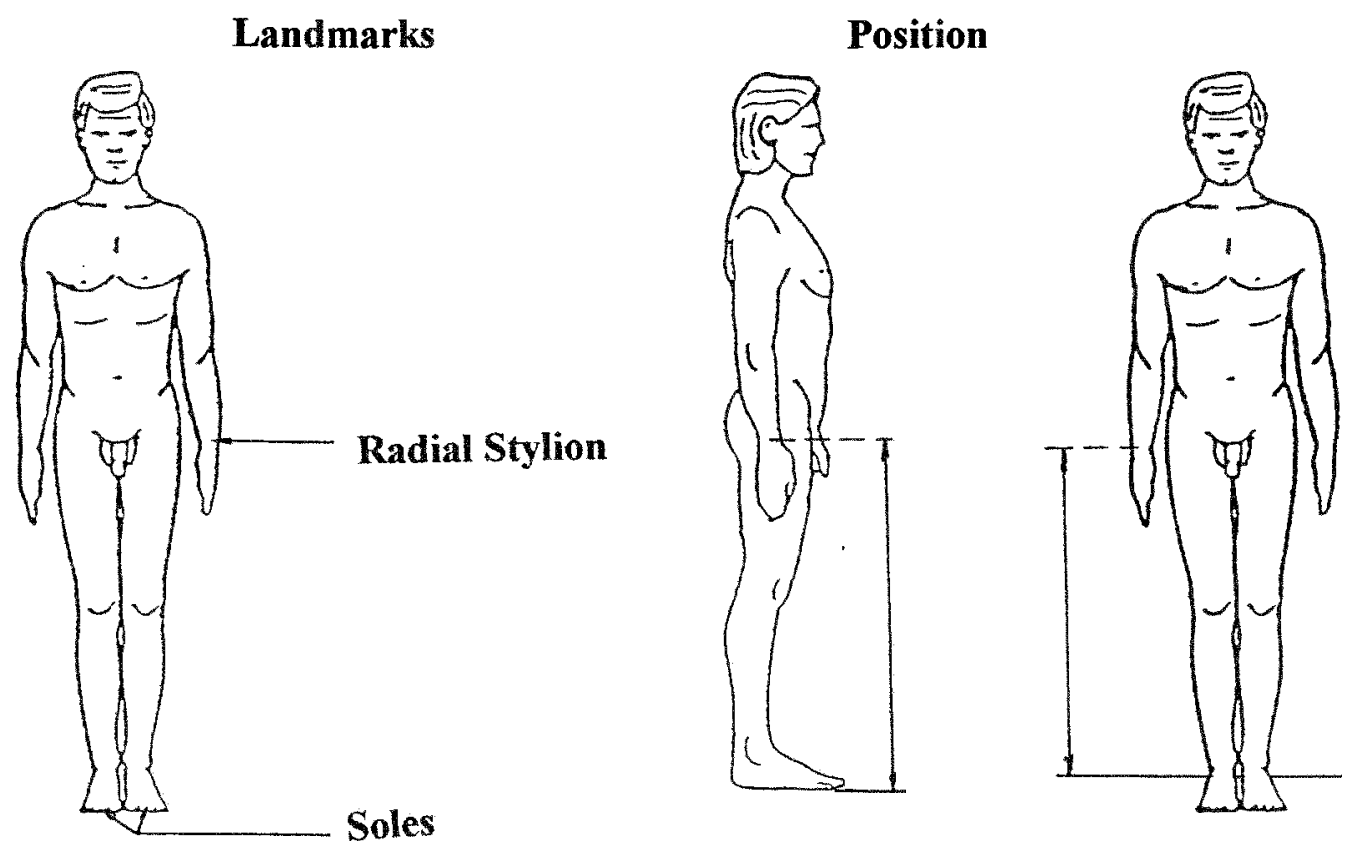

Definition: The height of stylion.

Landmarks: The most palpable point of the distal end of the radious, ( radial stylion), and the inferior surfaces of the feet, (soles or plantar surfaces).

Instruments: Movable anthropometer.

Position of subject: The subject stands on a flat surface, and his or her body weight is evenly distributed on both feet, heels together as closely as possible, legs and torso straight without stiffness and head erect with the line of vision parallel to the floor. The arms hang straight but loosely at the sides with the palms alongside but no touching the 
thighs. Subject remains in this position while the measurement is taken.

Position of measurer: The measurer stands at the subject's right side facing landmark as placed.

Procedure: The anthropometer's lower part is set on the floor surface while the upper part is hold and balance in a vertical position in the measurer's right hand. The moving arm of the anthropometer is lowered with the left hand until the blade point rests onto specified landmark (most palpable point of the radial stylion ). When the subject and measurer are also positioned, the subject is instructed to take a deep breath, and the measurement is made just before the subject exhales. The measurement is recorded to the nearest millimeter.

Remarks: Measurement is repeated three times. The subject has to step off after the first measurement, and take position again in between measurements. It is important that the recorder observe both the position of the subject to avoid slouching and also the position of the anthropometer to ensure that it is vertical and the blade point is brought down onto the specified landmark. 

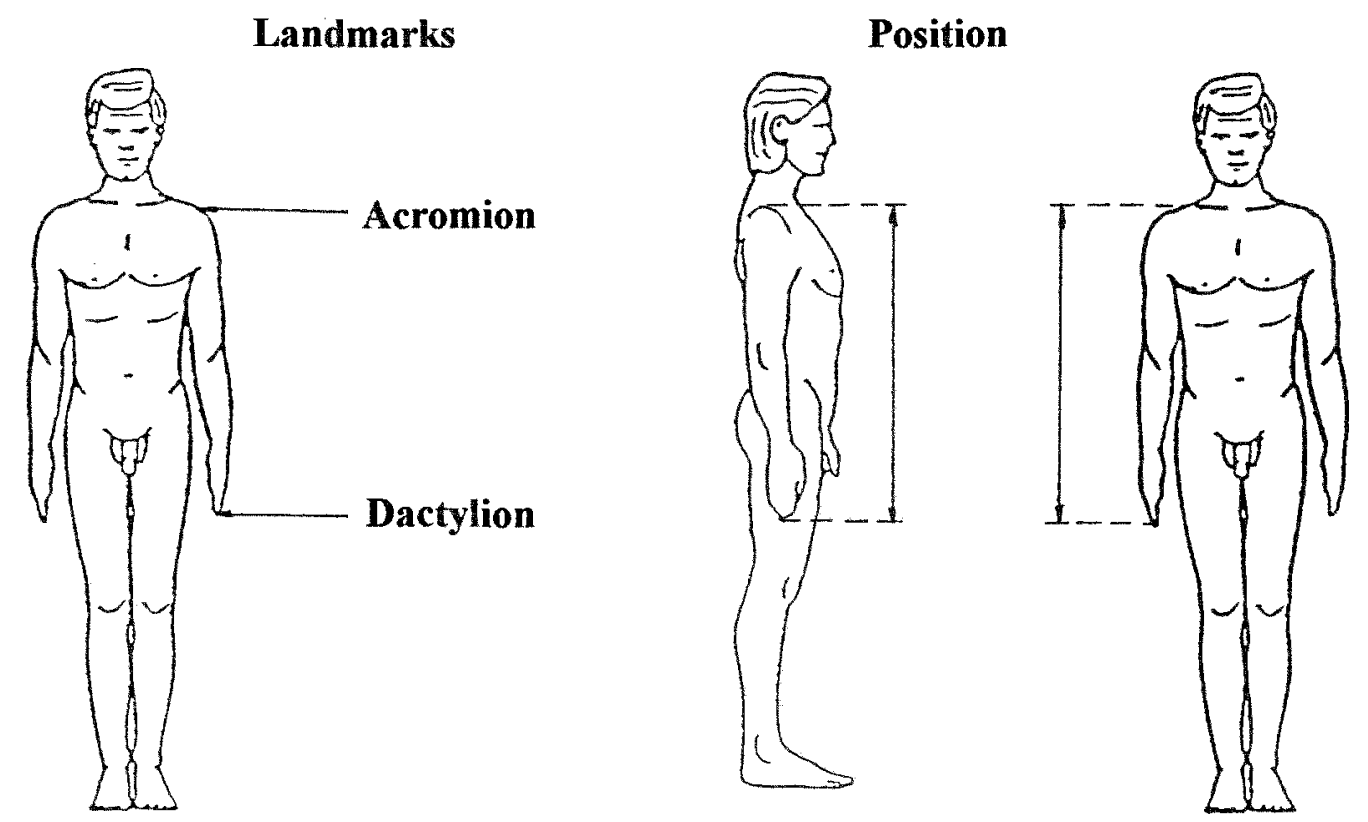

Definition: The vertical distance from acromion to the tip of the middle finger.

Landmarks: The most prominent posterior lateral bony of the the spine of the scapula or point of the shoulder, (acromion), and the tip of the distal phalange of the middle finger, (dactylion).

Instruments: Caliper or anthropometer configured as a sliding beam caliper.

Position of the subject: The subject stands on a flat surface, and his or her body weight is evenly distributed on both feet, heels together as closely as possible, legs and torso straight without stiffness and head erect with the line of vision parallel to the floor. The 
arms hang straight but loosely at the sides with the palms alongside but no touching the thighs. Subject remains in this position while the measurement is taken.

Position of the measurer: The measurer stands at the subject's right side facing landmark as placed.

Procedure: The fixed arm of the beam caliper is placed to make firm contact with the most prominent posterior lateral bony prominence of the shoulder joint (acromion), while the sliding arm of the caliper is shifted to make contact with the fleshy tip of the middle finger of the hand (dactylion ). The measurement is recorded to the nearest millimeter. Remarks: Measurement is repeated three times. The subject has to step off after the first measurement, and take position again in between measurements. It is important that the recorder observe both the position of the subject to avoid slouching and also the position of the anthropometer to ensure that it is positioned onto the specified landmark. 
Landmarks

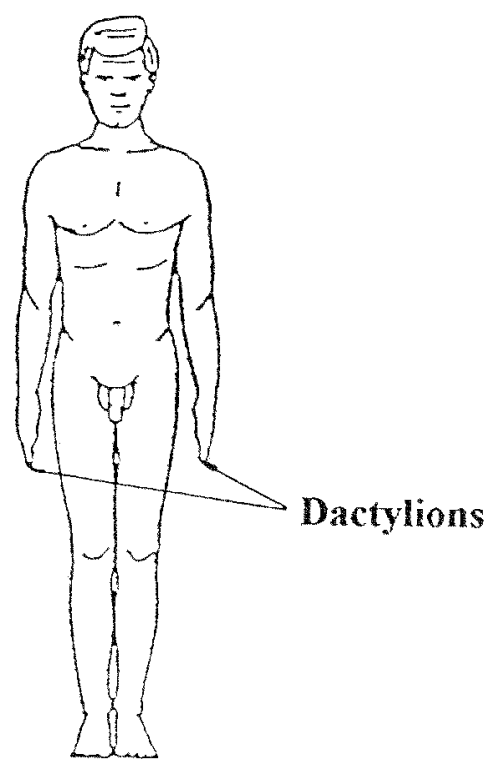

Position

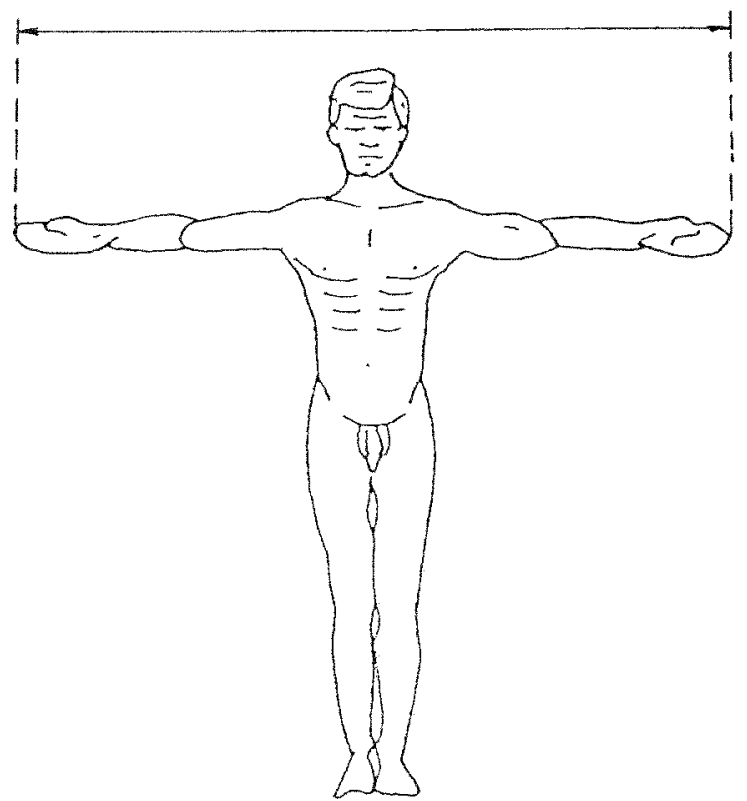

Definition: The distance between the tips of the right and left middle fingers when the subject's arms are maximally extended laterally.

Landmarks: The tips of the right and left distal phalanges of the middle fingers, (dactylions).

Instruments: Measure tape, a flat surface (usually two cross walls) and a millimeter scale (millimeter paper).

Position of subject: The subject stands with the feet together and so that his or her back is against the wall. The arms are outstretched laterally and maximally at the level of the 
shoulders, in contact with the wall, and with the palms facing forwards. The tip of the middle (longest) finger (excluding the fingernail) of the left hand is kept in contact with the corner at the cross wall.

Position of measurer: The measurer stands in front of the subject.

Procedure: A piece of millimeter paper is fastened on the wall in such position that. it form a tape measure on the wall with zero in the corner at the cross wall. With the subject properly positioned, the reading can be taken directly off the paper. The paper, of course, would be subject to wear and tear, and would be probably be influenced by humidity. A plastic cover over properly affixed or laminated millimeter paper would reduce wear and tear effects. The measurement is recorded to the nearest millimeter. Occasionally a small stool may be required to make this measurement in tall subjects.

Remarks: Measurement is repeated three times. The subject has to step off after the first measurement, and take position again in between measurements. 


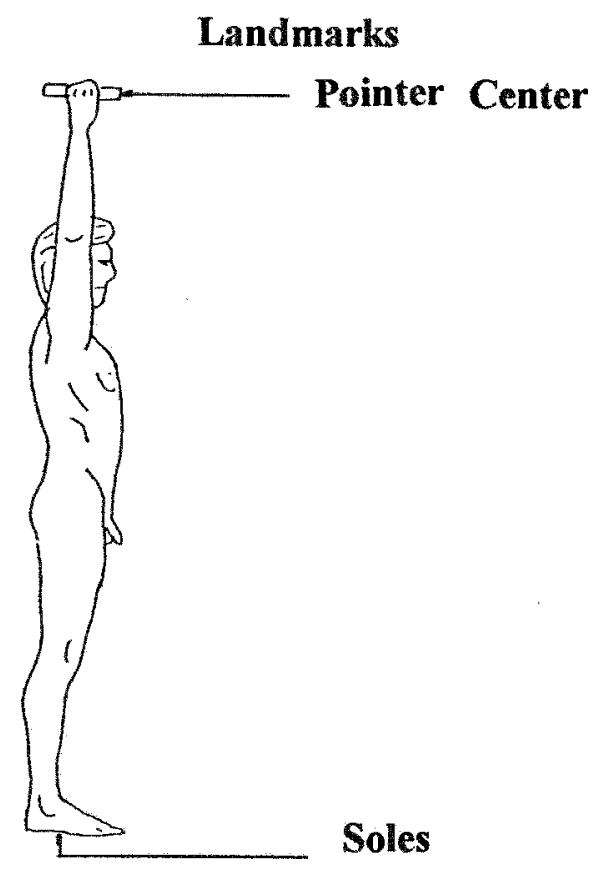

Position

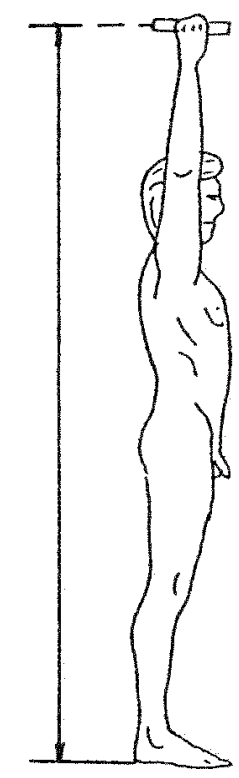

Definition: The height of a pointer held horizontal in the subject's fist when the arm is maximally extended upward.

Landmarks: The center of the cylindrical pointer and the inferior surfaces of the feet, (soles or plantar surfaces).

Instruments: Measure tape, a flat surface (wall) and a millimeter scale (millimeter paper).

Position of subject: The subject stands on a flat surface, and his or her body weight is evenly distributed on both feet, heels together as closely as possible, legs and torso straight without stiffness and head erect with the line of vision parallel to the floor and so 
that his or her back is against the wall. A pointer is held horizontal in the subject's right fist and the right arm is maximally extended upward with the palms facing inwards. Subject remains in this position while the measurement is taken.

Position of measurer: The measurer stands at the subject's right side.

Procedure: A piece of millimeter paper is fastened on the wall in such position that it form a tape measure on the wall with zero in the floor. When the subject and measurer are also positioned, the subject is instructed to take a deep breath, and the measurement is made just before the subject exhales. The reading can be taken directly off the paper. The paper, of course, would be subject to wear and tear, and would be probably be influenced by humidity. A plastic cover over properly affixed or laminated millimeter paper would reduce wear and tear effects. The measurement is recorded to the nearest millimeter. Occasionally a small stool may be required to make this measurement in tall subjects. Remarks: Measurement is repeated three times. The subject has to step off after the first measurement, and take position again in between measurements. 
Landmarks

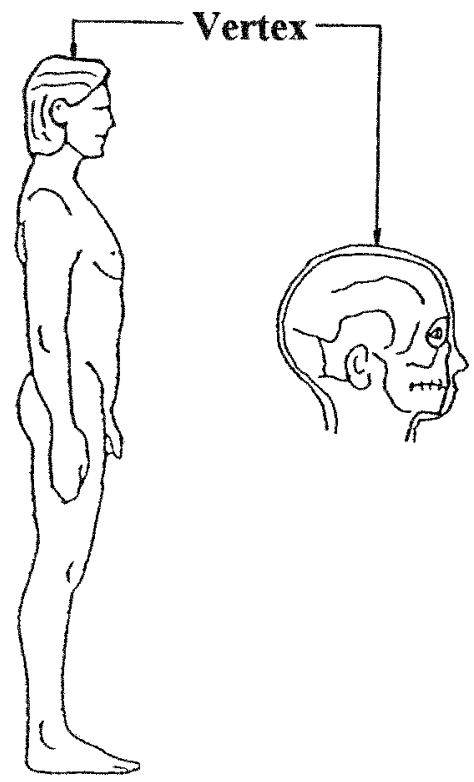

Position

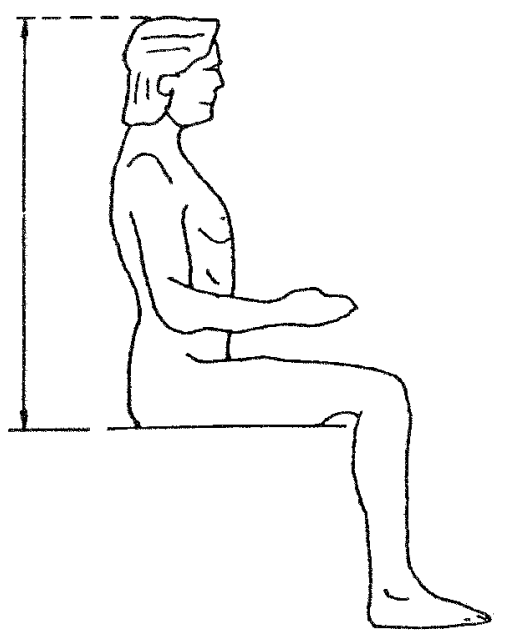

Definition: The height, from the sitting surface, to the top of the head.

Landmarks: The most superior part of the skull, (vertex), and the sitting surface.

Instruments: Movable anthropometer and table. Table should be sufficiently high so that subject's legs hang freely.

Position of subject: The subject sits on the table with the legs hanging unsupported over the edge of the table and with the hands resting on the thighs. The knees are directed straight ahead. The backs of the knees are near the edge of the table but not in contact with it. The subject sits as erect as possible, with the path of vision parallel to the plane of 
the floor. In positioning, it is useful to approach the subject from the left side and to apply gentle pressure simultaneously with the right hand over the lumbar area and with the left hand on the superior part of the sternum. This reinforces the erect position.

Position of measurer: The measurer stands at the subject's left side.

Procedure: The lower half of the anthropometer is set on the table surface, and it is positioned vertically in the midline behind the subject so that it nearly touches the sacral and interscapular regions. The measurer's left hand is placed under the subject's chin to assist in holding the proper position. The left hand moves the blade of the anthropometer onto the vertex (the most superior point on the head in the sagittal plane). When the subject and measurer are so positioned, the subject is instructed to take a deep breath, and the measurement is made just before the subject exhales. Firm pressure is applied to compress the hair. The measurer should observe the level of the anthropometer blade without parallax; hence, a small stool may be required. The measurement is recorded to the nearest millimeter.

Remarks: Measurement is repeated three times. The subject has to stand up after the first measurement, and take position again in between measurements. It is important that the recorder observe both the position of the subject to avoid slouching and also the position of the anthropometer to ensure that it is vertical and the blade is brought down onto the specified landmark. If too much pressure is applied to the anthropometer blade, it may 
slide to one side off the vertex. It is important that the subject's arms rest relaxed on the thighs. The subjects should not place their hands on the side of the table and push themselves erect. 


\section{3- SITTING EYE HEIGHT}

Landmarks

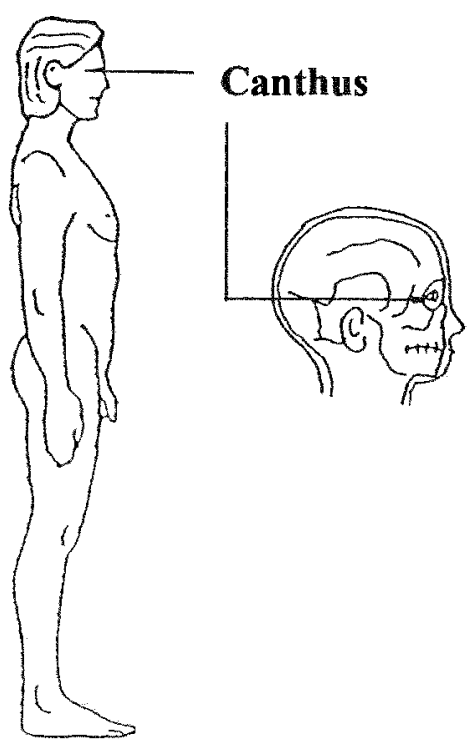

Position

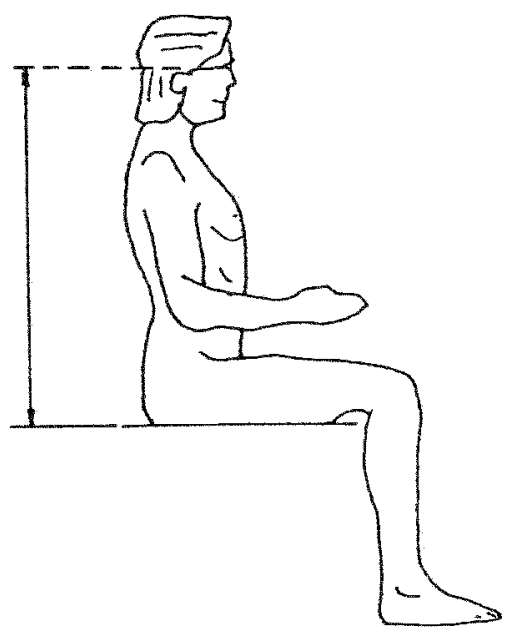

Definition: The height of the inner corner of the eye.

Landmarks: The inner corner of the eye, (canthus), and the sitting surface.

Instruments: Movable anthropometer and table. Table should be sufficiently high so that subject's legs hang freely.

Position of subject: The subject sits on the table with the legs hanging unsupported over the edge of the table and with the hands resting on the thighs. The knees are directed straight ahead. The backs of the knees are near the edge of the table but not in contact with it. The subject sits as erect as possible, with the path of vision parallel to the plane of 
the floor. In positioning, it is useful to approach the subject from the left side and to apply gentle pressure simultaneously with the right hand over the lumbar area and with the left hand on the superior part of the sternum. This reinforces the erect position.

Position of measurer: The measurer stands in front of subject.

Procedure: The lower half of the anthropometer is set on the table surface, and it is hold and balance in a vertical position in the measure's right hand. The measurer's left hand is placed under the subject's chin to assist in holding the proper position, then the left hand moves the blade of the anthropometer onto the specified landmark (inner corner of the eye). When the subject and measurer are so positioned, the subject is instructed to take a deep breath, and the measurement is made just before the subject exhales. The measurer should observe the level of the anthropometer blade without parallax. The measurement is recorded to the nearest millimeter.

Remarks: Measurement is repeated three times. The subject has to stand up after the first measurement, and take position again in between measurements. It is important that the recorder observe both the position of the subject to avoid slouching and also the position of the anthropometer to ensure that it is vertical and the blade is brought down onto the specified landmark. It is important that the subject's arms rest relaxed on the thighs. The subjects should not place their hands on the side of the table and push themselves erect. 


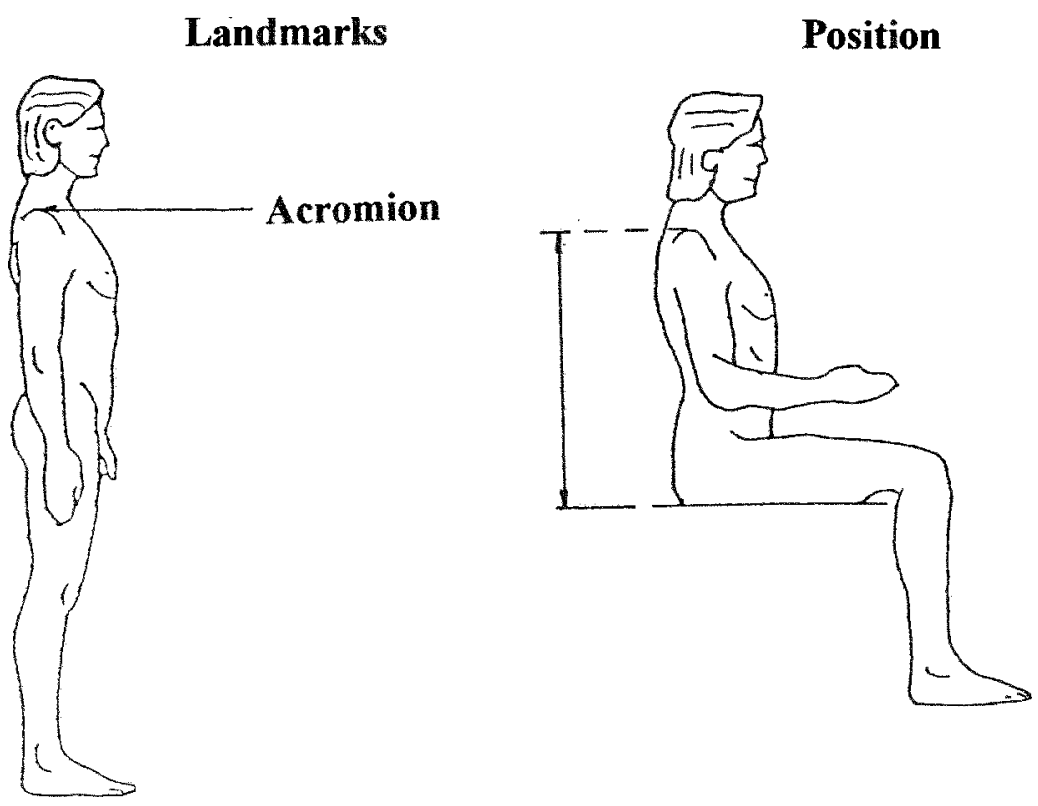

Definition: The height of acromion above the sitting surface.

Landmarks: The most prominent posterior lateral bony of the supine of the scapula or point of the shoulder, (acromion), and the sitting surface.

Instruments: Movable anthropometer and table. Table should be sufficiently high so that subject's legs hang freely.

Position of subject: The subject sits on the table with the legs hanging unsupported over the edge of the table. The knees are directed straight ahead. The backs of the knees are near the edge of the table but not in contact with it. The subject sits as erect as possible, 
with the path of vision parallel to the plane of the floor. The subject's arms are vertical, with the elbows resting lightly against the sides of the body. The elbows are flexed to about 90 degrees so that the forearms and the supinated hands are extended forwards horizontally. The fingers are together and extended in the direction of the longitudinal axes of the forearms. In positioning, it is useful to approach the subject from the left side and to apply gentle pressure simultaneously with the right hand over the lumbar area and with the left hand on the superior part of the sternum. This reinforces the erect position. Subject remains in this position while the measurement is taken.

Position of measurer: The measurer stands at the subject's left side.

Procedure: The lower half of the anthropometer is set on the table surface, and it is hold and balance in a vertical position in the measure's right hand. The measurer's left hand is placed under the subject's chin to assist in holding the proper position, then the left hand moves the blade of the anthropometer onto the specified landmark (most prominent lateral bony prominence of the shoulder joint). When the subject and measurer are so positioned, the subject is instructed to take a deep breath, and the measurement is made just before the subject exhales. The measurer should observe the level of the anthropometer blade without parallax. The measurement is recorded to the nearest millimeter.

Remarks: Measurement is repeated three times. The subject has to stand up after the first measurement, and take position again in between measurements. It is important that the 
recorder observe both the position of the subject to avoid slouching and also the position of the anthropometer to ensure that it is vertical and the blade is brought down onto the specified landmark. If too much pressure is applied to the anthropometer blade, it may slide to one side off the landmark. It is important that the subject's arms rest relaxed on the thighs. The subjects should not place their hands on the side of the table and push themselves erect. 


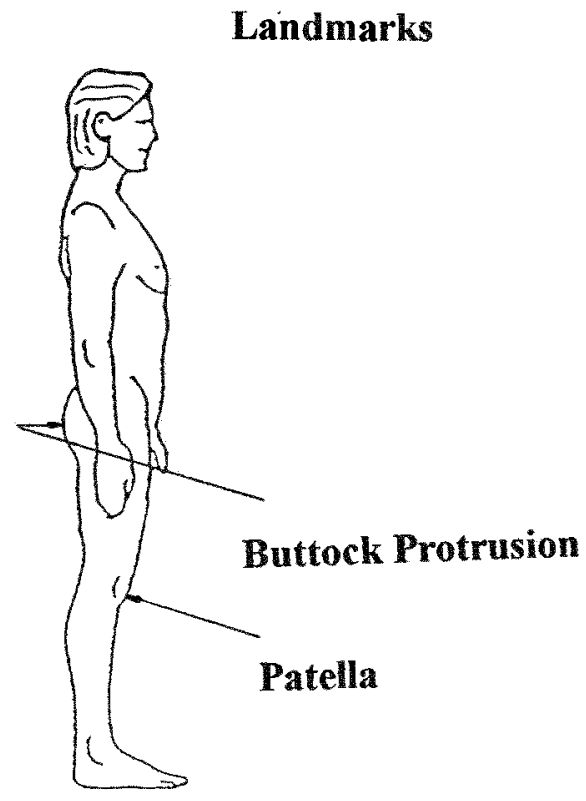

Position

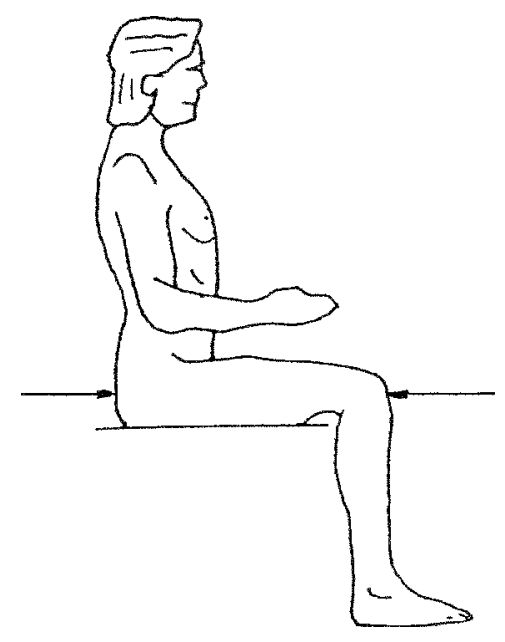

Definition: The horizontal distance from the rearmost surface of the buttocks to the front of the kneecaps.

Landmarks: The most posterior prominence of the gluteal region or buttock and the anterior surface of the kneecap, (patella).

Instruments: Caliper or anthropometer configured as sliding beam caliper , table and adjustable footrest.

Position of subject: The subject sits erect on a cushionless flat surface (table), feet on an adjustable footrest so that the knees are flexed to 90 degrees, the long axis of the thighs 
parallel. The trunk is erected without stiffness and the head is also erect with the path of vision parallel to the plane of the floor. The subject's arms are vertical, with the elbows resting lightly against the sides of the body. The elbows are flexed to about 90 degrees so that the forearms and the supinated hands are extended forwards horizontally. The fingers are together and extended in the direction of the longitudinal axes of the forearms. In positioning, it is useful to approach the subject from the left side and to apply gentle pressure simultaneously with the right hand over the lumbar area and with the left hand on the superior part of the sternum. This reinforces the erect position. Subject remains in this position while the measurement is taken.

Position of measurer: The measurer stands at the subject's right side.

Procedure: The caliper or anthropometer is hold so that its blades are between the index and middle fingers and resting on the base of the thumb. The fixed arm is positioned to make firm contact with the most prominent lateral bony prominence of the buttoks, while the sliding arm is aligned with the most distal palpable point of the kneecaps (patella). The measurement is recorded to the nearest millimeter.

Remarks: Measurement is repeated three times. The subject has to stand up after the first measurement, and take position again in between measurements. It is important that the recorder observe both the position of the subject to avoid slouching and also the position of the anthropometer to ensure that it is positioned onto the specifies landmark. 


\section{Landmarks}

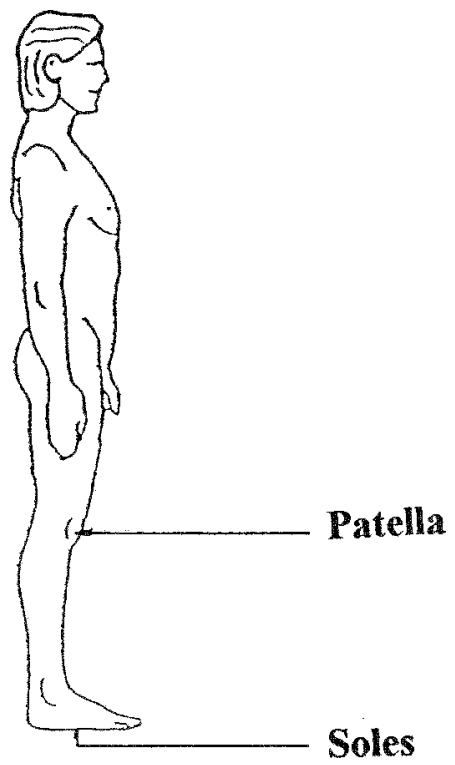

Position

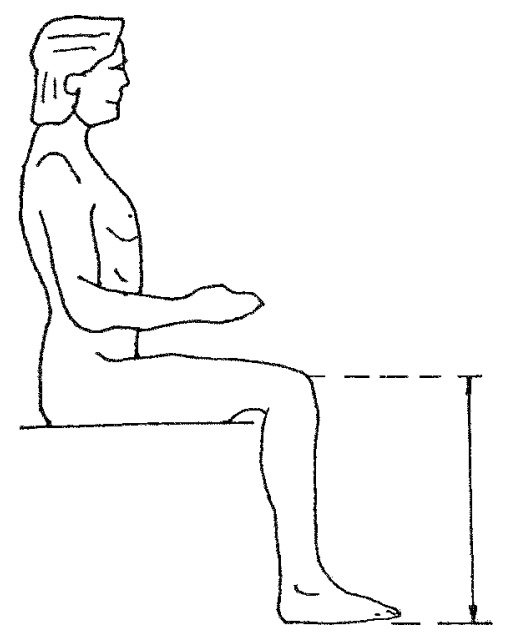

Definition: The height, from the footrest surface, of the musculature just above the knee.

Landmarks: The most superior prominence bony of the kneecap, (patella), and the inferior surfaces of the feet, (soles or plantar surfaces).

Instruments: Movable anthropometer, table and adjustable footrest.

Position of subject: The subject sits erect on a cushionless flat surface (table), feet on an adjustable footrest so that the knees are flexed to 90 degrees, the long axis of the thighs parallel. The trunk is erected without stiffness, head is also erect with the path of vision parallel to the plane of the floor and hands are rested on the thighs. In positioning, it is 
useful to approach the subject from the left side and to apply gentle pressure simultaneously with the right hand over the lumbar area and with the left hand on the superior part of the sternum. This reinforces the erect position. Subject remains in this position while the measurement is taken.

Position of measurer: The measurer stands at the subject's right side.

Procedure: The lower half of the anthropometer is set on the footrest surface, and it is hold and balance in a vertical position in the measure's right hand. The measurer's left hand moves the sliding blade of the anthropometer onto the specified landmark (musculature just above the knee). The measurement is recorded to the nearest millimeter.

Remarks: Measurement is repeated three times. The subject has to stand up after the first measurement, and take position again in between measurements. It is important that the recorder observe both the position of the subject to avoid slouching and also the position of the anthropometer to ensure that it is positioned onto the specified landmark. 

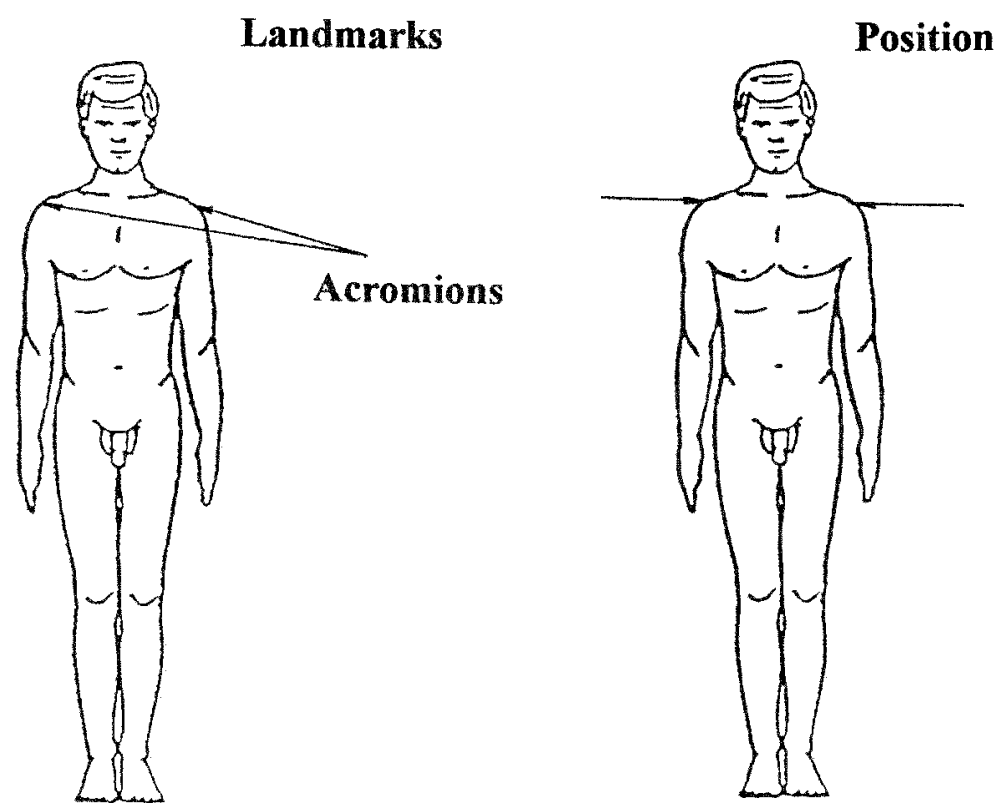

Definition: The distance across the shoulders from right to left acromion.

Landmarks: Left and right most prominent posterior lateral bony of the supine of the scapula, point of the shoulder, (acromions).

Instruments: Caliper or anthropometer configured as sliding beam caliper.

Position of subject: The subject stands, because sitting interferes with the posture required for measurement. The subject stands on a flat and his or her body weight is evenly distributed on both feet, heels together as closely as possible, legs and torso straight without stiffness and head erect with the line of vision parallel to the floor. The 
arms hang straight but loosely at the sides with the palms alongside but no touching the thighs. Subject remains in this position while the measurement is taken.

Position of measurer: The measurer stands back of the subject.

Procedure: Standing directly behind the subject, the measurer runs his hands from the base of the neck outwards to the tips of the shoulders, relaxing any tension. The most lateral borders of the acromial processes are palpated and, holding the anthropometer or caliper so that its blades are between the index and middle fingers and resting on the base of the thumb, the blades are applied firmly to the most lateral borders of the acromial processes. The width is read to the nearest millimeter.

Remarks: Measurement is repeated three times. The subject has to step off after the first measurement, and take position again in between measurements. It is important that the recorder observe both the position of the subject to avoid slouching and also the position of the anthropometer to ensure that it is positioned onto the specified landmark. If too much pressure is applied to the anthropometer blade, it may slide to one side off the landmark. 

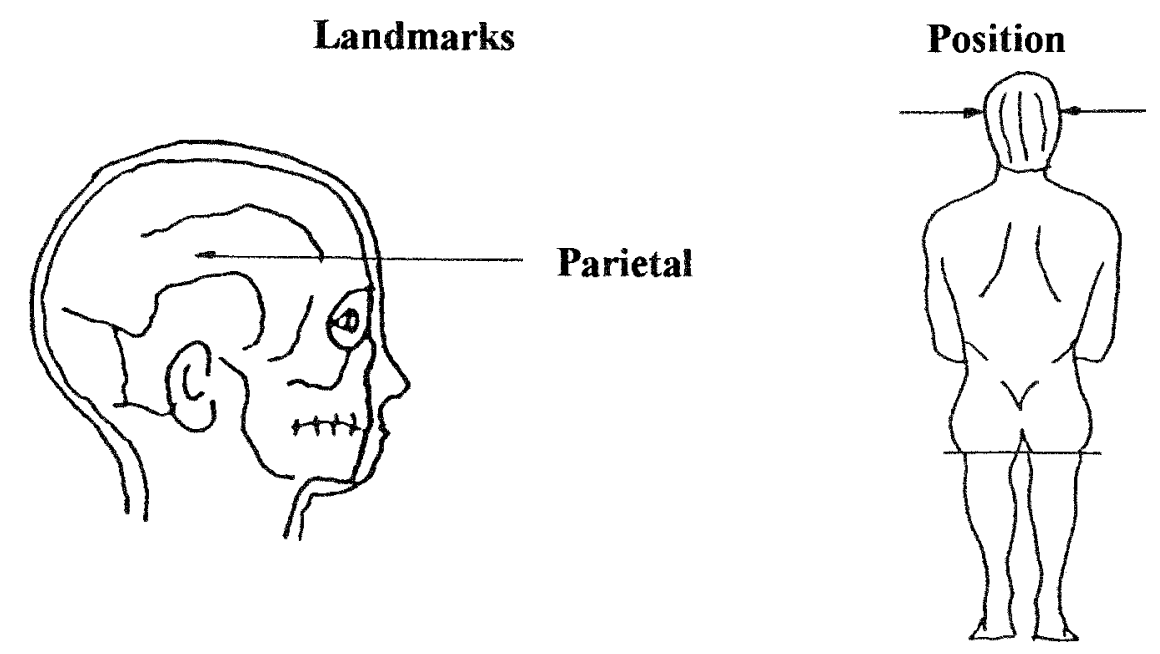

Definition: The maximum breadth of the head.

Landmarks: The most lateral points of the parietal bones on each side of the skull.

Instruments: Sliding or spreading caliper.

Position of subject: The measurement is made with the subject in a natural standing or sitting position. The subject's head should be held erect with the line of vision parallel to the floor.

Position of measurer: The measurer stands in front of the subject.

Procedure: Upon palpation of the most lateral points of the parietal bones (eurion) on 
each side of the head, the measurer places the caliper tips directly on the landmarks, with his or her fingers just beneath the caliper tips to prevent them from slipping .Measurement is made with caliper tips in a horizontal plane. When the subject and measurer are so positioned, the subject is instructed to take a deep breath, and the measurement is made just before the subject exhales. The measurement is recorded to the nearest millimeter. Remarks: Measurement is repeated three times. The subject has to step off after the first measurement, and take position again in between measurements. It is important that the recorder observe both the position of the subject to avoid slouching and also the position of the caliper to ensure that it is positioned onto the specified landmark. 
Landmarks

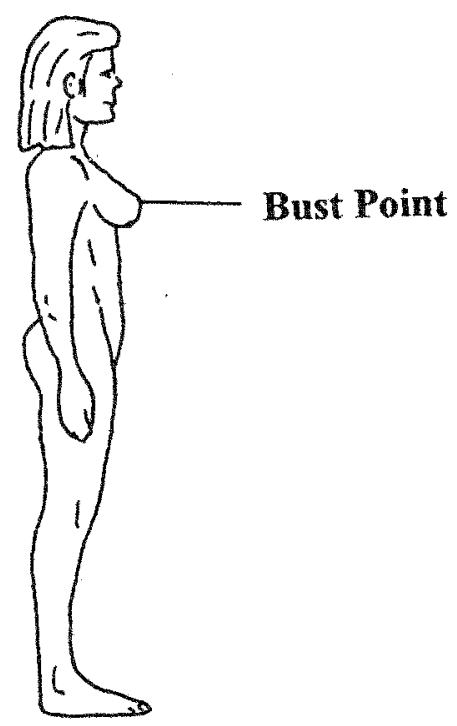

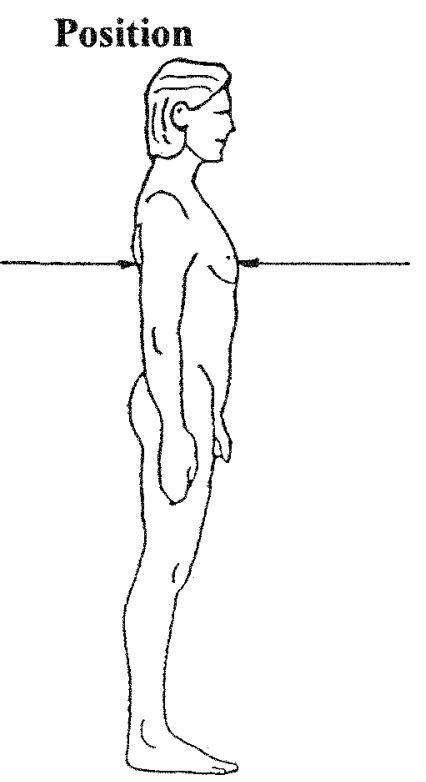

\section{Definition:}

- Chest: The depth of the torso measured at nipple level.

- Bust: The horizontal distance from the subject's back to the tip of her bra.

Landmarks: The most anterior prominence of the breast at the nipple level and the most posterior aspect of the thorax.

Instruments: Sliding or spreading caliper.

Position of subject: The subject stands on a flat surface, and his or her body weight is evenly distributed on both feet, heels together as closely as possible, legs and torso 
straight without stiffness and head erect with the line of vision parallel to the floor. The arms hang straight but loosely at the sides with the palms alongside but no touching the thighs. Subject remains in this position while the measurement is taken.

Position of measurer: The measurer stands at the subject's right side.

Procedure: The measurer places the caliper tips directly on the landmarks, with his or her fingers just beneath the caliper tips to prevent them from slipping .Measurement is made with caliper tips in a horizontal plane. When the subject and measurer are so positioned, the subject is instructed to take a deep breath, and the measurement is made just before the subject exhales. The measurement is recorded to the nearest millimeter.

Remarks: Measurement is repeated three times. The subject has to step off after the first measurement, and take position again in between measurements. It is important that the recorder observe both the position of the subject to avoid slouching and also the position of the anthropometer to ensure that it is positioned onto the specified landmark. 
Landmarks

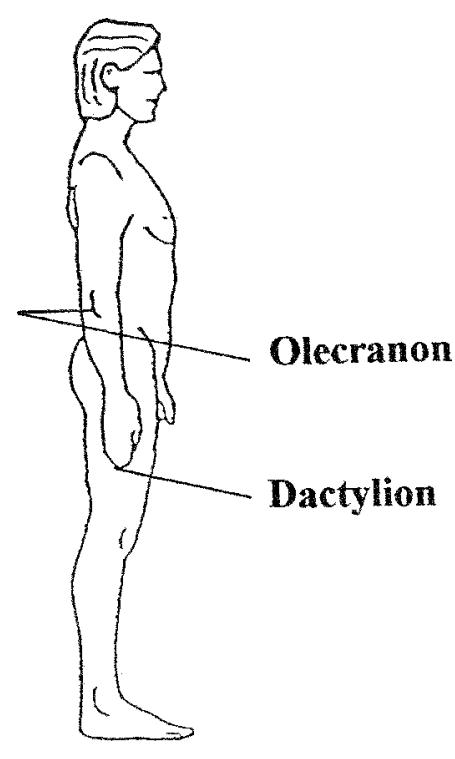

Position

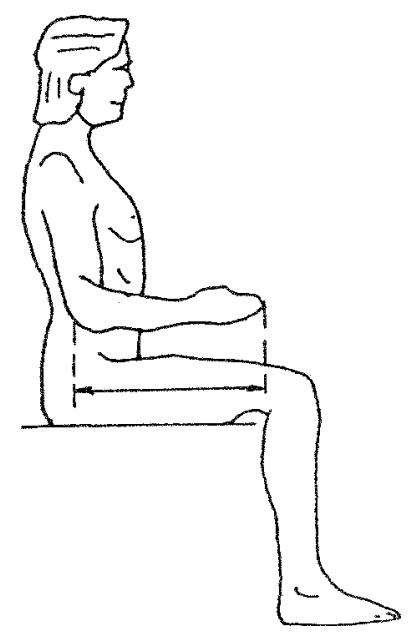

Definition: The distance from the tip of the elbow to the tip of the longest finger.

Landmarks: The tip of the distal phalange of the middle finger, (dactylion), and the most posterior point of the olecranon.

Instruments: Caliper or anthropometer configured as sliding beam caliper.

Position of subject: The subject sits on the table with the legs hanging unsupported over the edge of the table. The knees are directed straight ahead. The backs of the knees are near the edge of the table but not in contact with it. The subject sits as erect as possible, with the path of vision parallel to the plane of the floor. The subject's arms are vertical, 
with the elbows resting lightly against the sides of the body. The elbows are flexed to about 90 degrees so that the forearms and the supinated hands are extended forwards horizontally. The fingers are together and extended in the direction of the longitudinal axes of the forearms. Subject remains in this position while the measurement is taken.

Position of measurer: The measurer stands at the subject's right side.

Procedure: The fixed arm of the beam caliper is placed to make firm contact with the most posterior surface overlying the elbow (olecranon), while the sliding arm of the caliper is shifted to make contact with the fleshy tip of the middle finger (dactylion) of the extended hand. During this measurement, the arms of sliding caliper are perpendicular to the longitudinal axis of the forearm. The measurement is recorded to the nearest millimeter.

Remarks: Measurement is repeated three times. The subject has to step off after the first measurement, and take position again in between measurements. It is important that the recorder observe both the position of the subject to avoid slouching and also the position of the caliper to ensure that it is positioned onto the right landmark. 


\section{3-Anatomical and Anthropometric Terminology Glossary.}

\section{A}

Acromion: The most lateral point of the lateral edge of the spine of the scapula.

Anterior : Pertaining to the front of the body; as opposed to posterior.

B

Bust point: The most anterior protrusion of the right bra pocket.

Buttock or gluteal region: The prominence on each side formed by the gluteal muscles.

Buttock protrusion: The maximum posterior protrusion of the right buttock.

$\mathrm{C}$

Canthus: A corner or angle formed by the meeting of the eyelids.

Chest: The anterior surface of the torax, overlying the pectoral muscles.

Coronal plane: Any vertical plane at right angles to the midsagital plane.

D

Dactylion: The tip of the middle finger.

Distal: The end of a body segment farthest from the head, as opposed to proximal. 
$\mathrm{E}$

Endocanthus: The inside corner or angle formed by the meeting of the eyelids.

External: Away from the central long axis of the body; the outer portion of a body segment.

F

Femur: The thigh bone.

$\mathrm{H}$

Hip: The region between the iliac crest and the greater troahanter of the femur.

I

Iliac crest: The superior rim of the pelvic bone.

Inferior: Below, in relation to another structure; lower.

Internal: Near the central long axis of the body; the inner portion of a body segment.

L

Lateral: Lying near or toward the sides of the body; as opposed to medial. 
Midsagittal plane: The vertical plane which divides the body into right and left halves.

$\mathrm{O}$

Olecranon: The proximal end of the ulna.

$\mathbf{P}$

Parietal: Convex bones, that form part of the walls of the calvaria.

Patella: The kneecap.

Phalanges: The bones of the fingers and toes.

Plantar: Pertaining to the sole of the foot.

Posterior: Pertaining to the back of the body; as opposed to anterior.

Proximal: The end of a body segment nearest the head; as opposed to distal.

R

Radiale: The upper most point on the lateral margin of the proximal end of the radius.

Radius: The bone of the forearm on the thumb side of the arm. 
Sagital: Pertaining to the anteroposterior median plane of the body, or to a plane parallel to the median.

Scapula: The shoulder blade.

Stylion: The most distal point on the styloid process of the radius.

Superior: Above, in relation to another structure; higher.

$\mathrm{U}$

Ulna: One of the bones of the forearm on the little finger side of the arm.

V

Vertex: The top of the head.

W

Waist: Part of the body between the ribs and the hips. 
4- Illustrated Glossary of Anatomical Planes, Orientations and Points.

Anatomical Planes and Orientations.

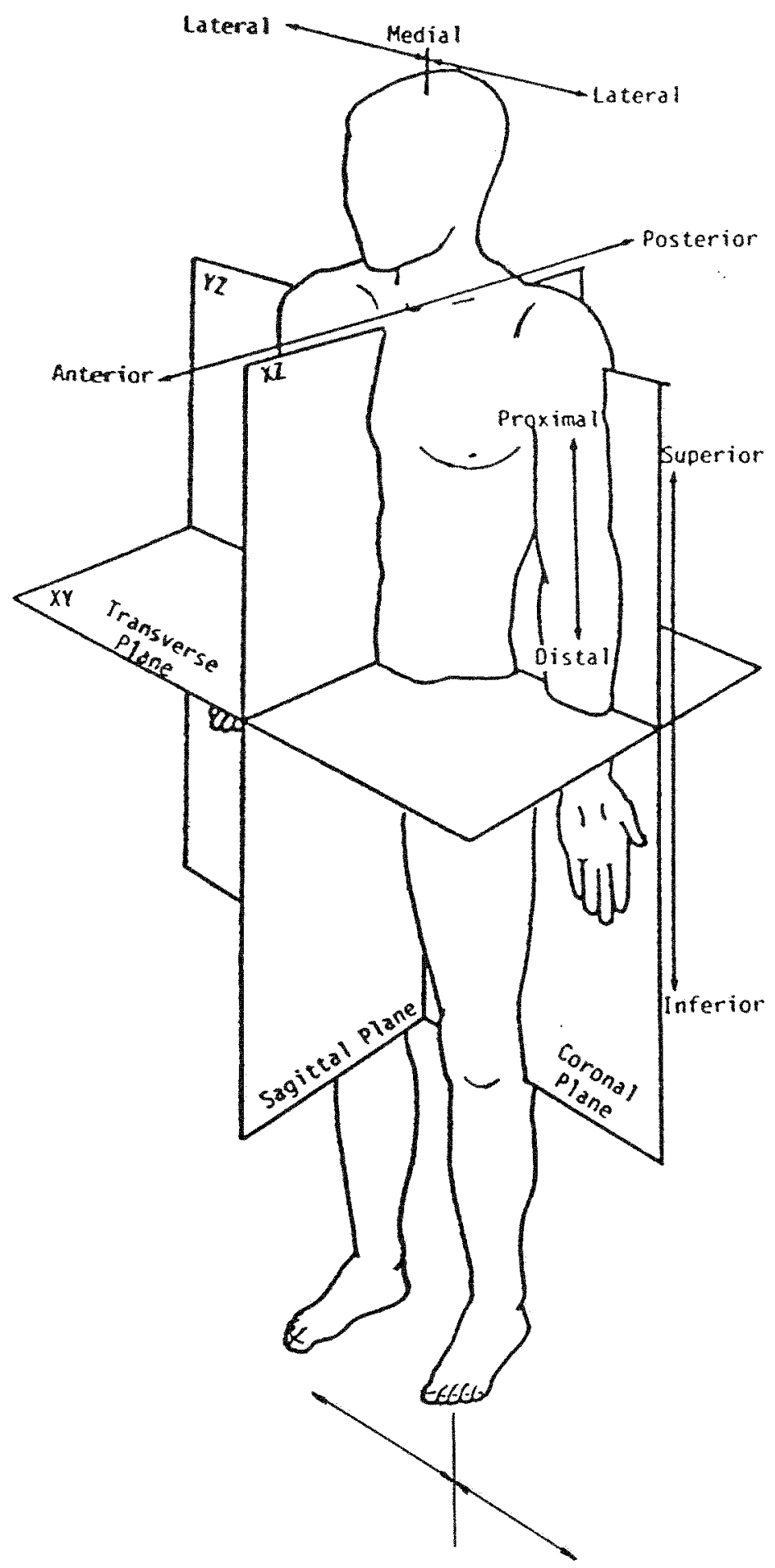


Anatomical Points.

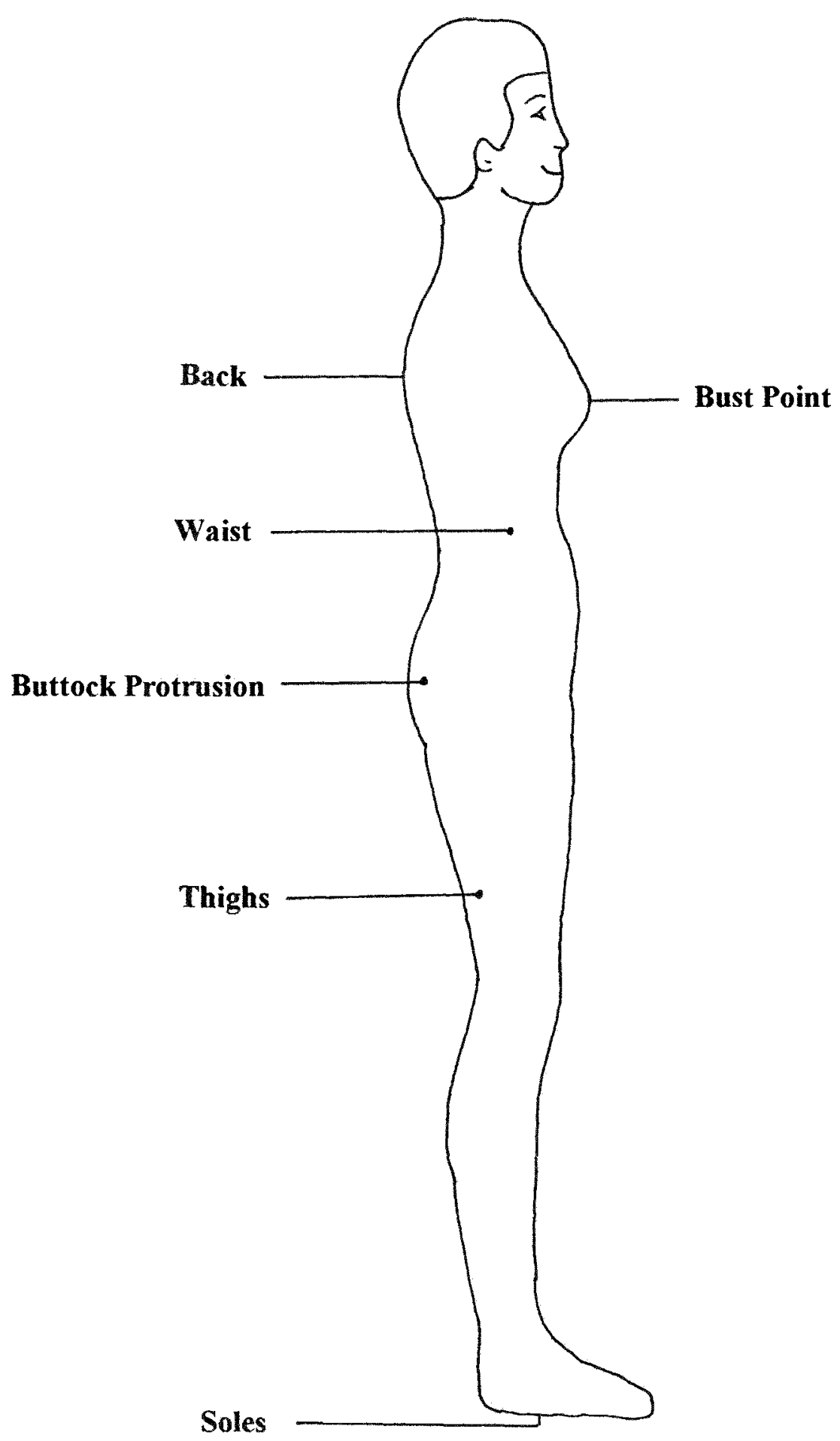




\section{Anatomical Points.}

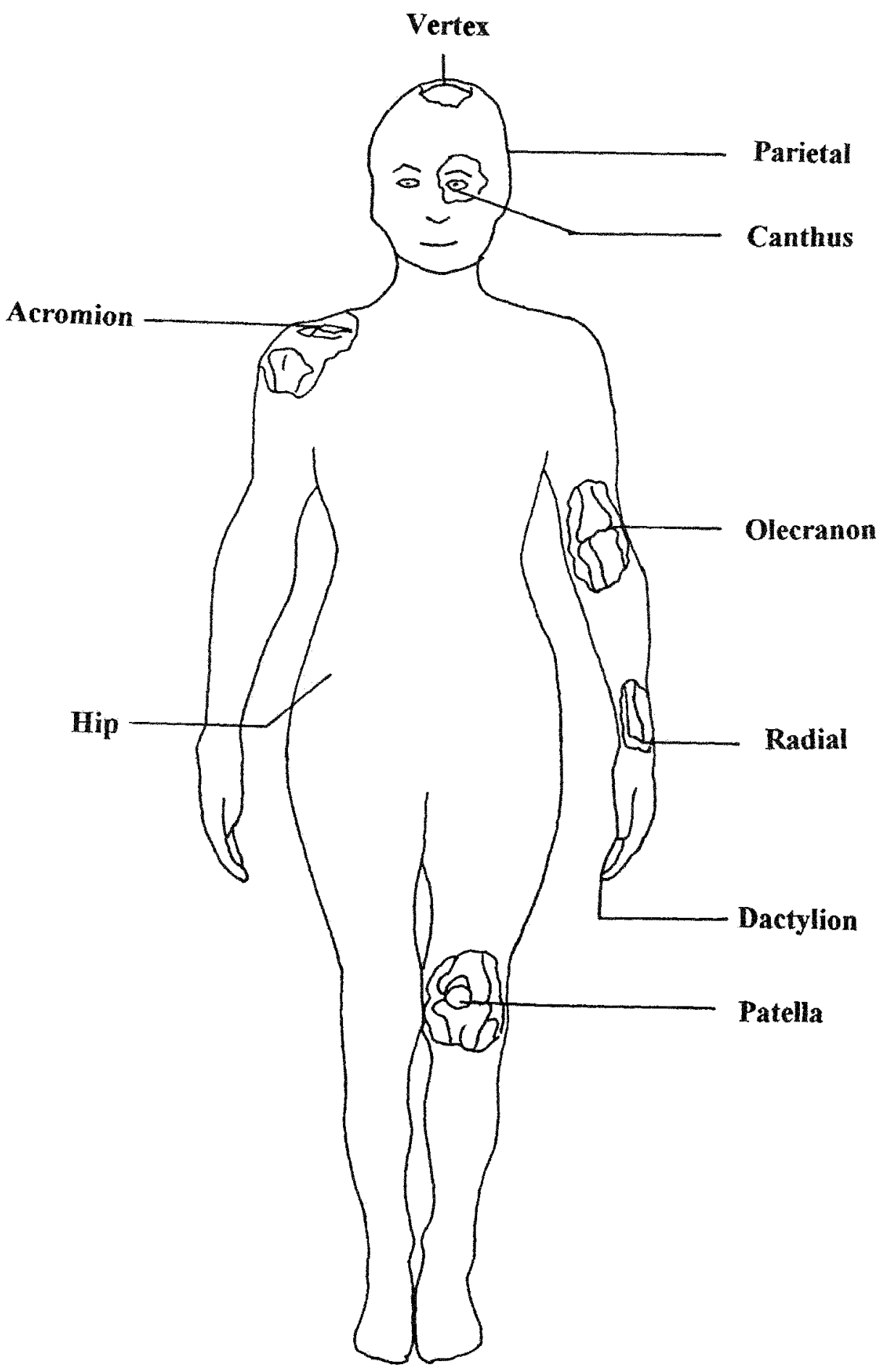




\section{Appendix B}

\section{Sample Size Calculation}

For any confidence limit:

$$
\begin{gathered}
\mathrm{d}=(\mathrm{K})^{*}\left[\mathrm{SD} /(\mathrm{N})^{1 / 2}\right] . \\
\text { or } \\
(\mathrm{N})^{1 / 2}=(\mathrm{K} * \mathrm{SD}) / \mathrm{d} \\
\text { or } \\
\mathrm{N}=[(\mathrm{K} * \mathrm{SD}) / \mathrm{d}] .
\end{gathered}
$$

Using stature as a reference dimension and with its distribution normally distributed:

$$
\begin{gathered}
\mathrm{N}=[(1.96 * 59) / 10]{ }^{2} \\
\mathrm{~N} \pm 134
\end{gathered}
$$

where:

$\mathrm{N}=$ Sample size required.

$\mathrm{SD}=$ Stature standard deviation $(59 \mathrm{~mm})$, from the pilot study conducted in this study 
$\mathrm{d}=$ The desired accuracy of the measurement $(10 \mathrm{~mm})$, from the measurement reliability tests conducted in this study. How close we wish our estimate to be to the true value of the population parameter, $K=$ Statistical value on the standard normal distribution for the $95 \%$ confidence limit (1.96). 


\section{Appendix $\mathrm{C}$}

\section{Subject Information Form}

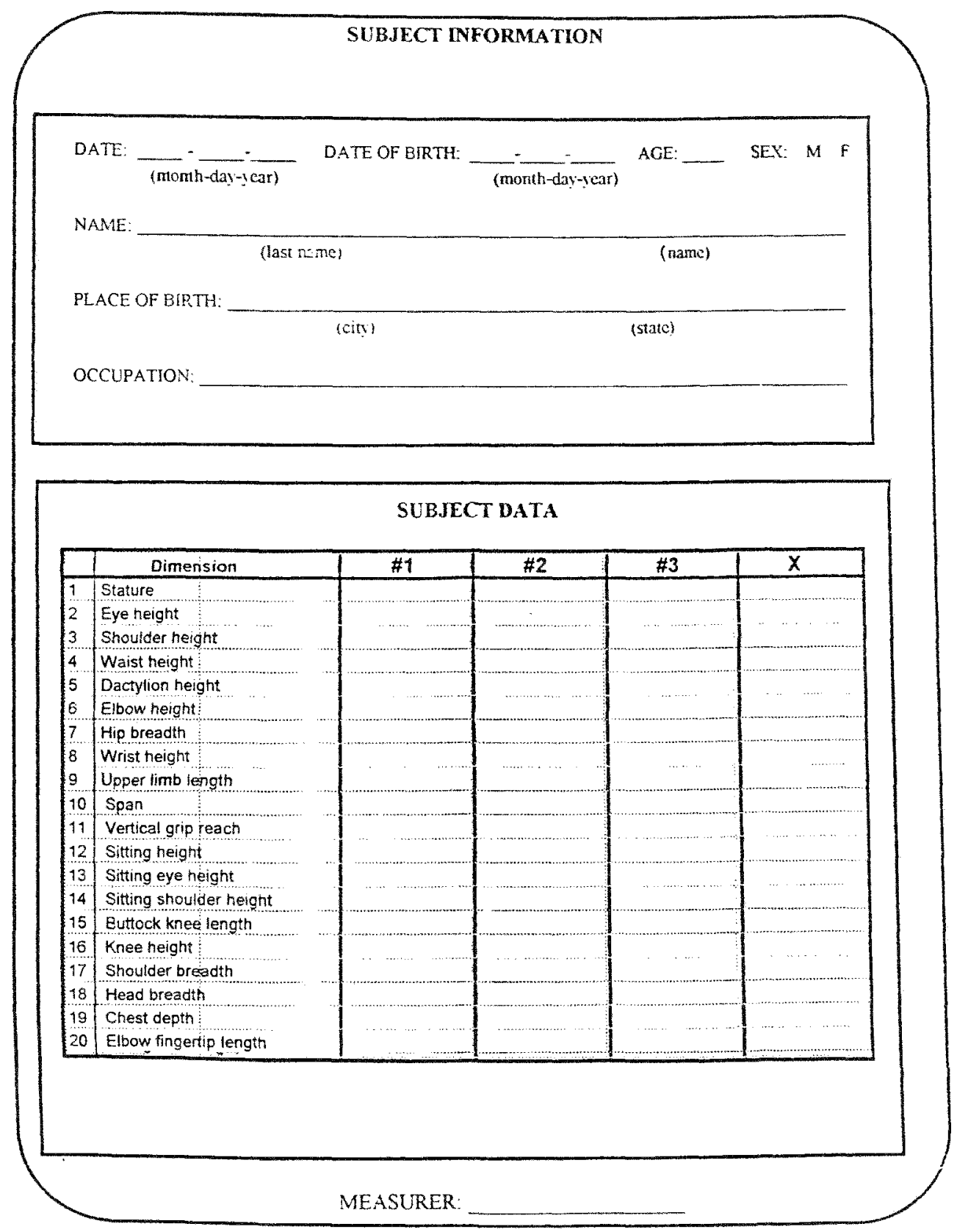

